\title{
UNIVERSITÄT
}

LEIPZIG

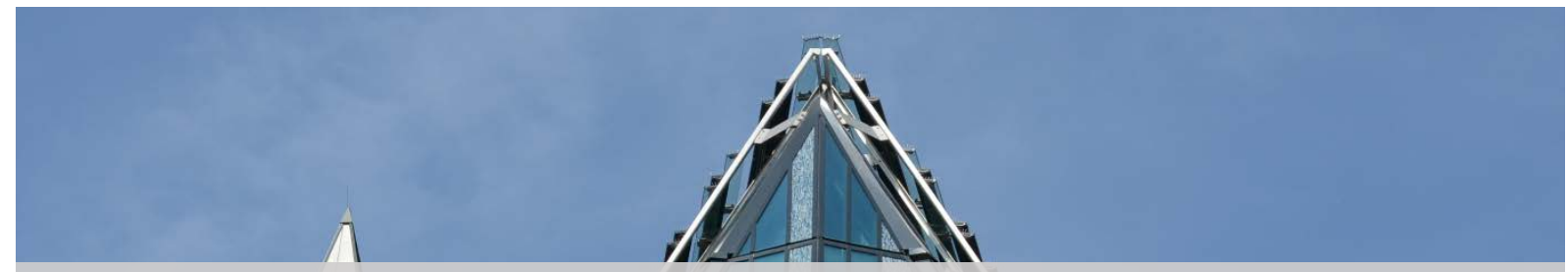

\section{Kommunaler Investitionsbedarf und ÖPP in Sachsen}

Ergebnisse einer empirischen Studie des ÖPPKompetenzzentrums Sachsen 2011/2012

Mario Hesse, Oliver Lück und Matthias Redlich
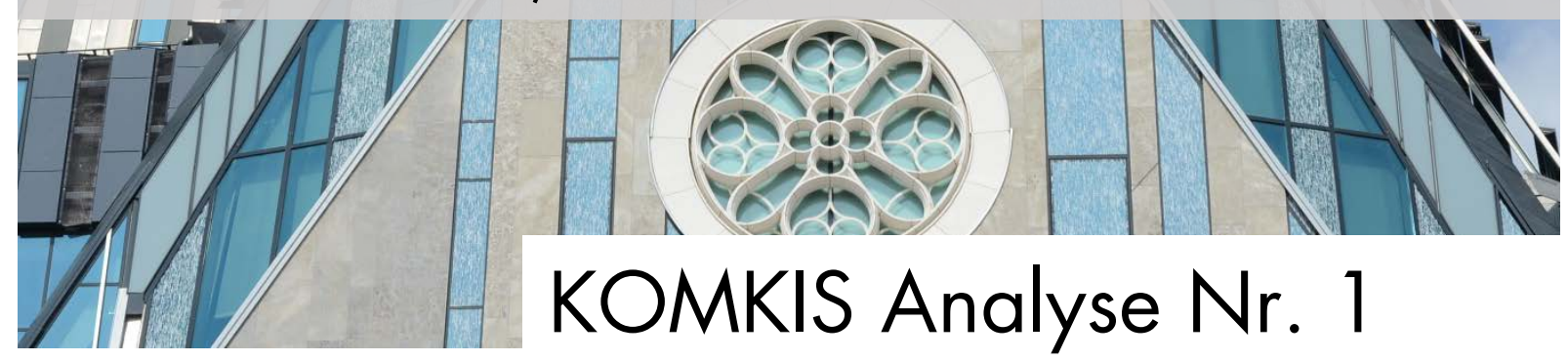

KOMKIS Analyse Nr. 1 
KOMKIS Analyse | Kommunaler Investitionsbedarf und ÖPP in Sachsen

Bibliographische Information der Deutschen Nationalbibliothek: Die Deutsche Nationalbibliothek verzeichnet diese Publikation in der Deutschen Nationalbibliographie; detaillierte bibliographische Daten sind im Internet über http:// dnb. d-nb. de abrufbar.

\section{ISSN 2511-7432}

Erscheinungsjahr 2012

\section{Ansprechperson: Mario Hesse}

T +49 341 9733-624 | F + 49341 9733-589 | hesse@wifa.uni-leipzig.de

(c) Kompetenzzentrum für kommunale Infrastruktur Sachsen; alle Rechte vorbehalten. Städtisches Kaufhaus, Universitätsstraße 16, 04109 Leipzig.

Foto: Paul Trainer | Universität Leipzig 


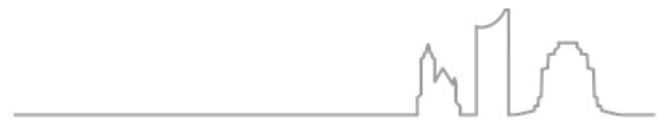

\section{Vorwort}

Vor dem Hintergrund der angespannten Finanzlage in den Kommunen und eingebettet in einen Prozess der Binnenmodernisierung der Kommunalverwaltungen, der Einführung der Doppik und einer intensiven Debatte um die effizientere und effektivere Bereitstellung öffentlicher Dienstleistungen sowie deren Bereitstellungsstrukturen steigt die Attraktivität von lebenszyklusorientierter Infrastrukturbeschaffung für die kommunale Ebene.

Damit nimmt auch der Bedarf an unterstützender Beratung der kommunalen Ebene zu. Diese hängt einerseits mit den naturgemäß begrenzten Kapazitäten - bei gleichzeitig erhöhtem Abstimmungsdarf zwischen den Akteuren auf lokaler Ebene und der hohen Komplexität der Thematik über einen längeren Realisierungszeitraum - zusammen. Hier kann durch wissenschaftliche Expertise und praxisfundierte Begleitung ein Mehrwert geschaffen werden. Gleichzeitig können durch ein intensives Erfahrungsmanagement Optimierungspotentiale aus bestehenden ÖPP-Projekten generiert werden.

Bei heutigen lebenszyklusorientierten Infrastrukturprojekten werden alle Phasen einer Infrastruktureinrichtung ganzheitlich über ihre gesamte Lebensdauer hinweg betrachtet und dabei ggf. Effizienz- und Einspareffekte im Vergleich zur konventionellen Realisierung aufgezeigt. Dies kann eine transparente und mit Blick auf notwendige Finanzströme antizipative Wirkung entfalten, die den Prozess nachhaltiger steuert als der konventionelle Fall.

Die Städte und Gemeinden im Freistaat Sachsen stehen diesem Ansatz derzeit noch verhalten gegenüber, was häufig daraus resultiert, dass lebenszyklusorientierte Infrastrukturbeschaffung und deren Folgen und Wirkungen teilweise unreflektiert diskutiert und in den Modellen vermischt werden. Die vorliegende Untersuchung hat das Ziel, Ansprüche an und Erfahrungen mit Infrastrukturbeschaffung - konventionell oder 


\section{UNIVERSITATT LEIPZIG}

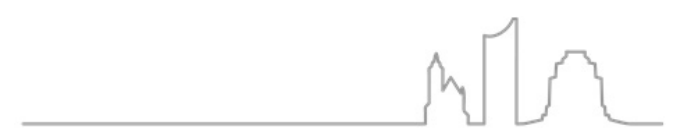

ÖPP - Kompetenzzentrum Sachsen am Institut für Öffentliche Finanzen und Public Management

lebenszyklusbasiert - in den sächsischen Kommunen darzulegen und darauf aufbauend den Städten und Gemeinden im Freistaat in der Kommunalberatung unterstützend und kritisch zur Seite zu stehen. Eine einzelfallbezogene Analyse statt pauschaler Urteile ist hierbei stets notwendig.

Dr. Oliver Rottmann

Geschäftsführer ÖPP Kompetenzzentrum Sachsen, Universität Leipzig 


\section{Inhaltsübersicht}

Abbildungsverzeichnis 2

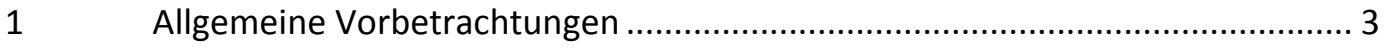

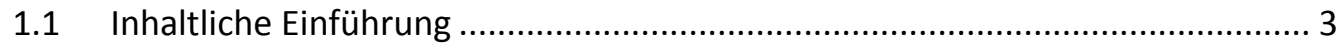

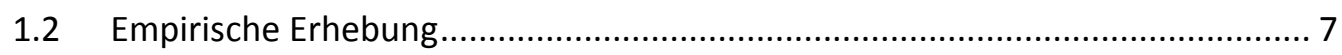

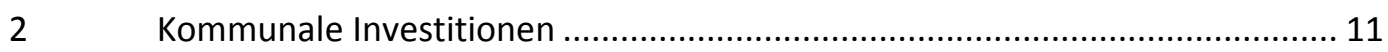

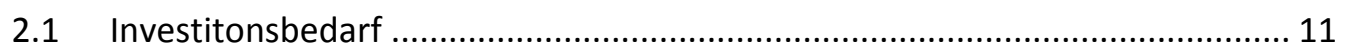

2.2 Qualität der derzeitigen Baumaßnahmen .................................................... 18

$3 \quad$ Bewertung von Öffentlich-Privaten Partnerschaften..................................... 25

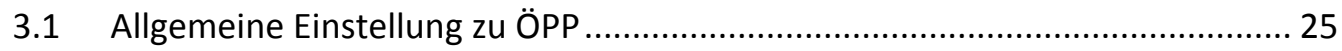

3.2 Erwartungen der Kommunen gegenüber ÖPP .................................................. 33

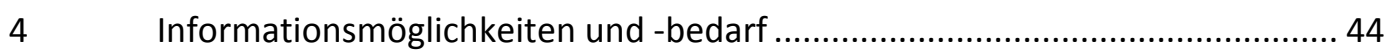

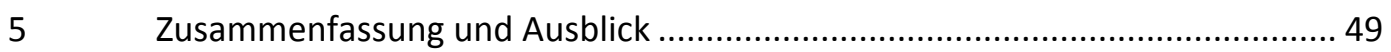

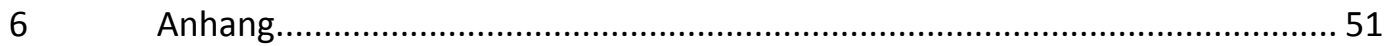




\section{hy 5 ? \\ ÖPP - Kompetenzzentrum Sachsen \\ am Institut für Öffentliche Finanzen und Public Management}

Seite 2 | 58

\section{Abbildungsverzeichnis}

Abbildung 1: Einwohnerstruktur der Stichprobe und der Grundgesamtheit......

Abbildung 2: Gegenüberstellung der derzeitig und zukünftig notwendigen Investitionen.

Abbildung 3: Investitionsbedarf gemessen an der Leistungskraft. 16

Abbildung 5: Bewertung der konventionellen Realisierung....................................... 19

Abbildung 6: Einzelbetrachtung der Planungszeit und -kosten. .................................. 20

Abbildung 7: Einzelbetrachtung der Baukosten und Bauzeit...................................... 20

Abbildung 8: Einzelbetrachtung der Bauqualität. ....................................................... 22

Abbildung 9: Einzelbetrachtung der Betriebskosten, Betriebsqualität und des personellen Aufwands............................................................... 23

Abbildung 10: Erfahrung mit alternativen Beschaffungsvarianten............................... 27

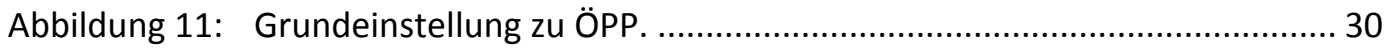

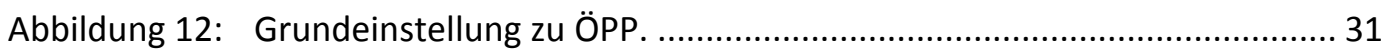

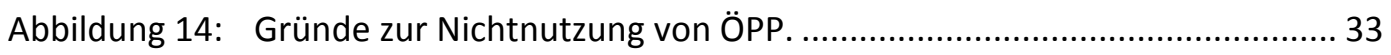

Abbildung 15: Bereitschaft zur Übertragung von Projektleistungen. ............................ 36

Abbildung 16: Erwartungen an ÖPP-Projekte......................................................... 37

Abbildung 17: Erwartungen an ÖPP-Projekte, Differenziert nach Einstellung zu

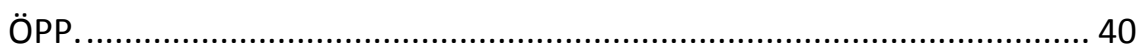

Abbildung 18: Meinungsbild zu generellen ÖPP-Aussagen........................................ 42

Abbildung 19: Gründe für und gegen Besuche von ÖPP-Veranstaltungen...................... 44

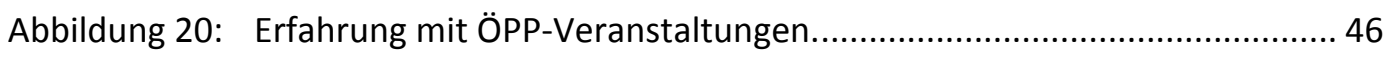

Abbildung 21: Bekanntheitsgrad des ÖPP-Kompetenzzentrums Sachsen..................... 47 


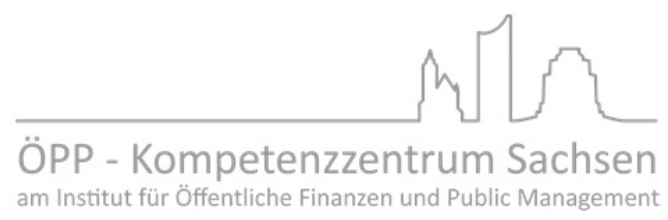

Seite $3 \mid 58$

\section{Allgemeine Vorbetrachtungen}

\subsection{Inhaltliche Einführung}

Der Handlungsdruck zum Aus- und Umbau sowie dem nachhaltigen Erhalt der öffentlichen Infrastruktur ist in den letzten Jahren nicht zuletzt durch demografische Veränderungen und gestiegene Erwartungen und Anforderungen der Bürger an die staatliche Aufgabenerfüllung ${ }^{1}$ immer größer geworden und stellt die Zukunftsfähigkeit der öffentlichen Finanzen vor große Herausforderungen. Trotz enormer Investitionen in die öffentliche Infrastruktur im Freistaat Sachsen in den 1990er und 2000er Jahren sind auch hier für die Zukunft keine stark abnehmenden Investitionsbedarfe zu erwarten. ${ }^{2}$ Zugleich ist festzustellen, dass die fiskalische Situation der sächsischen Kommunen trotz insgesamt positiver Finanzierungssalden und wieder steigender Steuereinnahmen in den letzten Jahren angespannt bleibt. ${ }^{3}$

Um Finanzmittel zu sparen und/oder für andere Aufgabenbereiche einsetzen zu können, wurden in der Vergangenheit häufig notwendige Aufwendungen für den Erhalt und den Ausbau von Infrastruktureinrichtungen zurückgestellt. Sowohl die Ausgaben für Investitionen als auch für den Erhalt der vorhandenen kommunalen Infrastruktur wurden seit 2000 bundesweit, aber auch in Sachsen, stark prozyklisch „,nach Kassenlage“ getätigt. ${ }^{4}$ In

1 Dazu genauer Röber, Manfred/Redlich, Matthias (2012): Bürgerbeteiligung in Deutschland, Österreich und der Schweiz, in: Schröter, Eckhard; von Maravic, Patrick; Röber, Jörg (Hrsg.): Zukunftsfähige Verwaltung? Herausforderungen und Lösungsstrategien in Deutschland, Österreich und der Schweiz.

2 Zum Investitionsbedarf der Kommunen vgl. KfW Bankengruppe (Hrsg.) (2012): KfW-Kommunalpanel 2011, in: http://www.kfw.de/kfw/de/l/II/Download_Center/Fachthemen/Research/PDF-Dokumente_ KfW_Kommunalpanel/ KfW-Kommunalpanel_2011_LF.pdf, insbes. S. 42ff; Der Bauinduistrieverband Sachsen/Sachsen-Anhalt hat die Ergebnisse der Untersuchung aus dem Jahr 2008 regionalisiert aufbereitet: Bauindustrieverband Sachsen/Sachsen-Anhalt (Hrsg.) (2012): Schwarzbuch Bauwirtschaft, Kommunaler Investitionsbedarf in Sachsen und Sachsen-Anhalt.

3 Zur finanziellen Lage der sächsischen Kommunen in den Jahren 2000-2010 siehe Lenk, Thomas/Hesse, Mario (2011): Gemeindefinanzbericht Sachsen 2010/2011, in: Sachsenlandkurier, 5/2011, S. 36ff.

4 Vgl. ebenda, S. 80, 84. 


\section{UNIVERSITÄT LEIPZIG}

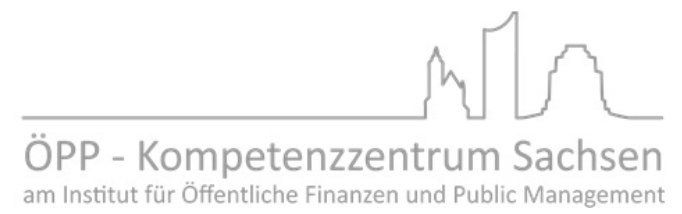

Seite 4 | 58

der Folge kam es zu nicht ausreichenden Investitions- und Erhaltungsinvestitionsquoten, die einen milliardenschweren Sanierungsstau entstehen ließen, der die öffentlichen Haushalte nun zusätzlich belastet. ${ }^{5}$ Das kommunale Investitionsprogramm im Rahmen des Konjunkturpaketes II aus dem Jahr 2009, das noch bis zum Jahr 2011 seine Wirkung entfaltete, sorgte zwar zwischenzeitlich für ein höheres Investitionsniveau. Dieses kann jedoch nicht als Trendumkehr gewertet werden. ${ }^{6}$ Die vorhandenen und zunehmenden öffentlichen Probleme führen dazu, dass die meisten Städte und Gemeinde vor der Herausforderung stehen, zur Sicherstellung der (Pflicht-)Leistungserfüllung die vorhandenen Ressourcen effizienter und nachhaltiger einzusetzen und insbesondere für die Aufrechterhaltung eines Angebots freiwilliger Leistungen andere Finanzierungsmöglichkeiten zu erschließen. Insbesondere im Bereich der Pflichtaufgaben, wie bspw. Kindertageseinrichtungen und Schulen sind gesetzliche Pflichten zur Erbringung der Leistungen zu beachten. Diesbezüglich gilt beispielswiese, den ab 1. August 2013 geltenden Rechtsanspruch auf einen Platz in einer Tageseinrichtung oder in der Kindertagespflege für unter Dreijährige zu erfüllen. ${ }^{7}$

5 Der Investitionsrückstand auf kommunaler Ebene betrug im Jahr 2011 laut dem KfW Kommunalpanel 99,9 Mrd. Euro. Vgl. KfW Bankengruppe (Hrsg.) (2012): KfW-Kommunalpanel 2011, in: http://www.kfw.de/kfw/de/l/II/Download_Center/Fachthemen/Research/PDF-Dokumente_

KfW_Kommunalpanel/KfW-Kommunalpanel_2011_LF.pdf, S. 47; Zum Sanierungsstau im Verkehrsbereich siehe z. B. Deutscher Städtetag (2012): Sanierungsstau gefährdet Verkehrsinfrastruktur in den Städten Bund muss mehr Investitionshilfen bereitstellen. in: http://www.staedtetag.de/10/presseecke/ pressedienst/artikel/2012/02/08/00836/index.html, Pressemitteilung vom 9. Februar 2012.

6 Für Sachsen wurde auf Basis der Daten des Difu für die Jahre 2011 bis 2020 ein kommunaler Investitionsbedarf von rund 27 Mrd. Euro berechnet, vgl. Bauindustrieverband Sachsen/Sachsen-Anhalt (Hrsg.) (2012): Schwarzbuch Bauwirtschaft, Kommunaler Investitionsbedarf in Sachsen und Sachsen-Anhalt, S. 54f.

7 Vgl. siehe dazu die Regelungen des KiFöG und SGB VIII. 


\section{UNIVERSITATT LEIPZIG}

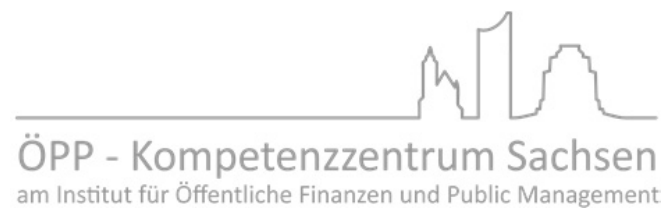

Seite 5 | 58

Bei der Errichtung und für den Erhalt der Infrastruktureinrichtungen greift die öffentliche Hand deshalb verstärkt auf alternative Beschaffungs- und Finanzierungskonzepte zurück. ${ }^{8}$

Nach der Jahrtausendwende sind so die ersten Öffentlich-Privaten Partnerschaften (ÖPP) entstanden. Dem kommunalen Bedarf folgend, stand bei den „ÖPP der ersten Generation" der Finanzierungsaspekt deutlich im Vordergrund. Die öffentliche Kritik an derartigen Verlagerungen (Stichwort "Schattenhaushalte") und aufkommende Forderungen nach Wirtschaftlichkeitsnachweisen förderten die Standardisierung und führten zu einer deutlichen Neufokussierung des ÖPP-Beschaffungsansatzes. ${ }^{9}$ Bei heutigen ÖPPProjekten, den „ÖPP der zweiten Generation“, werden mit Hilfe des ÖPP-Ansatzes alle Phasen einer Infrastruktureinrichtung ganzheitlich über ihre gesamte Lebensdauer hinweg betrachtet (Lebenszyklusansatz) und dabei ggf. Effizienz- und Einspareffekte im Vergleich zur konventionellen Realisierung aufgezeigt. Die Finanzierung wird dabei zu einem Aspekt einer Gesamtbetrachtung, bei der Planen, Bauen, Betreiben, Finanzieren und Weiternutzung/Verwertung, im Gegensatz zu vielen konventionell geplanten Projekten, als wirtschaftliche Einheit betrachtet und in einer integralen Planung vor der Realisierung analysiert werden. Bereits am Anfang des Projekts erfolgt die Auswahl eines privatwirtschaftlichen Partners, der im Unterschied zur konventionellen Beschaffung nicht nur Einzelleistungen bei Bau- und Betrieb übernimmt, sondern - angesichts seiner später selbst zu erbringenden Betriebsleistungen - die Planung ganzheitlich durch-

Deutsche Bauindustrie (2010): Öffentlich Private Partnerschaften (ÖPP) im Hochbau: Argumente gegen Vorurteile, in: http://www.oepp-plattform.de/media/attachments/HBi_Positionspapier_Internet1.pdf; Deutsches Institut für Urbanistik (2005): Public Private Partnership Projekte, Eine aktuelle Bestandsaufnahme in Bund, Ländern und Kommunen, http://www.fortuna-eg.de/assets/Uploads/Inhalt/service/ fortunabko.pdf; European PPP Expertise Center (EPEC) (2012): Market Update, Review of the European PPP Market in 2011, in: http://www.eib.org/epec/resources/epec_market_update_2011_en_web.pdf.

9 Wichtige Standardisierungen in Form von Leitfäden, Musterverträgen und Kriterienkatalogen wurden von Arbeitsgruppen, Task Forces und Kompetenzzentren des Bundes und der Länder vorangebracht. Vgl. exemplarisch die ÖPP-Schriftenreihe der ÖPP Deutschland AG; Bundesland Nordrhein-Westfalen (2006): Leitfaden: Wirtschaftlichkeitsuntersuchungen bei PPP-Projekten; Bundesministerium für Verkehr, Bau und Stadtentwicklung (2007): Leitfaden „PPP und Förderrecht“. 


\section{UNIVERSITÄT LEIPZIG}

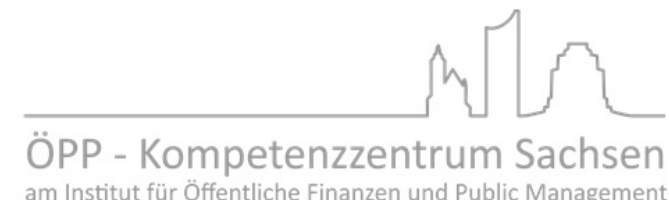

am Institut für Öffentliche Finanzen und Public Management

Seite $6 \mid 58$

führt. ${ }^{10}$ Als Ansatz eines wertschöpfungsübergreifenden Managements können dadurch frühzeitig Anreize generiert werden (in der Erstellungsphase), die im Hinblick auf spätere sich im Lebenszyklus akkumulierende Gesamtkosten dämpfend wirken. Die OutputOrientierung mit den verbundenen und schwierig über den Gesamtverlauf zu quantifizierenden Kosten kann dabei im Vergleich zur konventionellen Beschaffungsalternative Vorteile mit sich bringen. Die sich daraus ergebenden finanziellen Potenziale und Risiken werden in der Wirtschaftlichkeitsuntersuchung dargestellt und mit einer konventionellen Realisierung verglichen.

Die Bewertung eines Infrastrukturprojekts erfolgt somit nicht vorrangig auf Grund der entstehenden Baukosten zum Zeitpunkt der Errichtung, sondern bezieht die anfallenden Folgekosten für Instandhaltung und Betrieb mit ein. Diese sogenannte Lebenszyklusbetrachtung bildet die Grundlage für eine nachhaltige, kostensparende und -transparente Bewirtschaftung von Infrastruktureinrichtungen.

Dies hat dazu geführt, dass sich ÖPP in nahezu allen Bundesländern in der kommunalpolitischen Handlungspraxis als Alternative zur konventionellen Realisierung etabliert haben. Insgesamt haben die Anwendungsfelder, die Zahl der Projekte und deren Volumen in den vergangenen Jahren - mit wenigen Ausnahmen - kontinuierlich zugenommen. ${ }^{11}$ Im Freistaat Sachsen existiert jedoch bislang nur eine geringe Anzahl umgesetzter ÖPP-

10 Bauleistungen werden in aller Regel auch bei der konventionellen Realisierung von privatwirtschaftlichen Unternehmen erbracht. Gleiches gilt für Planungsleistungen, aber auch die technische Instandhaltung und das Facility Management öffentlicher Infrastruktur. Durch die Einzelvergabe an unterschiedliche Unternehmen können dabei Optimierungspotentiale und Synergieeffekte ungenutzt bleiben oder für deren Einbeziehung Kostensteigerungen entstehen, wenn diese erst nach Abschluss der Planung oder der Bauphase aufgedeckt wurden.

11 Vgl. Bundesministerium für Verkehr, Bau und Stadtentwicklung/Deutscher Sparkassen- und Giroverband (Hrsg.) (2009): PPP-Handbuch, Leitfaden für Öffentlich-Private Partnerschaften, 2. Vollständig überarbeitete und erweiterte Auflage, S. $10 f$. 


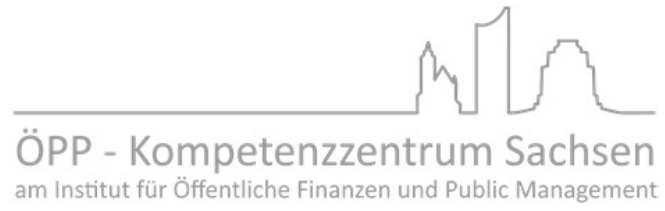

Seite 7 | 58

Projekte. ${ }^{12}$ Die beschriebene Ausgangslage unterscheidet sich aber grundsätzlich nicht von den anderen Bundesländern. Die meisten sächsischen Kommunen haben ebenso eine angespannte Haushaltslage und müssen zugleich steigende Leistungsanforderungen mit wachsenden demografischen Herausforderungen in Einklang bringen. ${ }^{13}$

\subsection{Empirische Erhebung}

Das ÖPP-Kompetenzzentrum Sachsen hat im Zeitraum Oktober bis November 2011 eine Umfrage zum Investitionsbedarf und zu kommunalen Bauprojekten in Sachsen in Verbindung mit ÖPP durchgeführt. Der verwendete Fragebogen (siehe Anhang) ist in drei Abschnitte unterteilt.

- Der erste Teil stellt Fragen zum notwendigen Investitionsbedarf und zur derzeitigen Umsetzung von Infrastrukturmaßnahmen. Dabei soll herausgearbeitet werden, wie sich die derzeitige Situation der Kommunen darstellt. Insbesondere soll eruiert werden, ob in den sächsischen Kommunen die konventionellen Projektumsetzungen so wirtschaftlich erfolgten, dass kein Bedarf für Beschaffungsalternativen entstanden ist.

- Der zweite Abschnitt beschäftigt sich mit dem momentanen Wissensstand und der Einstellung der Kommunen zu ÖPP. Ziel ist es herauszufinden, ob der weit gehende Verzicht auf ÖPP im Freistaat Sachsen sich ebenso in einer skeptischen oder ablehnenden Grundhaltung der Kommunen widerspiegelt. Ferner wird geprüft, ob spezifi-

12 Die Projektdatenbank der ÖPP Deutschland AG erfasst bislang sechs ÖPP-Projekte in Sachsen. Dazu zählen das Justizzentrum Chemnitz, das Landratsamt Schloss Sonnenstein in Pirna, das Parkhaus am Bundesverwaltungsgericht in Leipzig, das Rudolf-Harbig-Stadion in Dresden und eine Schwimmhalle in Burgstädt. Das Projekt „Parkhäuser/Tiefgaragen in Freiberg“ wurde nicht umgesetzt.

13 Zur finanziellen Situation der sächsischen Kommunen siehe Lenk, Thomas/Hesse, Mario (2011): Gemeindefinanzbericht Sachsen 2010/2011, in: Sächsischer Städte- und Gemeindetag (SSG) (Hrsg.): Sachsenlandkurier, 5/2011, Dresden; Lenk, Thomas (2009): Gemeindefinanzbericht Sachsen 2008/2009, Kommunalfinanzen vor dem Absturz, in: Sächsischer Städte- und Gemeindetag (SSG) (Hrsg.): Sachsenlandkurier, 5/2009, Dresden. 


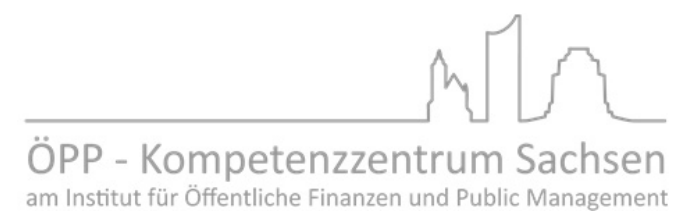

Seite $8 \mid 58$

sche Gründe existieren, die für und gegen den Einsatz von alternativen Beschaffungskonzepten sprechen und inwieweit eine Orientierung am Lebenszyklusgedanken möglich ist.

- Daran anschließend werden im letzten Abschnitt die Informationsmöglichkeiten und -bedarfe abgefragt, die in die Planung der Tätigkeit des ÖPP-Kompetenzzentrums Sachsen eingehen und die Aktivitäten des Zentrums an die Informationsbedarfe der Kommunen anpassen soll.

Der Fragebogen wurde an alle 458 sächsischen Städte und Gemeinden sowie die zehn Landkreise auf postalischem Wege verschickt (Grundgesamtheit). Zusätzlich wurde im Newsletter des Sächsischen Staatsministeriums des Innern und durch die kommunalen Spitzenverbände (Sächsischer Städte- und Gemeindetag, Sächsischer Landkreistag) auf die Umfrage aufmerksam gemacht. Insgesamt sind 95 beantwortete Fragebögen eingegangen, was einer Rücklaufquote von $20 \%$ der Grundgesamtheit entspricht. Dabei konnten die Fragebögen von 91 Städten und Gemeinden sowie von vier Landkreisen ausgewertet werden. Eine Differenzierung zwischen den Gruppen der kreisangehörigen Gemeinden, kreisfreien Städte und Landkreise kann aufgrund des geringen Gruppenbesatzes der beiden letztgenannten Gruppen nicht erfolgen. Sie ist auch nicht erforderlich, da alle drei Gruppen Träger der kommunalen Infrastruktur sind und sich daher die Frage nach Beschaffungsverfahren grundsätzlich gleichermaßen stellt.

Im Vergleich zur Einwohnerstruktur der Grundgesamtheit aller Städte und Gemeinden in Sachsen zeigt die Größenverteilung der Stichprobe eine weitgehende Übereinstimmung. ${ }^{14}$ Die Gruppe der Städte und Gemeinden mit weniger als 5.000 Einwohnern ist etwas unterrepräsentiert, während die größeren Kommunen etwas überrepräsentiert sind. Dies kann bereits ein Hinweis darauf sein, dass öffentlich-private Partnerschaften eher ein Thema für größere Kommunen mit einer größeren Verwaltung und mit einer umfangreicheren Investitionstätigkeit sind. Das relative Verhältnis der Städte und Ge- 
meinden über 5.000 Einwohnern relativ zueinander ist aber im Wesentlichen deckungsgleich zur Struktur in der Grundgesamtheit.

\section{Einwohnerstruktur der Stichprobe und der Grundgesamtheit}

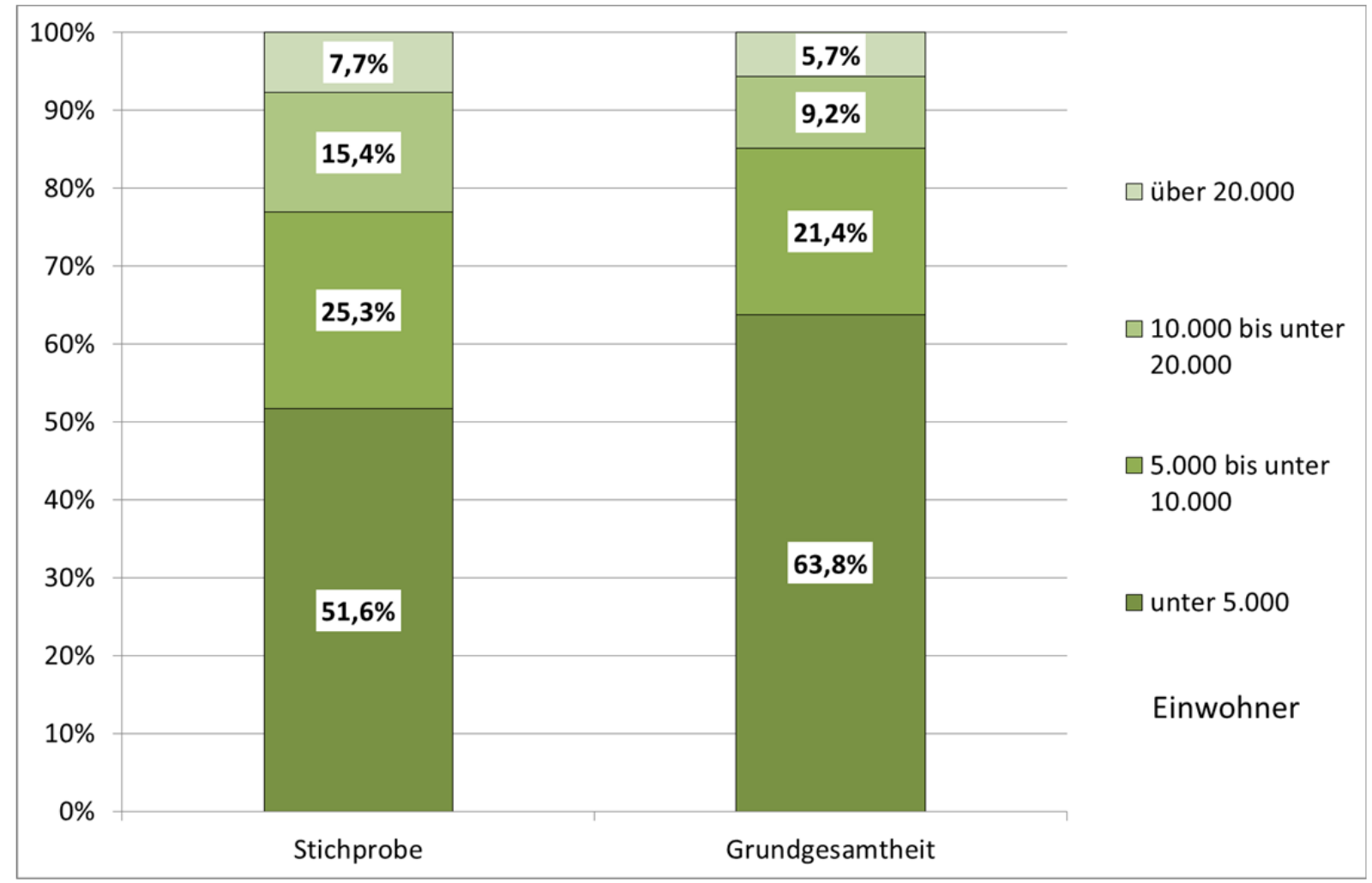

Abbildung 1: Einwohnerstruktur der Stichprobe und der Grundgesamtheit Quelle: Eigene Erhebung, eigene Darstellung.

Vor dem Hintergrund der Rücklaufquote und der Einwohnergrößenstruktur der Stichprobe im Vergleich zur Grundgesamtheit aller Kommunen im Freistaat Sachsen sind damit insgesamt repräsentative Auswertungen der Ergebnisse und die Ableitung allgemeingültiger Aussagen möglich. ${ }^{15}$

15 Der Stichprobenfehler liegt bei Zugrundlegung eines Vertrauensintervalls von $90 \%$ bei maximal 7,5 \%. Wird ein Vertrauensintervall von $95 \%$ vorausgesetzt, liegt er bei rund 9,0\%. Dies wird für die Beantwortung der Fragen des Fragebogens, die sich häufig auf Abschätzungen und Meinungsäußerungen beziehen, als hinreichend erachtet. 


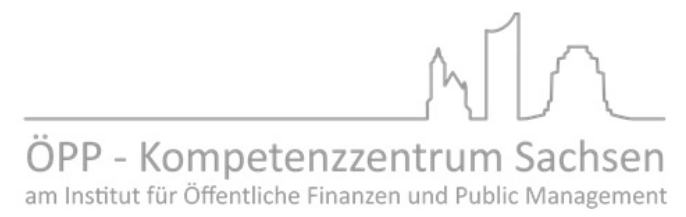

Seite $10 \mid 58$

Dennoch kann eine selektive Auswahl nicht vollständig ausgeschlossen werden. Es besteht eine mögliche Diskrepanz darin, dass insbesondere jene Kommunen geantwortet haben, die dem Thema ÖPP oder alternativen Beschaffungsformen im Allgemeinen grundsätzlich offener gegenüberstehen. Um Aussagen zu den Gründen für die Nichtbeantwortung des Fragebogens treffen zu können, wurden alle Kommunen, die bis zur Rücksendefrist noch nicht geantwortet hatten, noch einmal in elektronischer Form angeschrieben und gebeten, ggf. kurz die Gründe der Nichtbeantwortung zu benennen. Als Hauptgrund wurden dabei die nicht ausreichenden personellen Kapazitäten genannt. Insbesondere die Umstellung auf die doppische Haushaltsführung schien im Erhebungszeitraum zu Engpässen zu führen. Allerdings wird von einigen Kommunen ebenso die Irrelevanz des Themas ÖPP angeführt. Diese verwiesen dabei im Allgemeinen auf den zu hohen Aufwand der Vorbereitung, ihren zu geringen Kenntnisstand bei diesem Thema, die finanzielle Situation oder die als zu gering eingeschätzte Größe ihrer Infrastrukturprojekte. 


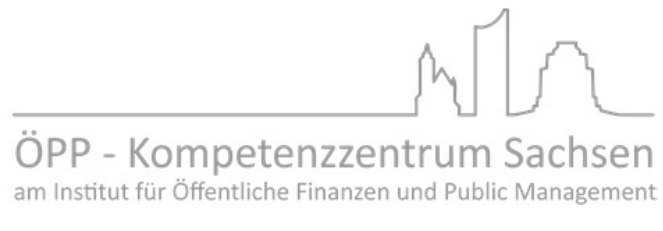

Seite $11 \mid 58$

\section{Kommunale Investitionen}

\subsection{Investitonsbedarf}

Der Investitionsbedarf in den deutschen Städten und Gemeinden ist, gerade vor dem Hintergrund der angespannten Haushaltssituation, als erheblich einzuschätzen. Der in den vergangenen Jahren angelaufene Sanierungs- und Instandhaltungsstau erstreckt sich über annähernd alle Investitionsbereiche. ${ }^{16}$

Die Gegenüberstellung der derzeitig und zukünftig als notwendig erachteten Investitionen (Abbildung 2) verdeutlicht, in welchen Bereichen die sächsischen Kommunen momentan investieren bzw. in welchen Bereichen Investitionen geplant werden. Die Schwerpunkte liegen derzeit auf dem Verkehrsbereich, in welchem $80 \%$ der befragten Kommunen investieren, der Straßenbeleuchtung (56\%) sowie bei Schulen (68\% der Kommunen), Kindertagesstätten (61\%) und bei Sport-und Freizeiteinrichtungen (48\%). Dies sind zugleich auch die Bereiche, in denen mittelfristig in den nächsten fünf Jahren die Hauptinvestitionsbedarfe gesehen werden. Zukünftig an Bedeutung gewinnen werden dabei die Verwaltungsgebäude sowie Sport- und Freizeiteinrichtungen, aber auch im Bereich der Kitas sehen mehr als zwei Drittel der Kommunen weiteren Investitionsbedarf.

Auffällig ist, dass die Zahl derjenigen Kommunen, die zukünftige Investitionsbedarfe sehen, größer ist als die derjenigen, die aktuell investieren. Daraus könnte geschlussfolgert werden, dass die wertmäßigen Volumina der Bedarfe größer sind als die tatsächlich realisierbaren Investitionen. Dem muss allerdings kritisch entgegengehalten werden, dass das kommunale Investitionsprogramm im Zuge des Konjunkturpakets II in den letzten drei Jahren zu nicht unerheblichen Investitionsmöglichkeiten geführt hat, die einen Teil

16 Vgl. KfW Bankengruppe (Hrsg.) (2012): KfW-Kommunalpanel 2011, in: http://www.kfw.de/kfw/de/l/II/ Download_Center/Fachthemen/Research/PDF-Dokumente_KfW_Kommunalpanel/KfW-

Kommunalpanel_2011_LF.pdf, S. 47; Engelhart, Recker (2007): Kommunale Infrastruktur und Public Private Partnership - Bedarf deutscher Kommunen in: Hauptverband der Deutschen Bauindustrie e.V. (Hrsg.): Kommunale Infrastruktur und Public Private Partnership Lösungen für Ingenieurbauwerke, S. 6-17. 


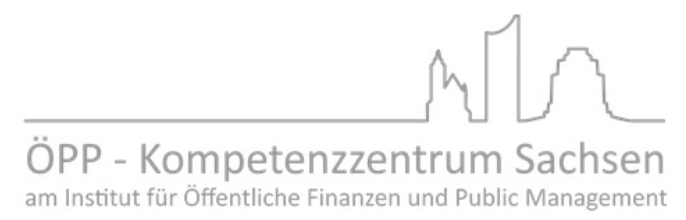

Seite $12 \mid 58$

des Bedarfsstaus beseitigt hat. Des Weiteren beziehen sich die Aussagen zu den Bedarfen auf einen längeren Zeithorizont ( 5 Jahre) als die Umsetzungsdauern aktuell in der Umsetzung befindlicher Maßnahmen. Insofern kann an dieser Stelle nicht trennscharf zwischen „objektiv bestimmbaren Bedarfen“ und „Investitionswünschen“ differenziert werden. Dennoch zeigen die Ergebnisse, in welchen kommunalen Infrastrukturbereichen in den kommenden Jahren vermehrt über Investitionsprojekte und damit auch über alternative Beschaffungsvarianten nachgedacht werden könnte.

In welchen der im Folgenden genannten kommunalen Investitionsbereiche werden in Ihrer Kommune derzeit Baumaßnahmen (Neubauten und Instandhaltung) durchgeführt bzw. augenblicklich geplant und in welchen Bereichen sind in den nächsten fünf Jahren in Ihrer Kommune Investitionen notwendig? (Mehrfachnennungen zulässig)

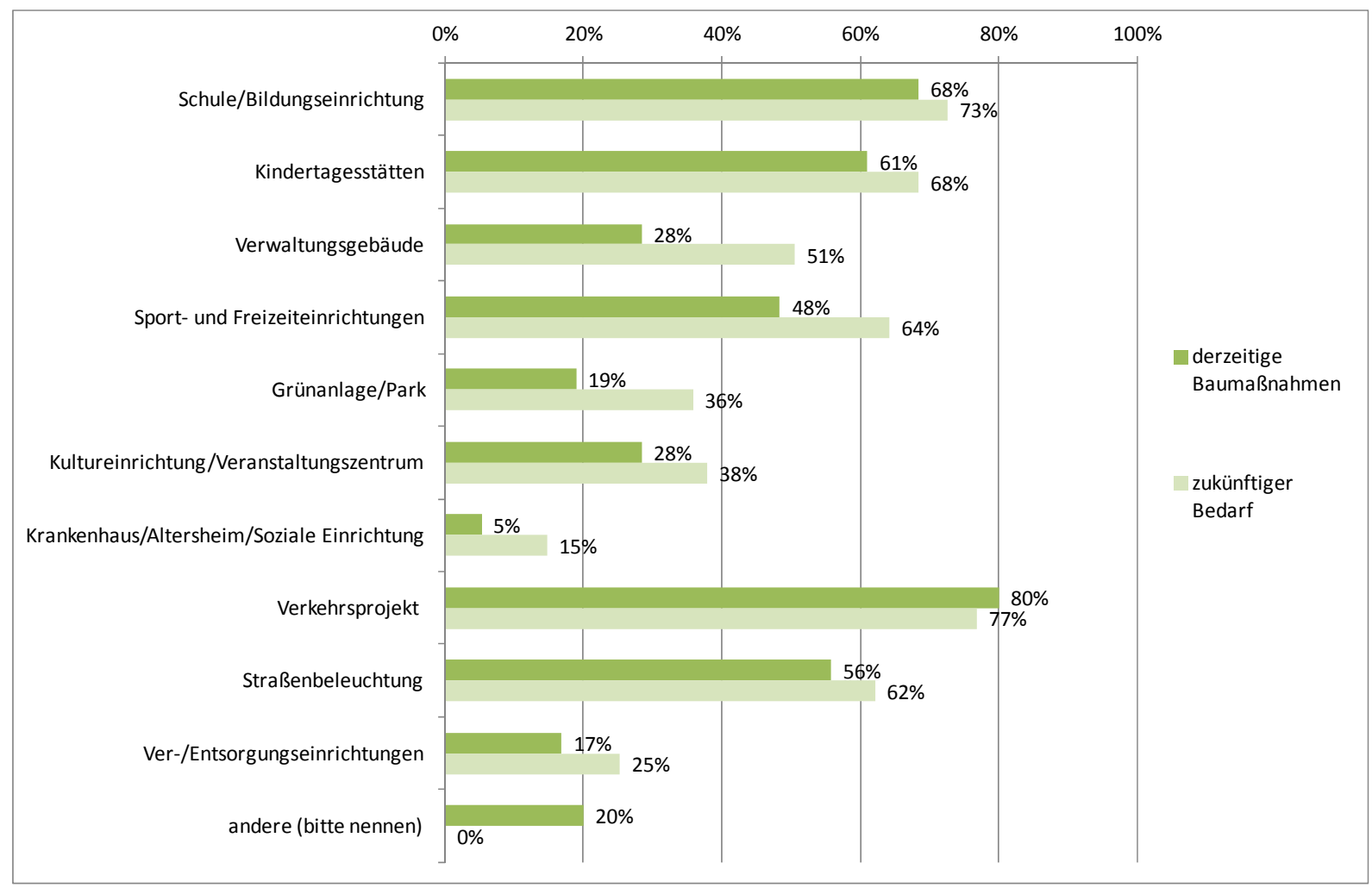

Abbildung 2: Gegenüberstellung der derzeitig und zukünftig notwendigen Investitionen, $n=95$ Quelle: Eigene Erhebung, eigene Darstellung. 


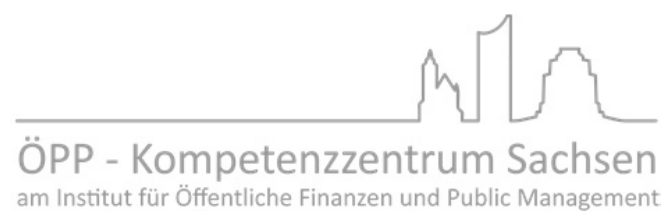

Seite $13 \mid 58$

In über zwei Drittel der antwortenden Kommunen werden derzeit Baumaßnahmen bei der Verkehrsinfrastruktur und im Schulbereich durchgeführt oder konkret geplant. Zugleich besteht aber darüber hinaus ein kontinuierlich hoher Bedarf für weitere Investitionen. Dies offenbart, dass hier in den letzten zehn Jahren - nach dem Abschluss vielfältiger, umfangreicher Sanierungs- und Neubaumaßnahmen in den 1990er und 2000er Jahren bereits wieder ein erheblicher Handlungsdruck entstanden ist. ${ }^{17}$ Die genauen Auslöser wurden im Fragebogen nicht erfragt. Mangelnde Aufwendungen für Instandhaltung und Sanierung in der bestehenden Infrastruktur können angesichts der erst Mitte bis Ende der 1990er Jahre durchgeführten, umfangreichen Instandsetzungsmaßnahmen aber als ein wesentlicher Aspekt angenommen werden. Anders ist es im Bereich der Kindertagesstätten. Hier geht es vielfach nicht nur um Sanierungsmaßnahmen, sondern um den Ausbau des Angebotes. Dies geschieht vor dem Hintergrund des bundespolitischen Ziels des Ausbau der Kinderbetreuung. In Sachsen besuchen $95 \%$ der Kinder zwischen drei und sechs Jahren eine Kindertagesstätte, von denen 81,4\% sogar eine Ganztagesbetreuung erhalten. Damit belegt Sachsen hinter Thüringen den zweiten Platz im Bundesländervergleich. In den westdeutschen Ländern sind nur knapp ein Viertel (27\%) der Kita-Kinder in Ganztagesbetreuung. Von den Kindern unter drei Jahren besuchen in Sachsen $38 \%$ eine Kindertageseinrichtung. ${ }^{18}$ Dennoch besteht noch weiterer Handlungsbedarf, um alle festgelegten Ziele der Bunderegierung bis Ende 2013 zu erreichen. ${ }^{19}$ Hierbei ist für die sächsischen Kommunen weniger das bundesweit formulierte Ausbauziel von $35 \%$ problematisch, als vielmehr der explizite Rechtsanspruch in Verbin-

Auch die regionalisierte Auswertung der Difu-Befragung durch den Bauindustrieverband Sachsen/SachsenAnhalt weist für den Bereich Schule einen Investitionsbedarf in Höhe von rund 2 Mrd. Euro bis 2020 aus; Vgl. Bauindustrieverband Sachsen/Sachsen-Anhalt (Hrsg.) (2012): Schwarzbuch Bauwirtschaft, Kommunaler Investitionsbedarf in Sachsen und Sachsen-Anhalt, S. 32ff.

18 Hinzu kommen $5 \%$ in der Kindertagespflege, vgl. hierzu den „Ländermonitor frühkindliche Bildungssysteme" der Bertelsmann Stiftung, http://www.laendermonitor.de.

19 Bund und Länder haben die Zielvereinbarung geschlossen bis zum Jahr 2013 das Betreuungsangebot für unter Dreijährige auf 35 \% zu erhöhen. Zudem besteht für alle Kinder ab dem vollendeten 1. Bis zum 3. Lebensjahr ein Rechtsanspruch auf einen Betreuungsplatz. 


\section{UNIVERSITÄT LEIPZIG}

\section{hy 5 ? \\ ÖPP - Kompetenzzentrum Sachsen \\ am Institut für Öffentliche Finanzen und Public Management}

Seite 14 | 58

dung mit der tatsächlichen Nachfrage nach Betreuungsplätzen, die bereits heute in vielen Landkreisen und Städten deutlich oberhalb der 35 \%-Marke liegt.

Die relativ große Anzahl an Bauprojekten in der Straßenbeleuchtung ist auf den von der EU bis zum Jahr 2015 vorgeschriebenen Austausch der Quecksilberdampflampen zurückzuführen. Angesichts dieser rechtlichen Vorgabe ist es nicht verwunderlich, dass 62 \% der Kommunen angegeben haben, in den nächsten fünf Jahren weitere Investitionen in diesem Bereich zu tätigen. Vor dem Hintergrund steigender Energiepreise ist zudem zu erwarten, dass das Thema auch darüber hinaus in den kommenden Jahren noch stärker im Fokus der Kommunen bleiben wird. Gerade bei Investitionen in diesen Bereich sind im besonderen Maße die zu erwartenden Einsparungen bei den laufenden Kosten für Energie und entstehenden Wartungskosten zu berücksichtigen, die sich je nach gewählter Realisierungsvariante im Lebenszyklus erheblich unterscheiden können. Beschaffungsvergleiche sind dabei ebenso auf Grund der rasanten Entwicklung innovativer Techniken, wie z. B. der Abdimmautomatik im Bereich der Bedarfssteuerung, geboten. Der finanzielle Nutzen dieser in der Anschaffung oft teureren Produkte wird vielfach erst im Zuge einer Wirtschaftlichkeitsanalyse mit dem Vergleich der während der gesamten Nutzungsdauer entstehenden Betriebskosten (Lebenszyklusbetrachtung) deutlich. Der zusätzliche Vergleich unterschiedlicher Beschaffungskonzepte kann dabei weitere Synergie- und Einspareffekte aufzeigen.

Im Bereich Grünanlagen/Parks sowie in den sozialen Einrichtungen ist die Anzahl aktuell durchgeführter oder geplanter Investitionen vergleichsweise gering. Ein Grund dafür liegt sicherlich in der Zugehörigkeit dieser Felder zu den freiwilligen kommunalen Selbstverwaltungsaufgaben. Somit können die Kommunen in diesen Bereichen über das $\mathrm{Ob}$ und das Wie der Aufgabenerfüllung selbst entscheiden. In Zeiten angespannter Kassen sind Verdrängungseffekte zu Gunsten anderer Ausgaben und zu Lasten dieser Investitionsbereiche aus Sicht der Kommunen naheliegend.

Ver- und Entsorgungseinrichtungen wurden seltener genannt, was sicherlich mit enormen Investitionsvolumina in der Vergangenheit zusammenhängt, auf der anderen Seite aber auch ein Zeichen dafür ist, dass die entsprechenden Investitions- und Finanzie- 


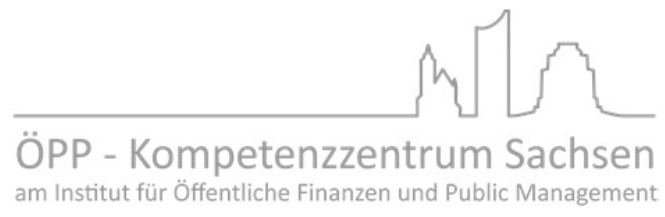

Seite 15 | 58

rungszyklen vielfach auf kommunale Unternehmen verlagert sind und damit die Kernhaushalte und die darin veranschlagten Investitionen nur noch zum Teil berühren.

Des Weiteren benannten die befragten Kommunen unter der Rubrik „Andere“ vor allem den Hochwasserschutz und die Feuerwehr als weitere Investitionsbereiche, in denen Baumaßnahmen durchgeführt bzw. aktuell geplant werden.

Werden diese Ergebnisse an den von den Kommunen gesehenen weiteren Investitionsbedarf in den nächsten fünf Jahren gespiegelt, so ergeben sich ähnliche Schwerpunktsetzungen. Der Großteil der Kommunen sieht Investitionsbedarf vor allem im Verkehrsbereich (77\% der Befragten) und im Bereich Schule (73\%). Wie auf Grund der gesetzlichen Lage zu erwarten war, sind weitere Investitionen in den Neubau von Kindertagesstätten (68\%) notwendig. Ein steigender Bedarf im Vergleich zu den derzeitig realisierten Investitionen ist dabei insbesondere im Bereich der Verwaltungsgebäude und der Sport- und Freizeiteinrichtungen festzustellen. Hier antworteten $51 \%$ bzw. $64 \%$ der sächsischen Kommunen, dass in der nahen Zukunft Investitionen angeschoben werden müssten. Dies kann als ein weiterer Indikator dafür dienen, dass technisch notwendige Instandhaltungs- und Sanierungsaufwendungen im freiwilligen Bereich mit Blick auf die Konsolidierung der Haushalte unterlassen wurden. 


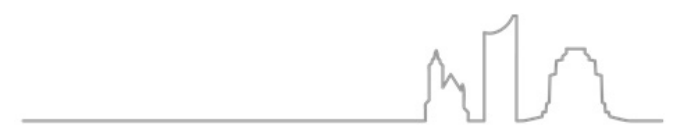

ÖPP - Kompetenzzentrum Sachsen am Institut für Öffentliche Finanzen und Public Management

Seite $16 \mid 58$

Wie hoch ist aus Ihrer Sicht der jeweilige Investitionsbedarf in Euro und wie hoch schätzen Sie diesen gemessen an der Leistungskraft Ihrer Kommune ein?

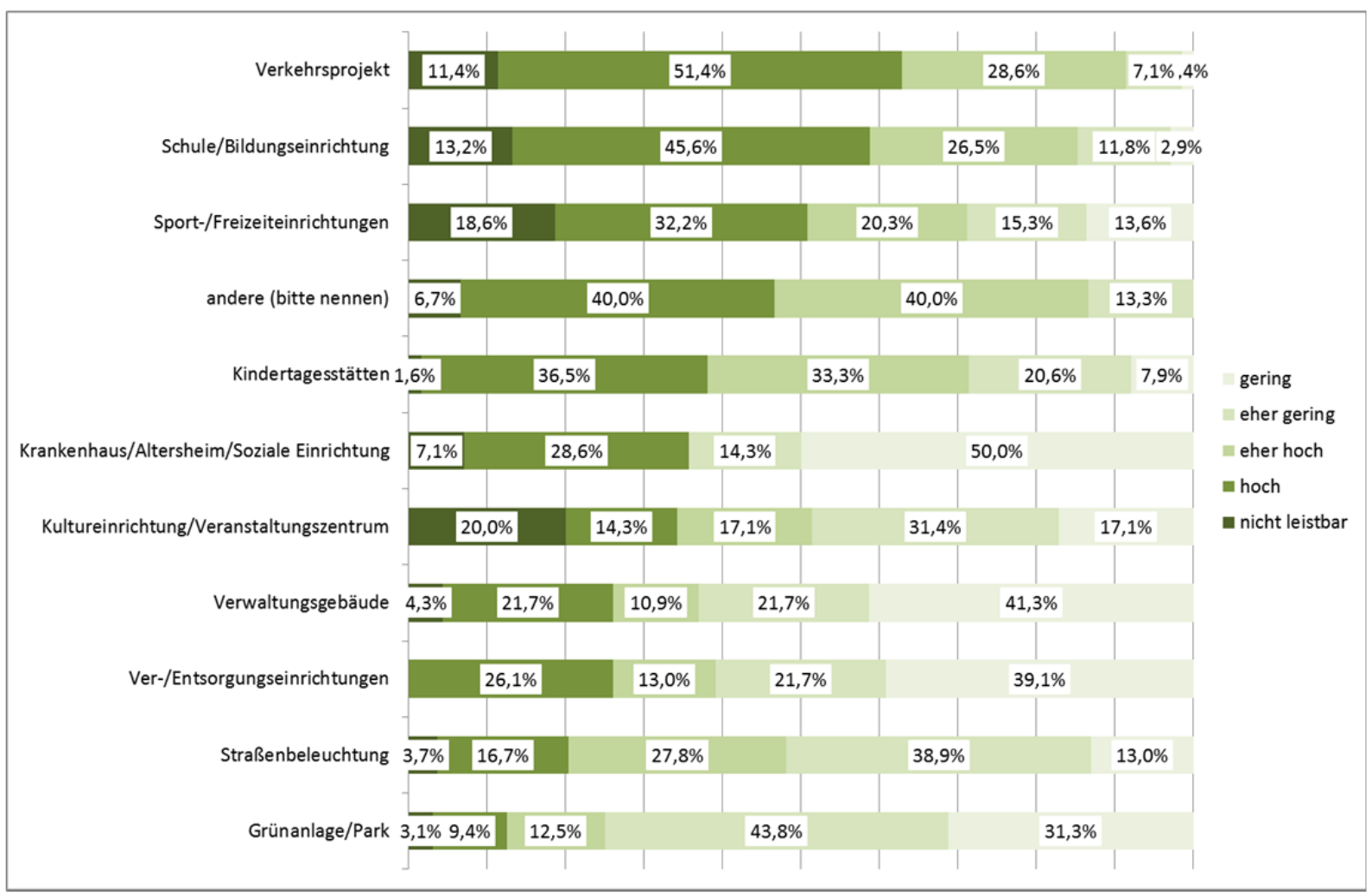

Abbildung 3: Investitionsbedarf gemessen an der Leistungskraft, $\mathrm{n}=92$

Quelle: Eigene Erhebung, eigene Darstellung.

Die finanziellen Verpflichtungen, die im Zuge der durchzuführenden Investitionen entstehen, werden von den sächsischen Kommunen in Abhängigkeit der jeweiligen kommunalen Leistungsfähigkeit recht unterschiedlich bewertet. So schätzen jeweils knapp $60 \%$ der Kommunen die notwendigen Investitionen im Verkehrsbereich $(62,8 \%)$ und bei Schulen/Bildungseinrichtungen (58,8\%) in Bezug auf die eigene Leistungsfähigkeit als „hoch“ bzw. „nicht leistbar“ ein. Als einen ebenso im Vergleich zur Leistungsfähigkeit sehr kostenintensiven Bereich identifizieren die Kommunen die Sport- und Freizeiteinrichtungen. 50,8\% schätzen hier die notwendigen finanziellen Belastungen als mindestens hoch ein. In den Bereichen Grünanlagen/Park, den Krankenhäusern sowie den Verund Entsorgungseinrichtungen wird der Investitionsbedarf hingegen aus quantitativer Sicht für relativ gering befunden. 
Zukünftige Investitionsbedarfe der sächsischen Kommunen aus qualitativer und quantitativer Perspektive

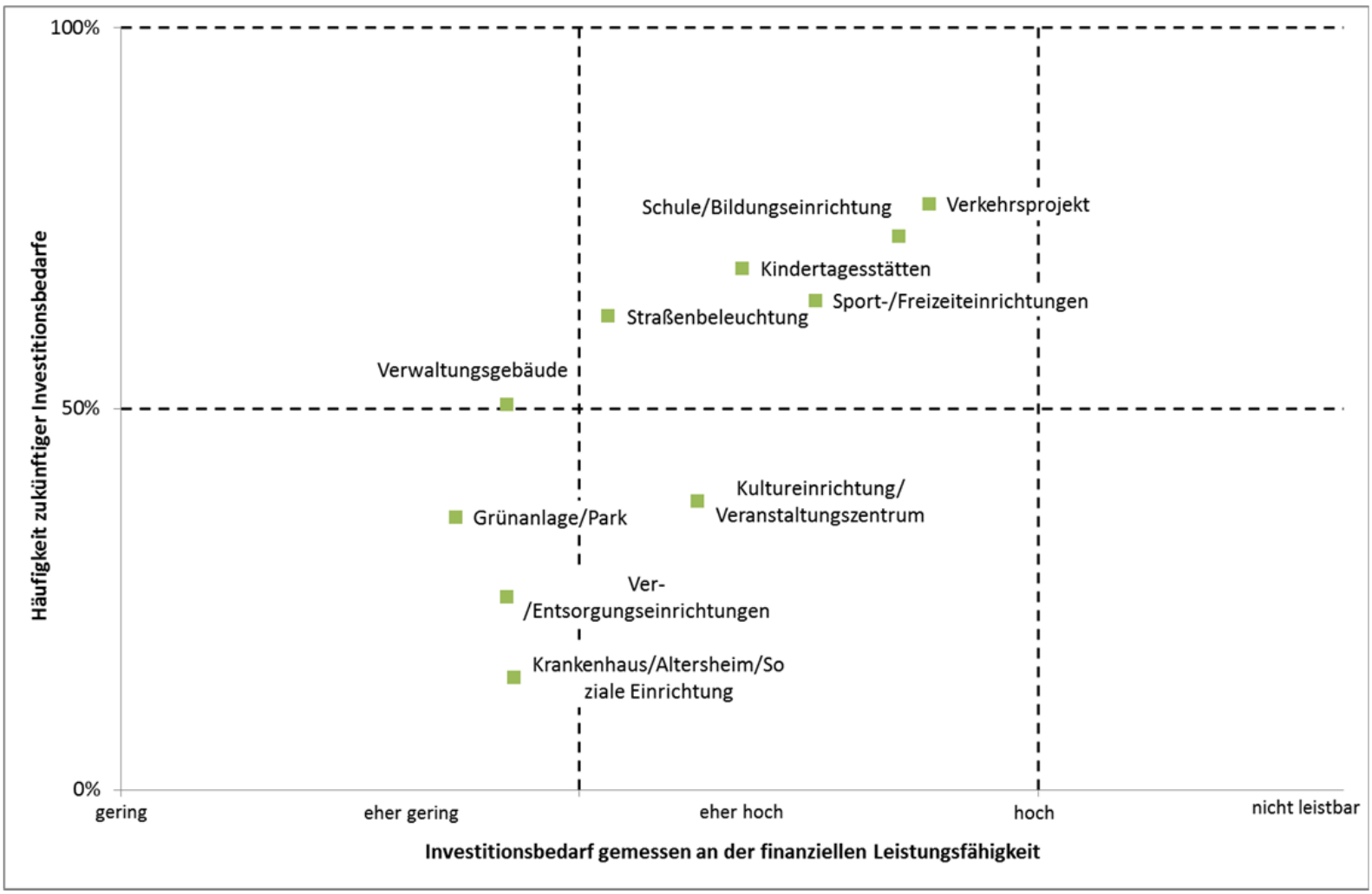

Abbildung 4: Investitionsbedarf gemessen an der Leistungskraft, $\mathrm{n}=92$

Quelle: Eigene Erhebung, eigene Darstellung.

Werden die beiden Fragen nach den investitionsbedeutsamen Aufgabenfeldern mit der Höhe der als notwendig angesehener Bedarfe gespiegelt, ${ }^{20}$ so lässt sich erkennen, dass zukünftig der Großteil der Investitionstätigkeiten auf fünf Aufgabenbereiche entfallen dürfte: Verkehrsprojekte, Schule und Bildungseinrichtungen, Kindertagesstätten, Sportund Freizeiteinrichtungen sowie Straßenbeleuchtung (mittlerer oberer Bereich der Abbildung). kraft durch ein arithmetisches Mittel standardisiert. Dabei wurde eine äquidistante Skala zugrunde gelegt. 
Demgegenüber finden sich Investitionen mit geringeren Investitionsbedarfen und geringeren Häufigkeiten im linken unteren Bereich der Abbildung. Es finden sich allerdings keine Investitionsbereiche, die von den Kommunen durchweg als tendenziell nicht leistbar eingestuft werden (oberer und unterer rechter Bereich der Abbildung)

\subsection{Qualität der derzeitigen Baumaßnahmen}

Alternative Beschaffungsansätze sind vor allem dann interessant, wenn durch deren Nutzung Verbesserungen gegenüber dem Status quo, z. B. durch die Nutzung von Effizienzpotentialen (insbesondere Einsparpotenzialen bei einem definierten Leistungsumfang) oder durch eine Verbesserung der Nachvollziehbarkeit und der Genauigkeit der Ergebnisse erzielt werden können. In diesem Zusammenhang wurden die Kommunen nach der Bewertung von konventionell realisierten Projekten hinsichtlich wichtiger, die Kosten und Qualität des Projekts bestimmender Aspekte befragt.

Die Befragung erfolgte nach einem Muster, welches das beste und das schlechteste Investitionsprojekt der jüngeren Vergangenheit thematisierte. Durch diese Betrachtung der Extremwerte wurde sich ein größerer Erkenntniswert für die Beschaffungswirklichkeit in den Kommunen erwartet als bei einer Frage nach durchschnittlichen Werten. 
Seite 19 | 58

Inwieweit sind bei Ihren über konventionelle Eigenrealisierung vollzogenen Projekten die nachfolgenden Punkte erreicht worden?

\begin{tabular}{|c|c|c|c|c|c|c|c|c|}
\hline & & $\begin{array}{c}\text { weit unter } \\
\text { der Planung }\end{array}$ & $\begin{array}{l}\text { unter der } \\
\text { Planung }\end{array}$ & $\begin{array}{c}\text { innerhalb der } \\
\text { Planung }\end{array}$ & $\begin{array}{l}\text { über der } \\
\text { Planung }\end{array}$ & $\begin{array}{c}\text { weit über der } \\
\text { Planung }\end{array}$ & $\begin{array}{c}\text { keine Angabe } \\
\text { möglich }\end{array}$ & \\
\hline \multirow{2}{*}{ Planungszeit } & bestes Projekt & $6,7 \%$ & $32,0 \%$ & $57,3 \%$ & $4,0 \%$ & $0,0 \%$ & $5,3 \%$ & \\
\hline & schlechtestes Projekt & $0,0 \%$ & $0,0 \%$ & $24,2 \%$ & $48,5 \%$ & $27,3 \%$ & $10,6 \%$ & \\
\hline \multirow{2}{*}{ Planungskosten } & bestes Projekt & $2,6 \%$ & $34,2 \%$ & $59,2 \%$ & $3,9 \%$ & $0,0 \%$ & $5,3 \%$ & \\
\hline & schlechtestes Projekt & $0,0 \%$ & $1,5 \%$ & $23,9 \%$ & $44,8 \%$ & $29,9 \%$ & $9,0 \%$ & \\
\hline \multirow{2}{*}{ Baukosten } & bestes Projekt & $9,1 \%$ & $54,5 \%$ & $27,3 \%$ & $9,1 \%$ & $0,0 \%$ & $3,9 \%$ & \\
\hline & schlechtestes Projekt & $0,0 \%$ & $0,0 \%$ & $11,4 \%$ & $44,3 \%$ & $44,3 \%$ & $5,7 \%$ & \\
\hline \multirow{2}{*}{ Bauzeit } & bestes Projekt & $5,4 \%$ & $28,4 \%$ & $55,4 \%$ & $10,8 \%$ & $0,0 \%$ & $5,4 \%$ & \\
\hline & schlechtestes Projekt & $0,0 \%$ & $3,0 \%$ & $14,9 \%$ & $47,8 \%$ & $34,3 \%$ & $7,5 \%$ & \\
\hline \multirow{2}{*}{ Bauqualität } & bestes Projekt & $2,8 \%$ & $5,6 \%$ & $80,3 \%$ & $11,3 \%$ & $0,0 \%$ & $7,0 \%$ & Legende \\
\hline & schlechtestes Projekt & $3,3 \%$ & $23,0 \%$ & $55,7 \%$ & $9,8 \%$ & $8,2 \%$ & $16,4 \%$ & $0 \%$ \\
\hline \multirow{2}{*}{ Betriebskosten } & bestes Projekt & $1,6 \%$ & $25,0 \%$ & $68,8 \%$ & $4,7 \%$ & $0,0 \%$ & $17,2 \%$ & $>0-<10 \%$ \\
\hline & schlechtestes Projekt & $0,0 \%$ & $5,1 \%$ & $39,0 \%$ & $45,8 \%$ & $10,2 \%$ & $20,3 \%$ & $20 \%$ \\
\hline \multirow{2}{*}{ Betriebsqualität } & bestes Projekt & $2,0 \%$ & $6,0 \%$ & $82,0 \%$ & $10,0 \%$ & $0,0 \%$ & $46,0 \%$ & $30-<40 \%$ \\
\hline & schlechtestes Projekt & $4,5 \%$ & $11,4 \%$ & $52,3 \%$ & $27,3 \%$ & $4,5 \%$ & $56,8 \%$ & $40-<50 \%$ \\
\hline \multirow{2}{*}{$\begin{array}{l}\text { Personeller } \\
\text { Aufwand }\end{array}$} & bestes Projekt & $3,6 \%$ & $19,6 \%$ & $66,1 \%$ & $10,7 \%$ & $0,0 \%$ & $33,9 \%$ & $50-<60 \%$ \\
\hline & schlechtestes Projekt & $0,0 \%$ & $2,0 \%$ & $42,0 \%$ & $46,0 \%$ & $10,0 \%$ & $40,0 \%$ & $>60 \%$ \\
\hline
\end{tabular}

Abbildung 5: Bewertung der konventionellen Realisierung, $n=77$ Quelle: Eigene Erhebung, eigene Darstellung.

Mit einer flüchtigen Analyse der Abbildung 5 könnten in diesem Zusammenhang zwei sehr verschiedene Punkte herausgestellt werden, die zwei konträre Positionen stützen. Zum einen kann festgestellt werden, dass bei den besten konventionell realisierten Projekten die Planungsvorgaben, was Planungszeit und Planungskosten sowie die Bauzeit und Baukosten betrifft, in ca. 90 \% der Fälle eingehalten oder sogar unterboten wurden. Insofern scheint kein Bedarf zur Nutzung alternativer Beschaffungskonzepte zu bestehen. Zum anderen ist allerdings ebenso festzustellen, dass bei den schlechtesten konventionell realisierten Projekten die Planungsvorgaben in teilweise weit über $70 \%$ der Fälle nicht erreicht wurden. Dieses Ergebnis hingegen unterstreicht einen Bedarf zur Nutzung alternativer Beschaffungskonzepte. Beide Aussagen sind empirisch abgesichert, fraglich ist jedoch, welche die Beschaffungswirklichkeit in den Kommunen eher trifft. Die 


\section{UNIVERSITÄT LEIPZIG}

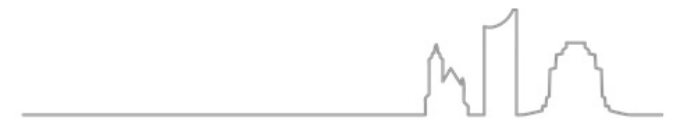

ÖPP - Kompetenzzentrum Sachsen am Institut für Öffentliche Finanzen und Public Management

Seite $20 \mid 58$

grafische Darstellung verdeutlicht zunächst einmal, dass es neben den gravierenden Abweichungen des jeweils besten und schlechtesten Projektes ebenso erhebliche Unterschiede zwischen den einzelnen Bereichen gibt.

\begin{tabular}{|c|c|c|c|c|c|c|c|}
\hline & & $\begin{array}{c}\text { weit unter } \\
\text { der Planung }\end{array}$ & $\begin{array}{l}\text { unter der } \\
\text { Planung }\end{array}$ & $\begin{array}{c}\text { innerhalb der } \\
\text { Planung }\end{array}$ & $\begin{array}{l}\text { über der } \\
\text { Planung }\end{array}$ & $\begin{array}{c}\text { weit über der } \\
\text { Planung }\end{array}$ & $\begin{array}{c}\text { keine Angabe } \\
\text { möglich }\end{array}$ \\
\hline \multirow{2}{*}{ Planungszeit } & bestes Projekt & $6,7 \%$ & $32,0 \%$ & $57,3 \%$ & $4,0 \%$ & $0,0 \%$ & $5,3 \%$ \\
\hline & schlechtestes Projekt & $0,0 \%$ & $0,0 \%$ & $24,2 \%$ & $48,5 \%$ & $27,3 \%$ & $10,6 \%$ \\
\hline \multirow{2}{*}{ Planungskosten } & bestes Projekt & $2,6 \%$ & $34,2 \%$ & $59,2 \%$ & $3,9 \%$ & $0,0 \%$ & $5,3 \%$ \\
\hline & schlechtestes Projekt & $0,0 \%$ & $1,5 \%$ & $23,9 \%$ & $44,8 \%$ & $29,9 \%$ & $9,0 \%$ \\
\hline
\end{tabular}

Abbildung 6: Einzelbetrachtung der Planungszeit und -kosten, $n=77$

Quelle: Eigene Erhebung, eigene Darstellung.

In den besten Projekten wurde die Planungsphase überwiegend (je zu fast $60 \%$ ) innerhalb des anvisierten Zeitrahmens realisiert. Rund $40 \%$ der Projekte konnten sogar schneller bzw. günstiger geplant werden. Insgesamt wurden so in den besten Projekten die für die Planung einkalkulierte Zeit und Kosten fast nie überschritten (je $96 \%$ ). Nur bei $4 \%$ dieser Projekte kam es in dieser Phase zu Verzögerungen. Ein konträres Bild dazu liefern allerdings die schlechtesten Projekte. Bei rund $76 \%$ kam es zu Zeit- und bei rund $75 \%$ zu Kostenüberschreitungen bereits in der Planungsphase. Im Gegensatz zu den besten Projekten ist hier nur ein Viertel innerhalb der Erwartungen geblieben.

\begin{tabular}{|c|c|c|c|c|c|c|c|}
\hline & & $\begin{array}{c}\text { weit unter } \\
\text { der Planung }\end{array}$ & $\begin{array}{l}\text { unter der } \\
\text { Planung }\end{array}$ & $\begin{array}{c}\text { innerhalb der } \\
\text { Planung }\end{array}$ & $\begin{array}{l}\text { über der } \\
\text { Planung }\end{array}$ & $\begin{array}{c}\text { weit über der } \\
\text { Planung }\end{array}$ & $\begin{array}{l}\text { keine Angabe } \\
\text { möglich }\end{array}$ \\
\hline \multirow{2}{*}{ Baukosten } & bestes Projekt & $9,1 \%$ & $54,5 \%$ & $27,3 \%$ & $9,1 \%$ & $0,0 \%$ & $3,9 \%$ \\
\hline & schlechtestes Projekt & $0,0 \%$ & $0,0 \%$ & $11,4 \%$ & $44,3 \%$ & $44,3 \%$ & $5,7 \%$ \\
\hline \multirow{2}{*}{ Bauzeit } & bestes Projekt & $5,4 \%$ & $28,4 \%$ & $55,4 \%$ & $10,8 \%$ & $0,0 \%$ & $5,4 \%$ \\
\hline & schlechtestes Projekt & $0,0 \%$ & $3,0 \%$ & $14,9 \%$ & $47,8 \%$ & $34,3 \%$ & $7,5 \%$ \\
\hline
\end{tabular}

Abbildung 7: Einzelbetrachtung der Baukosten und Bauzeit, $n=77$

Quelle: Eigene Erhebung, eigene Darstellung.

Bei den Baukosten ist auffällig, dass diese nur in unter $30 \%$ der Fälle den Planungsvorgaben entsprachen. Bei den schlechtesten Projekten werden diese in fast jedem Projekt überschritten (in ca. 90 \% der Projekte). Vielfach sind diese Überschreitungen sogar erheblich. Eine Unterschreitung fand nie statt und in nur ca. 11 \% der Fälle konnten die Planungsziele eingehalten werden. Im besten Projekt war eine Einhaltung der Vorgaben 


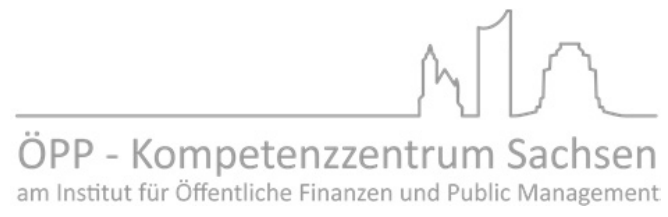

Seite $21 \mid 58$

immerhin in $27 \%$ der Fälle möglich. Allerdings wurden hier bei 64 \% der Projekte die geplanten Kosten nicht über-, sondern unterschritten. Dessen ungeachtet gaben immerhin noch $9 \%$ der Kommunen an, auch im besten Projekt die Baukosten überschritten zu haben. Wird von den positiven oder negativen Deutungsmöglichkeiten abgesehen, zeigt sich in diesem Bereich, dass die Planungsvorgaben entweder über- oder unterschritten werden. Deren Einhaltung ist im Bereich der Baukosten - zumindest in der betrachteten Auswahl der „Extremfälle“ - eher die Ausnahme.

Ein ähnliches Bild ergibt sich bei der Betrachtung der Bauzeit. Über 80 \% der antwortenden Kommunen gaben an, dass es im schlechtesten Projekt zu Verzögerungen gegenüber der Planung kam. Bei über einem Drittel waren diese sogar erheblich. Kürzere Bauzeiten gab es bei $3 \%$ bzw. bei den besten Projekten bei ca. $34 \%$. Allerdings kam es auch bei letzteren in rund $11 \%$ der Fälle zu Verzögerungen. In knapp über der Hälfte der besten Projekte konnten allerdings die Planungsvorgaben eingehalten werden. Die schlechtesten Projekte werden jedoch nur zu 15 \% innerhalb der Planung fertig. In diesen Fällen ist die Einhaltung der Bauzeit eher als Ausnahme zu werten und Überschreitungen sind als die Regel anzusehen. Von den besten Projekten wird jedes Dritte vorzeitig fertiggestellt. Exakt auf die Planung verlassen, konnte man sich bei diesen in rund $55 \%$ der Fälle.

Daran anknüpfend kann die analytische Frage gestellt werden, worin die Regel hinsichtlich der Effizienz öffentlicher Investitionsprojekte liegt. Eine solche Analyse ist mit den abgefragten Informationen nicht möglich und ist auch nicht Teil dieser Betrachtung. Dessen ungeachtet kann aus diesen Ergebnissen aber geschlossen werden, dass bei öffentlichen Beschaffungsprozessen eine genauere Projektvorbereitung unabdingbar ist. Aus den Recherchen des ÖPP-Kompetenzzentrums Sachsen zeigt sich immer wieder, dass aus Zeit- und Kostengründen bei konventionellen Eigenrealisierungen vielfach auf umfangreiche Bedarfs- und Substanzanalysen im Vorfeld, d. h. in der Planungsphase, verzichtet wird. In der Konsequenz - dies zeigen auch die Ergebnisse der Befragung entstehen ungenaue oder nur grob geschätzte Planungsvorgaben, die Abweichungen in den Kosten und der notwendigen Bauzeit bedingen. Ist die Bausubstanz bzw. der Baugrund besser als erwartet, dann entstehen positive Effekte. Ist dies nicht der Fall, kommt 


\section{UNIVERSITÄT LEIPZIG}

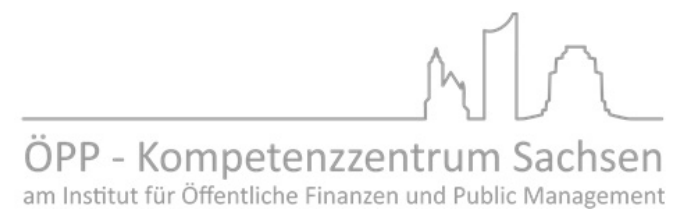

Seite 22 | 58

es zu negativen Abweichungen gegenüber der ursprünglichen Planung. Ähnlich gestaltet sich die Situation bei der Bedarfsanalyse. Die Nutzeransprüche werden vielfach erst in der Bauphase vollständig konkretisiert und voll umfänglich eingebracht. Verzögerungen und Kostensteigerungen entstehen dann, wenn diese im Vorfeld nicht bereits im vollen Umfang bedacht oder im laufenden Verfahren abgewehrt werden können. ${ }^{21}$ Insgesamt kann anhand der Zahlen ein Zusammenhang zwischen Kostensteigerungen und Bauzeitüberschreitungen hergestellt werden. Später eingebrachte Nutzerwünsche führen auf diese Weise während der Bauphase zu mitunter aufwendigen Planungsänderungen, die hohe Kosten verursachen und viel Zeit in Anspruch nehmen. Dass diese aber zugleich durch eine intensivere Vorbereitung vermeidbar sind, zeigen die besten Projekte. Dabei ist auffällig, dass Kostensenkungen in der Bauphase nicht im gleichen Maße zu Bauzeitverkürzungen führen. Planung $\quad$\begin{tabular}{c} 
Planung \\
\hline
\end{tabular}

\begin{tabular}{|c|c|c|c|c|} 
der Planung & Planung & $\begin{array}{c}\text { Planung } \\
\text { Planung }\end{array}$ \\
\hline
\end{tabular}

\begin{tabular}{|c|c|c|c|c|}
\hline $2,8 \%$ & $5,6 \%$ & $80,3 \%$ & $11,3 \%$ & $0,0 \%$ \\
\hline $3,3 \%$ & $23,0 \%$ & $55,7 \%$ & $9,8 \%$ & $8,2 \%$ \\
\hline
\end{tabular}

Abbildung 7: Einzelbetrachtung der Bauqualität, $n=77$ Quelle: Eigene Erhebung, eigene Darstellung.

Die Bauqualität wird im überwiegenden Teil der Projekte erfüllt oder sogar übererfüllt. Dies betrifft rund $92 \%$ der besten und ca. $74 \%$ der schlechtesten Projekte. Nur in rund $8 \%$ bzw. $26 \%$ wurden die geplanten Anforderungen nicht erreicht. Dies deutet darauf hin, dass die meisten Kommunen im Freistaat ihre Anforderungen im Ausschreibungsverfahren und während der Planung sehr genau definieren können. Mängel bei der Planung und Verzögerungen im Baugeschehen führen demnach durchaus zu erheblichen Kostenüberschreitungen, in aller Regel aber nicht zu Verminderungen der baulichen Qualität. Einschränkend ist jedoch zum einen anzumerken, dass daraus keine Rückschlüsse auf den abgelieferten Standard der Bauqualität gezogen werden können. Die nanzen, Ergebnisse der überörtlichen Kommunalprüfung, S. 141ff; Rechnungshof des Freistaates Sachsen (2009): Jahresbericht 2009, S. $387 f f$. 


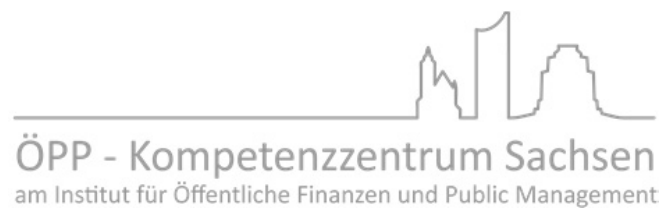

Seite $23 \mid 58$

Einhaltung der Planungsvorgaben gibt keine Auskunft über die Qualitätsansprüche, die der Planung zugrunde gelegt wurden, z. B. hinsichtlich des Einsatzes hochwertiger und umweltschonender Materialien und nachhaltiger Bewirtschaftung während der Betriebsphase. Zum anderen ist festzustellen, dass sich im Vergleich zu den vorherigen aufgeführten Bereichen die Anzahl der Kommunen, die zu diesem Punkt keine Angabe gemacht haben, stark erhöht.

\begin{tabular}{|c|c|c|c|c|c|c|c|}
\hline & & $\begin{array}{c}\text { weit unter } \\
\text { der Planung }\end{array}$ & $\begin{array}{l}\text { unter der } \\
\text { Planung }\end{array}$ & $\begin{array}{c}\text { innerhalb der } \\
\text { Planung }\end{array}$ & $\begin{array}{l}\text { über der } \\
\text { Planung }\end{array}$ & $\begin{array}{c}\text { weit über der } \\
\text { Planung }\end{array}$ & $\begin{array}{c}\text { keine Angabe } \\
\text { möglich }\end{array}$ \\
\hline \multirow{2}{*}{ Betriebskosten } & bestes Projekt & $1,6 \%$ & $25,0 \%$ & $68,8 \%$ & $4,7 \%$ & $0,0 \%$ & $17,2 \%$ \\
\hline & schlechtestes Projekt & $0,0 \%$ & $5,1 \%$ & $39,0 \%$ & $45,8 \%$ & $10,2 \%$ & $20,3 \%$ \\
\hline \multirow{2}{*}{ Betriebsqualität } & bestes Projekt & $2,0 \%$ & $6,0 \%$ & $82,0 \%$ & $10,0 \%$ & $0,0 \%$ & $46,0 \%$ \\
\hline & schlechtestes Projekt & $4,5 \%$ & $11,4 \%$ & $52,3 \%$ & $27,3 \%$ & $4,5 \%$ & $56,8 \%$ \\
\hline \multirow{2}{*}{$\begin{array}{c}\text { Personeller } \\
\text { Aufwand }\end{array}$} & bestes Projekt & $3,6 \%$ & $19,6 \%$ & $66,1 \%$ & $10,7 \%$ & $0,0 \%$ & $33,9 \%$ \\
\hline & schlechtestes Projekt & $0,0 \%$ & $2,0 \%$ & $42,0 \%$ & $46,0 \%$ & $10,0 \%$ & $40,0 \%$ \\
\hline
\end{tabular}

Abbildung 8: Einzelbetrachtung der Betriebskosten, Betriebsqualität und des personellen Aufwands, $n=77$ Quelle: Eigene Erhebung, eigene Darstellung.

Noch deutlicher wird diese Entwicklung für die Bereiche Betriebskosten und Betriebsqualität sowie den personellen Aufwand. Konnte die Kategorie „keine Angabe möglich“ bisher noch vernachlässigt werden, so kommt dieser nun eine enorme Aussagekraft zu. Rund ein Fünftel der sächsischen Kommunen kann zu den Betriebskosten keine Aussage treffen. Den personellen Aufwand kann sogar über ein Drittel der sächsischen Kommunen nicht bewerten. Bei der Qualität des Betriebes werden es noch einmal deutlich mehr, knapp unter 50 \% im besten Projekt bzw. sogar deutlich darüber im schlechtesten Projekt. Dabei ist zu berücksichtigen, dass dies grundsätzlich aus zwei Gründen der Fall sein kann: Zum einen weil keine Einschätzung gewollt ist. Dies geschieht regelmäßig, um als negativ empfundene Antworten zu vermeiden - was hierbei bei den Kategorien „über der Planung“ und „weit über der Planung“ insbesondere im besten Projekt von Relevanz sein kann. Zum anderen, weil tatsächlich keine Angabe gemacht werden kann, da die notwendigen Kenntnisse nicht vorhanden sind. Dies kann an unterschiedlichen Gründen liegen. Entweder die notwendigen, aber grundsätzlich vorhandenen Daten sind nicht bekannt bzw. nicht mit einem als angemessen empfundenen Aufwand verfügbar oder diese wurden gar nicht ermittelt. In jedem Fall können die Ergebnisse als ein Hin- 


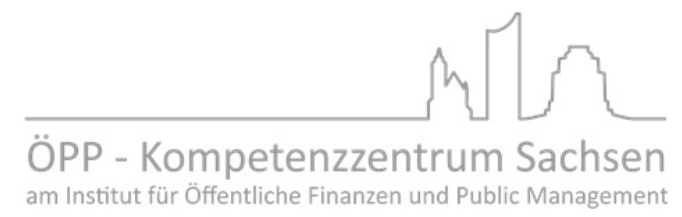

Seite $24 \mid 58$

weis darauf verstanden werden, dass Qualität und Kosten des Betriebs öffentlicher Infrastruktureinrichtungen deutlich weniger im Fokus liegen als Qualität und Kosten der Erstellung. Vor dem Hintergrund, dass im Betrieb rund zwei Drittel der im Lebenszyklus einer Infrastruktureinrichtung entstehenden Kosten anfallen ${ }^{22}$, sind dies durchaus bedenkliche Werte.

Zudem zeigen die vorhandenen Angaben, dass die Planungswerte im schlechtesten Projekt zu 56 \% überschritten werden, was die direkten und die indirekten Betriebskosten in Form von personellem Aufwand betrifft. Im besten Projekt werden die diesbezüglichen Planungen allerdings - sofern ggf. vorhandene Verzerrungswirkungen vernachlässigt werden - zu 95 \% (Betriebskosten) bzw. rund 90 \% (Personeller Aufwand) eingehalten oder unterboten. Die Betriebsqualität als Kategorie mit den wenigsten Angaben wird in den besten Projekten erwartungsgemäß erfüllt oder gar leicht übererfüllt. Auch unter den schlechtesten Projekten wird in der Hälfte der angegebenen Fälle die geplante Betriebsqualität erreicht - freilich zu höheren Kosten. Interessanterweise weisen die Antworten in rund einem Viertel der Fälle eine Übererfüllung der Betriebsqualität im schlechtesten Investitionsprojekt aus. Diese gehen gemäß der empirischen Daten jeweils mit einer Überschreitung der Betriebskosten einher, sodass in diesen Fällen von einer Abweichung der Planung vom tatsächlichen Betrieb ausgegangen werden kann. Dies könnte auf eine fehlerhafte Planung aber auch auf die unzureichende Abstimmung mit den Nutzern der Einrichtungen zurückzuführen sein, die zu Nachträgen zur Planung führen und damit Mehrkosten im Betrieb verursachen. 


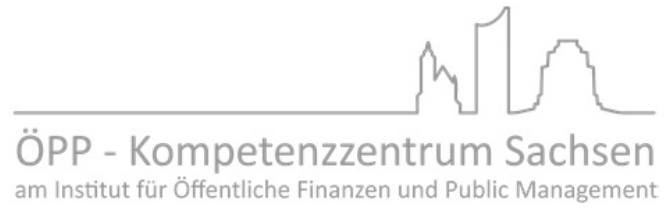

Seite $25 \mid 58$

Die Planung und Wirtschaftlichkeitsuntersuchung bei konventionellen Projekten umfasst angesichts der Ergebnisse der Befragung offenbar nur in den seltensten Fällen die gesamten Betriebskosten. Verbindliche Planungen mit fixen Entgelten und Leistungskatalogen über lange Zeiträume oder gar den gesamten Lebenszyklus der Immobile, wie es z. B. bei ÖPP üblich ist, existieren dem Anschein nach nur in seltenen Fällen.

\section{Bewertung von Öffentlich-Privaten Partnerschaften}

\subsection{Allgemeine Einstellung zu ÖPP}

In der öffentlichen Debatte ist der Begriff ÖPP nicht selten negativ besetzt. Obwohl sich Vertrags-ÖPP, wie sie beispielsweise im kommunalen Hochbaubereich existieren, grundsätzlich von institutionellen ÖPP, die u. a. im Ver- und Entsorgungsbereich genutzt wurden, unterscheiden, werden die Folgen und Wirkungen teilweise unreflektiert vermischt. Dabei wird ÖPP nicht selten abstrakt als Weg und ersten Schritt zur vollständigen Privatisierung von öffentlichen Aufgaben kritisiert. Allerdings wird dann oft unterschlagen, dass die öffentliche Hand auf vielfältige Weise privatwirtschaftliche Unternehmen mit der Erstellung öffentlicher Leistungen beauftragt. So ist es auch bei kommunalen Infrastrukturvorhaben der Normalfall, dass die Projektplanung an private Planungs- und Ingenieursbüros vergeben wird und ebenso die Durchführung von Bau-, Unterhaltungsund Sanierungsleistungen privaten Unternehmen obliegt, die ihre Aufträge mittels Ausschreibungen erhalten. Öffentlich-private Partnerschaften sind hierbei eine mögliche Alternativvariante zur organisatorischen Ausgestaltung der öffentlichen Leistungserbringung.

Bei Vertrags-ÖPP, wie sie bei Hochbauprojekten angewendet werden, findet zudem in der Regel nur formal eine Privatisierung statt, die Eigentumsverhältnisse ändern sich dabei nicht. Die Kommune ist weiterhin der alleinige Eigentümer der Infrastruktur. Dies unterscheidet sich grundsätzlich von institutionellen ÖPP und materiellen Privatisierungen, 


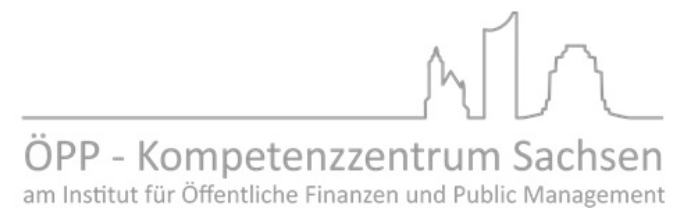

Seite $26 \mid 58$

bei denen der private Partner (Mit-)Eigentümer der Infrastruktur wird und entsprechend seiner Rechte den Leistungskatalog mitbestimmen kann. Privatisierungen und institutionelle ÖPP sind daher nicht mit Vertrags-ÖPP bei Infrastrukturprojekten gleichzusetzen.

Die Leistungsbestimmung und die Leistungskontrolle obliegen bei Vertrags-ÖPP weiterhin der Kommune, die entsprechende Einzelheiten vertraglich umfassend regeln kann und ggf. durch verschiedene Mechanismen, wie beispielsweise Bonus-/Malus-Regelungen auch in der Betriebsphase gegensteuern kann. Das operative Objektmanagement wird allerdings von einem privaten Partner verantwortet, der die notwendigen Leistungen in einer vertraglich vereinbarten Quantität und Qualität liefert.

Die Diskussion um die Nutzung von öffentlich-privaten Partnerschaften wird kontrovers geführt. So wird von Seiten der Kritiker argumentiert, dass durch ÖPP Arbeitsplätze vernichtet und wichtige Bereiche der kommunalen Daseinsvorsorge auf diese Weise zunehmend dem Primat der reinen Gewinnorientierung unterworfen werden. ${ }^{23}$ Unbestritten existieren bei derartigen Beschaffungsalternativen gewisse Realisierungsvoraussetzungen und spezifische Risiken, die geprüft und berücksichtigt werden müssen. Die oft sehr ideologisch geführte Debatte erschwert aber häufig einen objektiven Blick auf die Chancen und Risiken der Beschaffungsvariante. Aus diesen Gründen lag eine Intention des Fragebogens darin, zu erörtern, ob in sächsischen Kommunen diese Möglichkeiten bei Projektrealisierungen bereits in der Vergangenheit Berücksichtigung fand, wie gut die Kenntnisse der Kommunen bezüglich ÖPP sind und wie sich deren grundsätzliche Bereitschaft darstellt, Leistungen an Private Dritte zu übertragen. Fraglich ist, in welchem Umfang seitens der sächsischen Kommunen eine grundsätzlich positive oder negative Stimmung gegenüber dem Thema ÖPP herrscht und welche Hintergründe eine diesbezügliche Einschätzung hat. Liegenschaftsmanagement in ver.di. Bundesfachbereich Bund und Länder, S. $3 f$. 
Haben Sie zur Projektrealisierung schon einmal alternative Beschaffungsvarianten genutzt? (Mehrfachauswahl möglich)

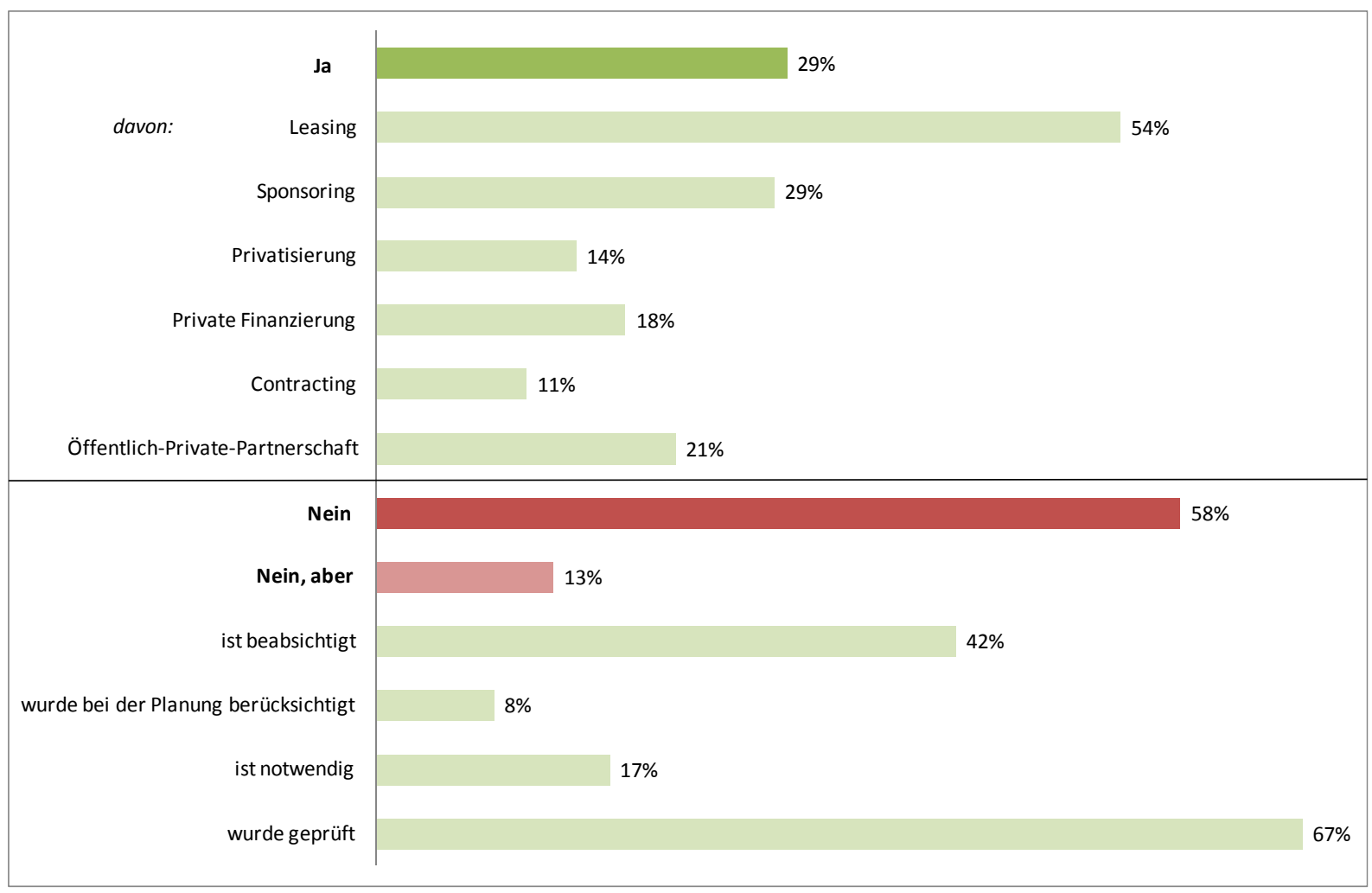

Abbildung 9: Erfahrung mit alternativen Beschaffungsvarianten, $\mathrm{n}=95$

Quelle: Eigene Erhebung, eigene Darstellung.

Die Frage, ob zur Projektrealisierung schon einmal alternative Beschaffungsvarianten genutzt wurden, bejahten 29 \% der befragten sächsischen Kommunen. Diese haben vor allem im Bereich der Finanzierung auf stärkere private Beteiligungen gesetzt. Neben Leasingerfahrungen (54\%) wurden vor allem Sponsoring (29\%) und private Finanzierung (18\%) genannt. In nur vier der mit Ja antwortenden Kommunen (14\%) kam es zu Privatisierungen. Vor dem Hintergrund, dass es auch in Sachsen seit Mitte der 1990er Jahre zahlreiche Privatisierungen ${ }^{24}$ im Bereich der kommunalen Stadt- und Wasserwerke sowie im Wohnungsbau gegeben hat, erscheint dieser Wert möglicherweise zu gering. 


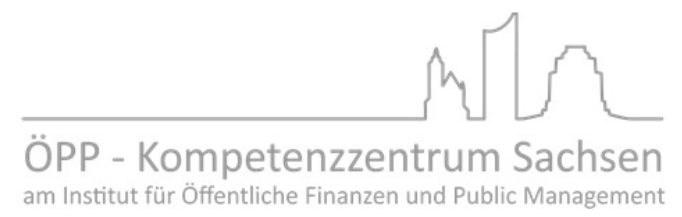

Seite $28 \mid 58$

Aufgrund der Frage nach einer „Beschaffungsvariante“ ist aber anzunehmen, dass die Kommunen entsprechende organisatorischen Umstrukturierungs- und Privatisierungsaktivtäten der Vergangenheit nicht unter dieser Position einordnen würden.

Dass immerhin sechs ( $21 \%$ ) der Kommunen, die bereits alternative Beschaffungsvarianten genutzt haben, angeben, dabei auf ÖPP zurückgegriffen zu haben, ist ein überraschend hoher Wert. In Sachsen wurden bisher lediglich sechs ÖPP-Projekte realisiert, ${ }^{25}$ jedoch haben nur drei dieser Kommunen an der Umfrage teilgenommen. Bei der Beantwortung der Frage könnte es auf Grund eines weiteren Begriffsverständnisses von ÖPP zu Überscheidungen gekommen sein, denn auch materielle Teilprivatisierungen stellen institutionelle ÖPP-Modelle dar. Öffentliche Hand und private Unternehmen arbeiten dabei als Partner in einem gemeinsamen Unternehmen zusammen. Ein anderer wahrscheinlicher Erklärungsansatz ist, dass in einigen Kommunen die Beschaffungsvariante ÖPP schon einmal umfassend, d. h. im Rahmen der Planung, geprüft wurde, aber letztlich keine ÖPP-Projektrealisierung stattgefunden hat. Im Rahmen seiner Arbeit hat das ÖPP-Kompetenzzentrum Sachsen bereits festgestellt, dass es in einigen sächsischen Kommunen Ansätze zur Nutzung des ÖPP-Beschaffungsansatzes gab. Die meisten Projekte wurden dabei aber aus verschiedenen Gründen nicht bis zur Realisierung vorangebracht.

Contracting wurden von $11 \%$ der Kommunen, die bereits alternative Beschaffungsverfahren genutzt haben, genannt. Hierbei stehen wie bei der öffentlich-privaten Partnerschaft nicht ausschließlich Finanzierungsaspekte, sondern auch Bauausführung, technische Instandhaltung und Wartung der entsprechenden technischen Anlagen im Mittelpunkt. Insofern ist Contracting eine Teilmenge der möglichen ÖPP-Varianten.

Die überwiegende Mehrheit der sächsischen Kommunen (71\%) hat zur Projektrealisierung bisher noch keine alternative Beschaffungsvariante genutzt. Allerdings gaben $13 \%$ deutschland.de/oepp-markt/projektdatenbank/. 
an, diese alternativen Varianten zwar noch nicht genutzt, aber sie bereits bei vergangenen Projekten in Erwägung gezogen zu haben oder deren Einbeziehung zukünftig nutzen zu wollen. So haben $67 \%$ dieser Kommunen alternative Beschaffungsmaßnahmen bereits allgemein geprüft. Bei $8 \%$ wurden diese bereits in den Planungen berücksichtigt und $42 \%$ beabsichtigen sie zukünftig zu nutzen. Welche alternative(n) Beschaffungsvariante(n) dabei geprüft wurde(n), wie diese Prüfung durchgeführt wurde und aus welchen Gründen letztlich keine Nutzung stattgefunden hat, war grundsätzlich nicht Teil der Befragung. Für die Beschaffungsvariante ÖPP wurde ungeachtet einer vorhandenen Prüfung im weiteren Fragebogenverlauf (Abbildung 13) nach den Gründen der bisherigen Nichtnutzung gefragt. ${ }^{26}$ Vorher sollte aber noch allgemein die Einstellung der Kommunen zu ÖPP-Projekten in Erfahrung gebracht werden. 


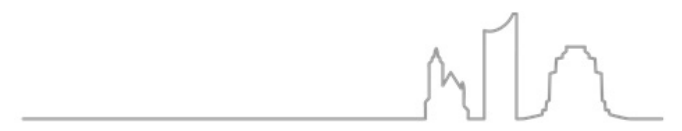

ÖPP - Kompetenzzentrum Sachsen am Institut für Öffentliche Finanzen und Public Management

Seite $30 \mid 58$

Wie ist Ihre derzeitige Haltung zu ÖPP- bzw. PPP-Projekten?

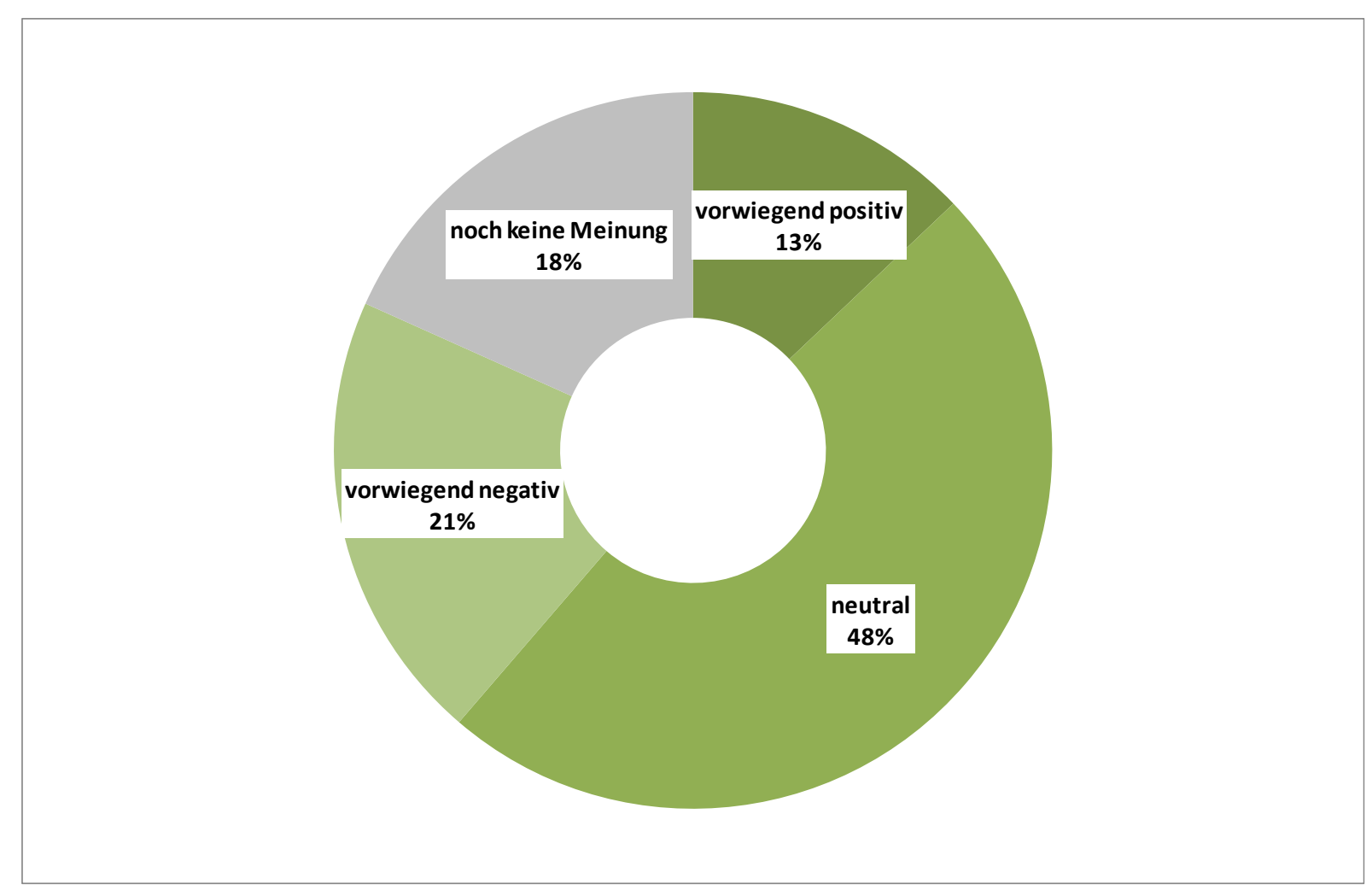

Abbildung 10: Grundeinstellung zu ÖPP, $n=93$

Quelle: Eigene Erhebung, eigene Darstellung.

Die sächsischen Kommunen haben hinsichtlich ÖPP keine eindeutig zustimmende oder ablehnende Position. Knapp die Hälfte der sächsischen Kommunen (48 \%) ist dem Thema ÖPP gegenüber neutral eingestellt. In rund einem Fünftel (18\%) der befragten Kommunen hat man sich noch keine verfestigte Meinung bezüglich dieser alternativen Beschaffungsvariante gebildet. Im Gegensatz zu diesem überwiegend offenen Meinungsbild gibt immerhin jede fünfte Kommune an, eine vorwiegend negative Haltung zu ÖPP zu haben.

Wird dieses allgemeine Stimmungsbild mit den konkreten Erfahrungen mit alternativen Beschaffungsvarianten verglichen (Abbildung 11), so zeigt sich, dass diejenigen Kommunen, die bereits in der Vergangenheit auf alternative Finanzierungs- und Beschaffungsmethoden zurückgegriffen haben, gegenüber ÖPP positiver eingestellt sind als diejeni- 
gen ohne entsprechende Erfahrungen. Von den sechs Kommunen, die angaben, bereits über konkrete Erfahrungen im ÖPP-Bereich zu verfügen, gaben vier eine positive Grundeinstellung an.

\section{Einstellung zu ÖPP- bzw. PPP-Projekten differenziert nach Erfahrungsstatus}

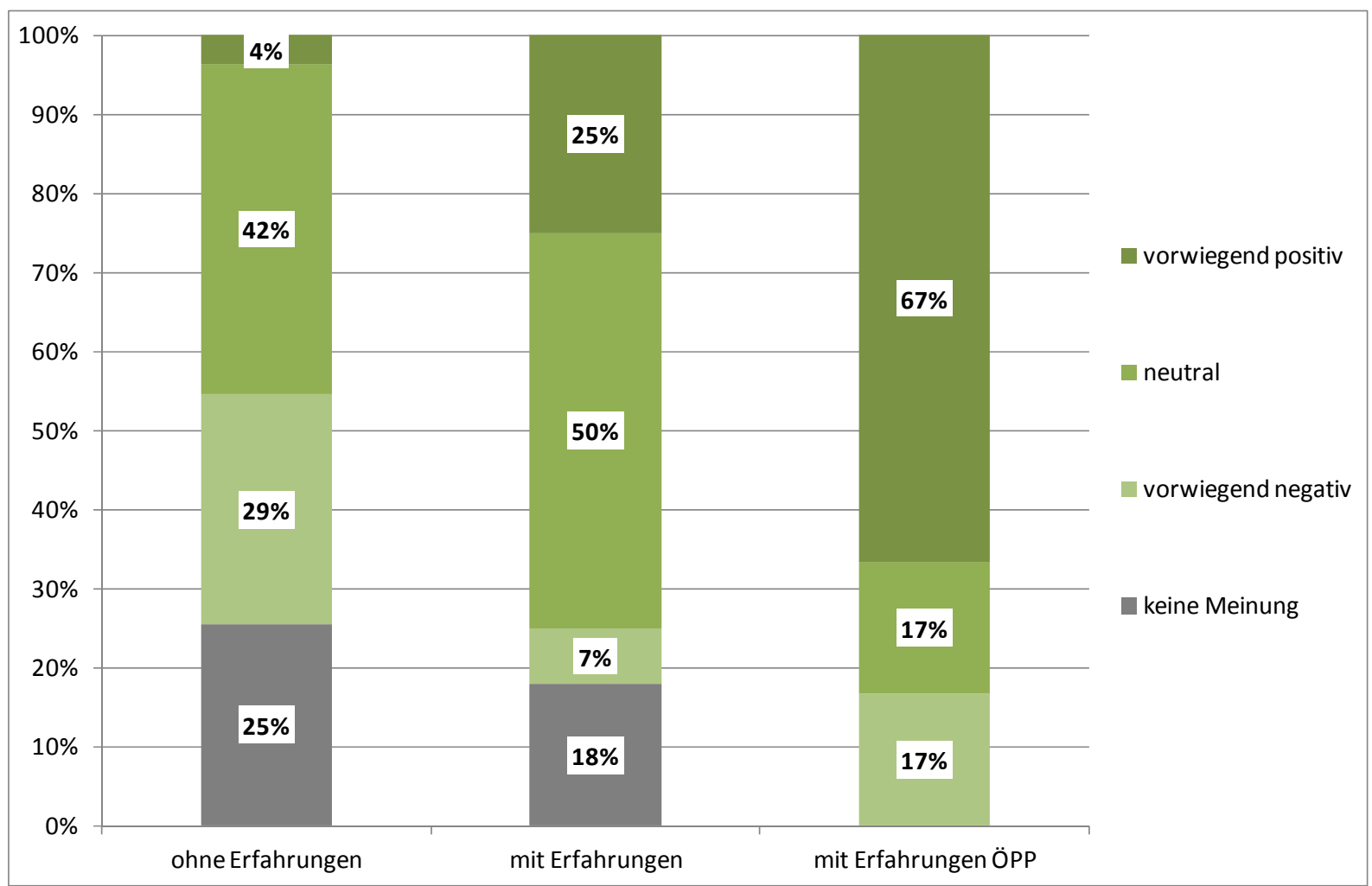

Abbildung 11: Grundeinstellung zu ÖPP, $n=93$

Quelle: Eigene Erhebung, eigene Darstellung.

Auch wenn die Ergebnisse auf Grund der relativ geringen Fallzahlen nicht überschätzt werden sollten, kann abgeleitet werden, dass mit dem Wissen um alternative Finanzierungs- und Beschaffungsverfahren auch eine offenere Grundhaltung gegenüber ÖPP einhergeht. Dieses Resultat ist sicherlich vor dem Hintergrund der bis jetzt sehr geringen Anzahl durchgeführter ÖPP-Projekte im Freistaat zu sehen. Fehlende praktische Erfahrung und mangelnde theoretische Kenntnisse begünstigen dabei das vorwiegend indifferente Meinungsbild. 


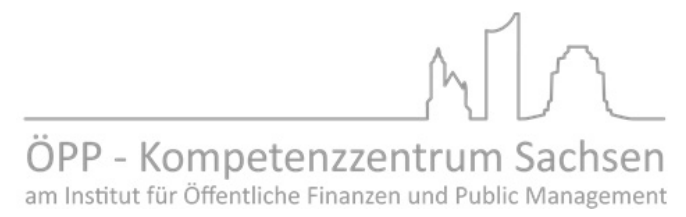

Seite $32 \mid 58$

Wie schätzen Sie das Wissen über ÖPP in Ihrer Kommunalverwaltung insgesamt ein?

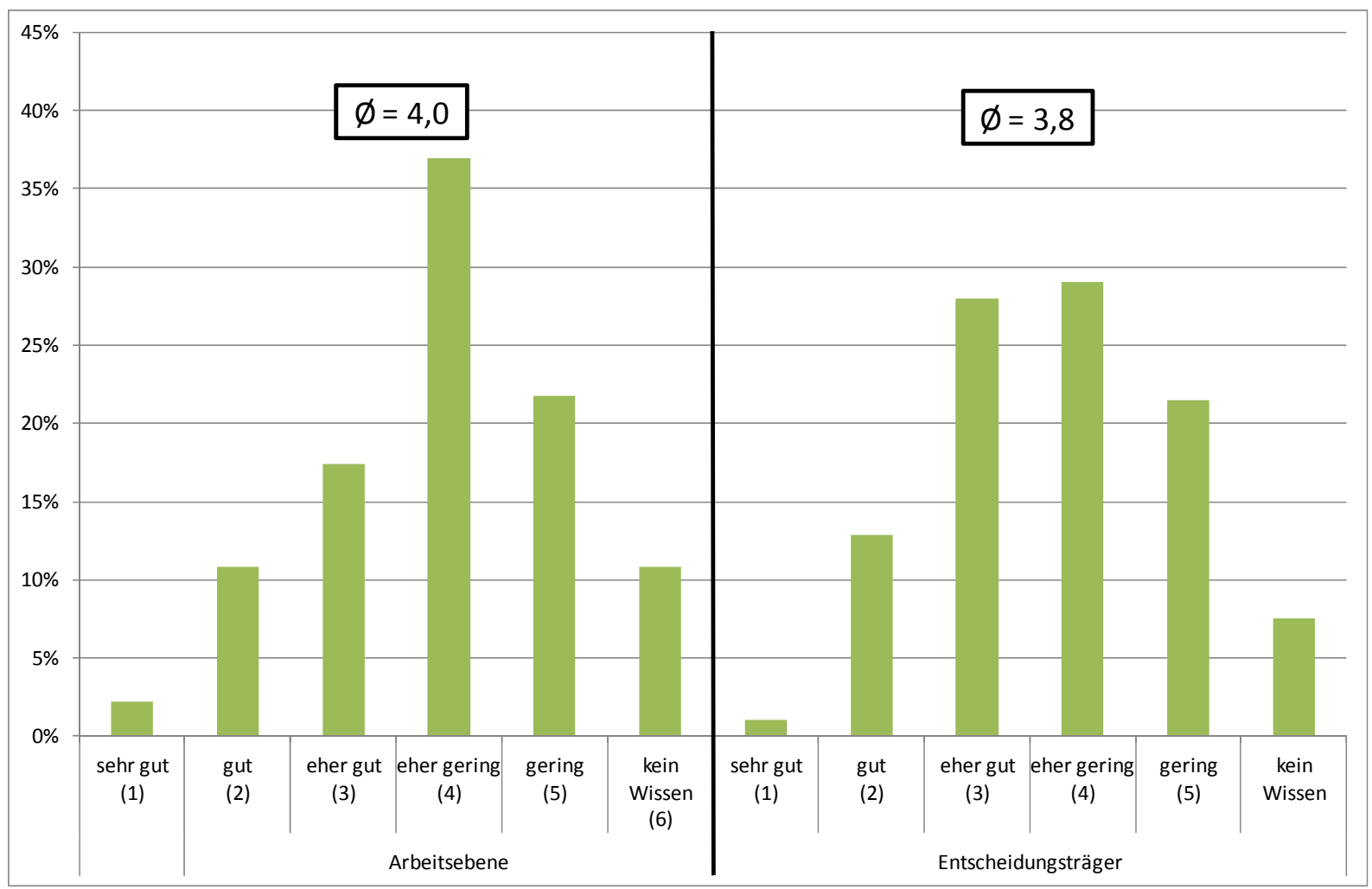

Abbildung 12: Absolute Verteilung des Wissens über ÖPP in der Verwaltung, $n=93$ Quelle: Eigene Erhebung, eigene Darstellung.

Die sächsischen Kommunen schätzen das Wissen über ÖPP in der eigenen Kommunalverwaltung sowohl auf der Arbeitsebene als auch auf der Ebene der Entscheidungsträger im Durchschnitt als eher gering ein (vgl. Abbildung 13). Die überwiegend neutrale Haltung der sächsischen Kommunen dem Thema ÖPP gegenüber, korrespondiert somit mit einer geringen oder fehlenden Sachkenntnis. Die Abbildung zeigt, dass auf der Ebene der Entscheidungsträger die Antworten etwas gleichmäßiger verteilt sind, als auf der Arbeitsebene. Dabei wird deutlich, dass in immerhin rund $30 \%$ der Kommunen „eher gute" oder bessere Kenntnisse vorherrschen. Die meisten Antworten entfielen jedoch auf die Kategorien "eher gering" und "gering". Eine intensive Auseinandersetzung mit dem Thema ÖPP hat offensichtlich bisher in der Mehrzahl der sächsischen Kommunen kaum stattgefunden. Vor diesem Hintergrund werden ganz unterschiedliche Gründe für die Nichtnutzung von ÖPP als Beschaffungsvariante angeführt. 


\subsection{Erwartungen der Kommunen gegenüber ÖPP}

Was sind bzw. waren die Gründe für die Nichtnutzung von ÖPP als Beschaffungsvarianten? (Mehrfachnennungen möglich)

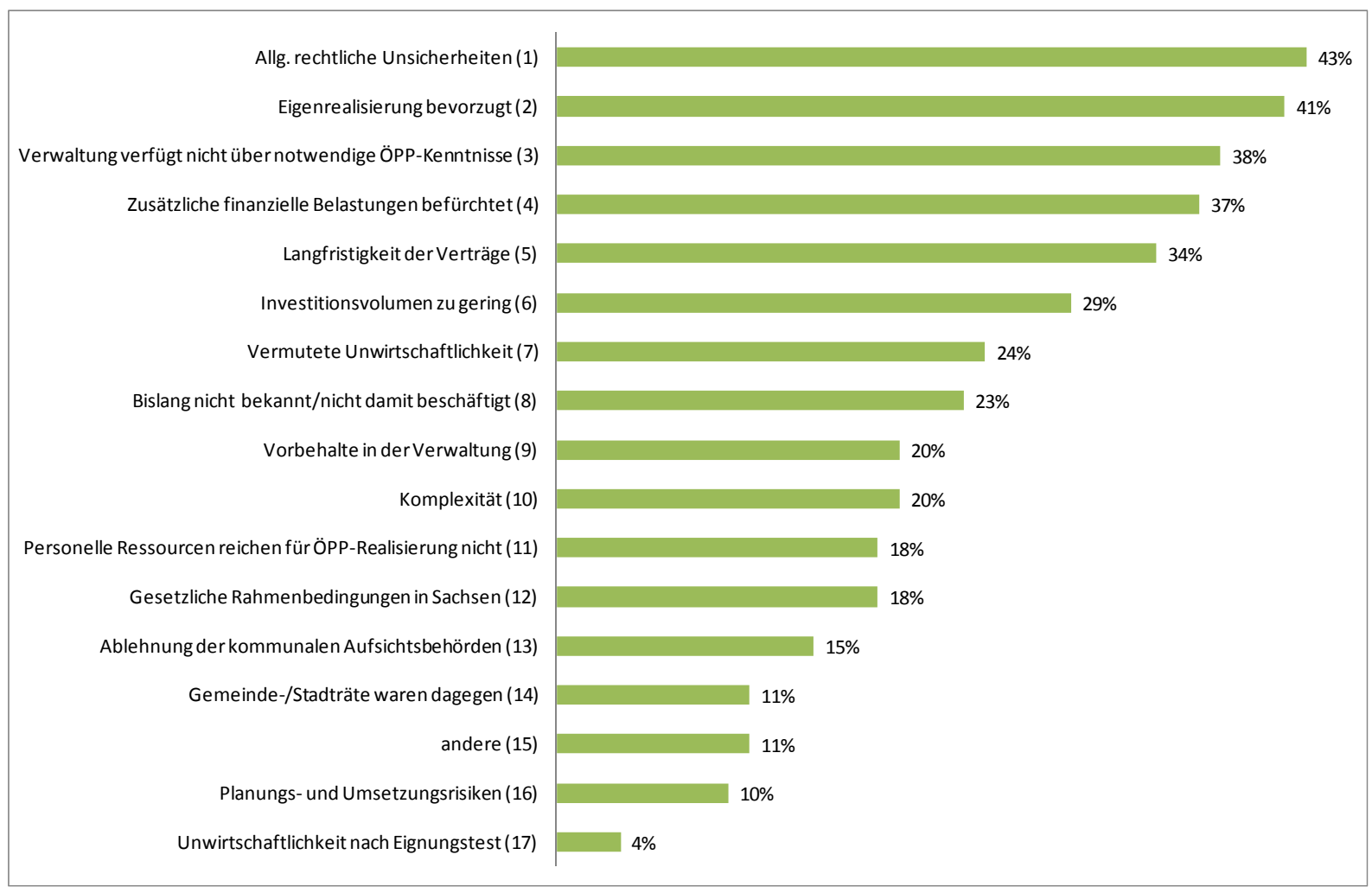

Abbildung 13: Gründe zur Nichtnutzung von ÖPP, $\mathrm{n}=82$

Quelle: Eigene Erhebung, eigene Darstellung.

Die sächsischen Kommunen begründen ihre starke Zurückhaltung bei der Nutzung von ÖPP-Projekten vor allem durch einen mangelnden Informationsstand (Ränge 1, 3, 8 und 9). Darunter fallen auch die Unsicherheiten hinsichtlich der rechtlichen Vorgaben. Hierbei ist zu berücksichtigen, dass im Freistaat Sachsen die Anforderungen an ÖPP- 


\section{UNIVERSITÁT LEIPZIG}

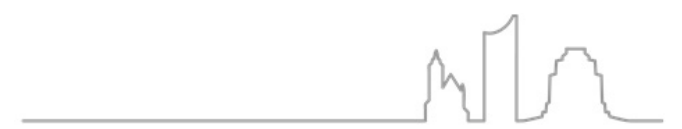

ÖPP - Kompetenzzentrum Sachsen

am Institut für Öffentliche Finanzen und Public Management

Seite 34 | 58

Realisierungen wesentlich höher sind als an konventionelle Realisierungen. ${ }^{27}$ Gerade kleinere Kommunen stellt dies vor besondere Herausforderungen, da personelle Ressourcen gebunden werden. Zudem wurden im Freistaat Sachsen zur Sicherstellung einer soliden Haushaltsplanung insbesondere Finanzierungs-ÖPP, die primär auf eine über den vorgesehenen Kreditrahmen hinausreichende Ausweitung der Verschuldung abzielen, verhindert (sog. „ÖPP der 1. Generation“). Dies konterkarierte die daraus resultierenden negativen Verschuldungsentwicklungen, wie sie in anderen Bundesländern zum Teil auftraten. Gleichzeitig entstanden dabei aber rechtliche Unsicherheiten, die die sächsischen Kommunen am Einsatz von ÖPP aus anderen Gründen hindern. Allgemeine rechtliche Unsicherheiten werden deshalb von den befragten Kommunen mit 43 \% als Hauptgrund neben fehlenden Fachkenntnissen (38\%) genannt. Die spezifischen rechtlichen Rahmenbedingungen in Sachsen spielten für die sächsischen Kommunen in der Frage der Nichtnutzung eine geringere Rolle (18\%).

In einen engen Zusammenhang mit der geringen Kenntnis und der Skepsis gegenüber der Thematik ÖPP ist eine starke Zustimmung zur pauschalen Präferenz für die Eigenrealisierung zu stellen (41\%). Hierbei ist nochmals in Erinnerung zu rufen, dass bei der Eigenrealisierung ein Großteil der verbundenen Leistungen nicht von der Verwaltung selbst, sondern ebenfalls von privatwirtschaftlichen Unternehmen erbracht wird. Insofern ist ein „Heraushalten“ privater Akteure bei der Eigenrealisierung nicht gegeben.

Eine zweite Gruppe von Antworten lässt sich aus den Rängen 4 bis 7 bilden. Hier werden projektspezifische Positionen angeführt, die Nachteile aus der finanziellen Bindung und der Langfristigkeit der Verträge thematisieren, die für ÖPP charakteristisch sind. Diese Resultate zeigen, dass eine intensive Auseinandersetzung mit ÖPP im Einzelfall erforder-

27 Die VwV Komminvest stellt an die Beurteilung der Wirtschaftlichkeit von kreditähnlichen Rechtsgeschäften die Voraussetzungen der dauernden Leistungsfähigkeit, den Grundsatz der sparsamen und wirtschaftlichen Haushaltsführung sowie die Sicherstellung der Aufgabenerfüllung. Hier gleichen die Anforderungen denen an konventionelle Projekte. Abweichungen ergeben sich insbesondere bei der Intensität der Prüfung und entsprechenden Nachweispflichten der Kommunen durch die Bezugnahme auf das Einzelprojekt. Ferner schreibt die VwV Komminvest für den Wirtschaftlichkeitsvergleich die Durchführung einer Parallelausschreibung vor. 


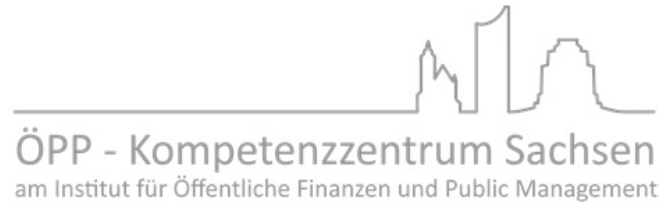

Seite 35 | 58

lich ist und die Kommunen eine gesunde Skepsis gegenüber pauschalen Versprechen einer Vorteilhaftigkeit von ÖPP aufweisen.

Eine dritte Gruppe mit bereits deutlich geringeren Zustimmungsanteilen bezieht sich auf die konkreten Rahmenbedingungen in Sachsen (Ränge 12, 13 und 14), wobei die rechtlichen Rahmen, die Rolle der Aufsichtsbehörden als (potenziell) ablehnende Instanzen und Widerstände in den Gemeinde- und Stadträten genannt wurden. Diese Punkte sind durchaus nicht unbedeutend, ihre Positionierung zeigt aber, dass in den wenigsten Kommunen entsprechende Planungen so weit vorangeschritten waren, dass eine Befassung der genannten Instanzen mit den Projekten notwendig erschien.

Eine relativ geringe Rolle bei der Begründung der Nichtnutzung spielen Planungs- und Umsetzungsrisiken (10\%) sowie die nicht vorhandene Wirtschaftlichkeit des ÖPPProjekts (4\%). Auch wenn sich bei den letztgenannten Fällen eine Realisierung mittels ÖPP wirtschaftlich letztlich nicht rechnete, wurde deren Nutzung offenbar geprüft.

Öffentlich-Private Partnerschaften charakterisieren sich vor allem durch die Vergabe von mehreren Phasen des Lebenszyklus' an einen privaten Partner. Auf dieser Lebenszyklusorientierung "aus einer Hand“ basieren die Effizienzvorteile, die durch die Nutzung von ÖPP im Vergleich zu konventionellen Eigenrealisierungen gewonnen werden sollen. Dem zuvor steht jedoch die Frage, welche Phasen des Lebenszyklus' eines Investitionsprojektes die Kommunen in Sachsen überhaupt bereit wären, an einen privaten Partner zu übertragen. 


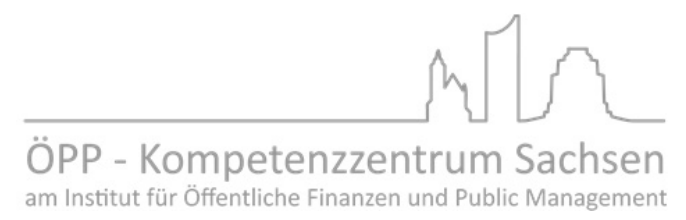

Seite $36 \mid 58$

Könnten Sie sich vorstellen einem privaten Unternehmen folgende Projektleistungen zu übertragen?

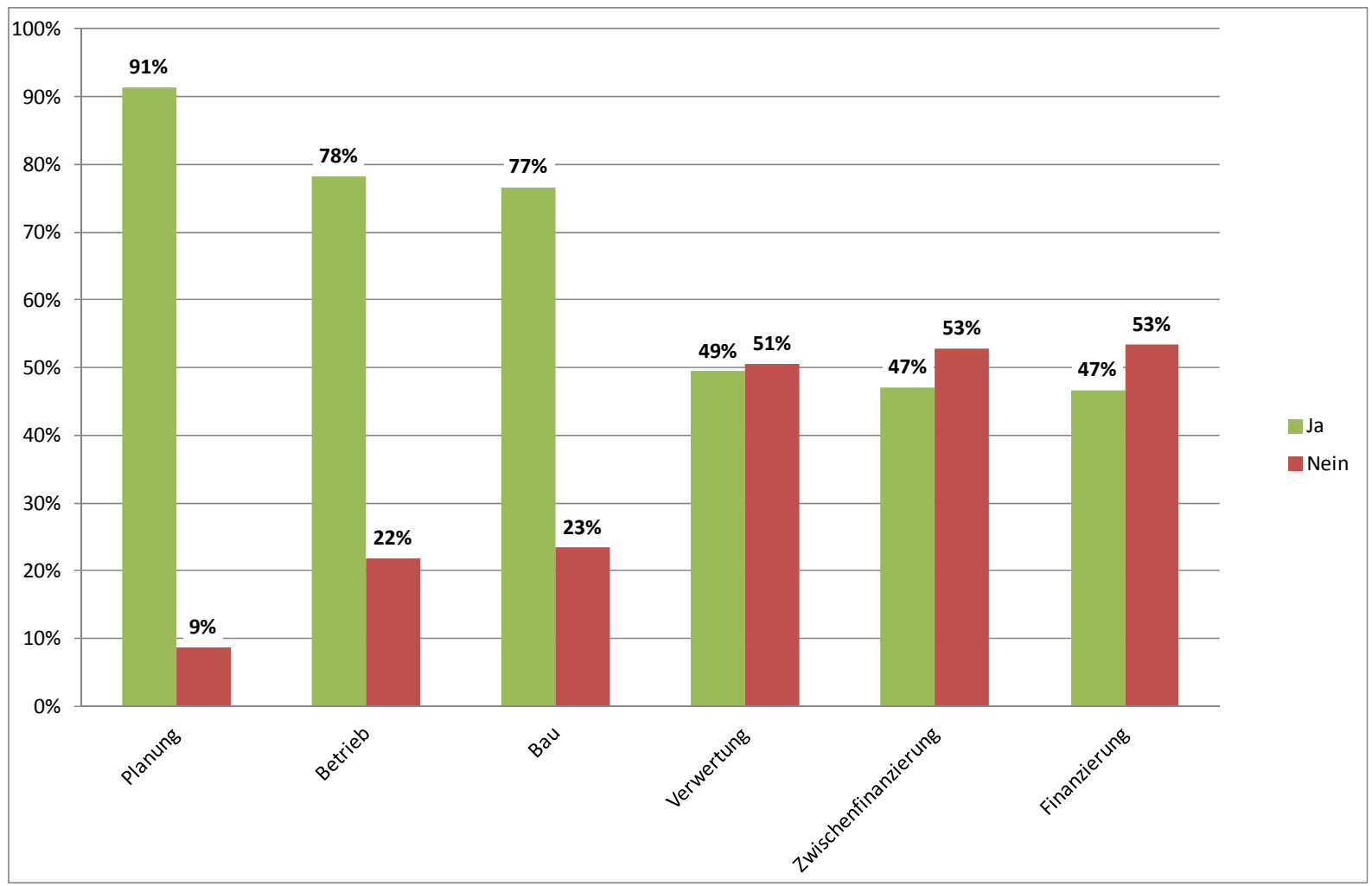

Abbildung 14: Bereitschaft zur Übertragung von Projektleistungen, $n=91$ Quelle: Eigene Erhebung, eigene Darstellung.

Die Befragung ergab, dass sich eine deutliche Mehrheit der Kommunen vorstellen kann, die Leitung von Planung (91 \%), Bau (80 \%) und Betrieb (76\%) abzugeben. Dieses Ergebnis ist insofern nicht verwunderlich als die meisten Kommunen bereits heute Planungsleistungen, Bauausführung und Betriebsdienstleistungen nicht selbst erbringen und dafür auf private Unternehmen zurückgreifen. Insofern verwunderlich ist allerdings, dass sich reichlich ein Fünftel der Kommunen nicht vorstellen können, Projektleistungen im Bau an ein privates Unternehmen abzugeben. Dies gilt umso mehr, da insbesondere in diesem Bereich bei den derzeitigen konventionellen Realisierungen kaum eigene kommunale Angestellte und Unternehmen eingebunden sind. Im Gegensatz dazu sind Ablehnungen bei den Betriebsleistungen teilweise zu erwarten gewesen, da zu diesem Bereich auch das traditionell noch selbst oder von eigenen Unternehmen erbrachte Facility 


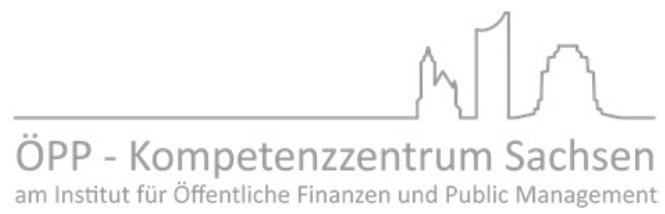

Seite 37 | 58

Management inkl. Hausmeistertätigkeiten zählt. Insgesamt kann vor diesem Hintergrund allerdings auf ein prinzipiell günstiges Umfeld für Planung, Bau und Betrieb aus einer Hand geschlossen werden.

Ein gespaltenes Bild ergibt sich für die Finanzierungs- und die Verwertungsphase. Jeweils etwa die Hälfte der Kommunen kann sich nicht vorstellen, die Zwischen- (53\%) und die Endfinanzierung (53\%) abzugeben. Insofern lässt sich die immer wieder geäußerte Vermutung, dass ÖPP vorrangig als Finanzierungsinstrument gesehen wird, nicht pauschal bestätigen. Jeweils 47 \% möchten die Zwischen- bzw. Endfinanzierung weiter vollständig in kommunaler Hand behalten.

Welche Aspekte sind für Sie für eine mögliche Nutzung von ÖPP als Beschaffungsvariante von besonderer Bedeutung?

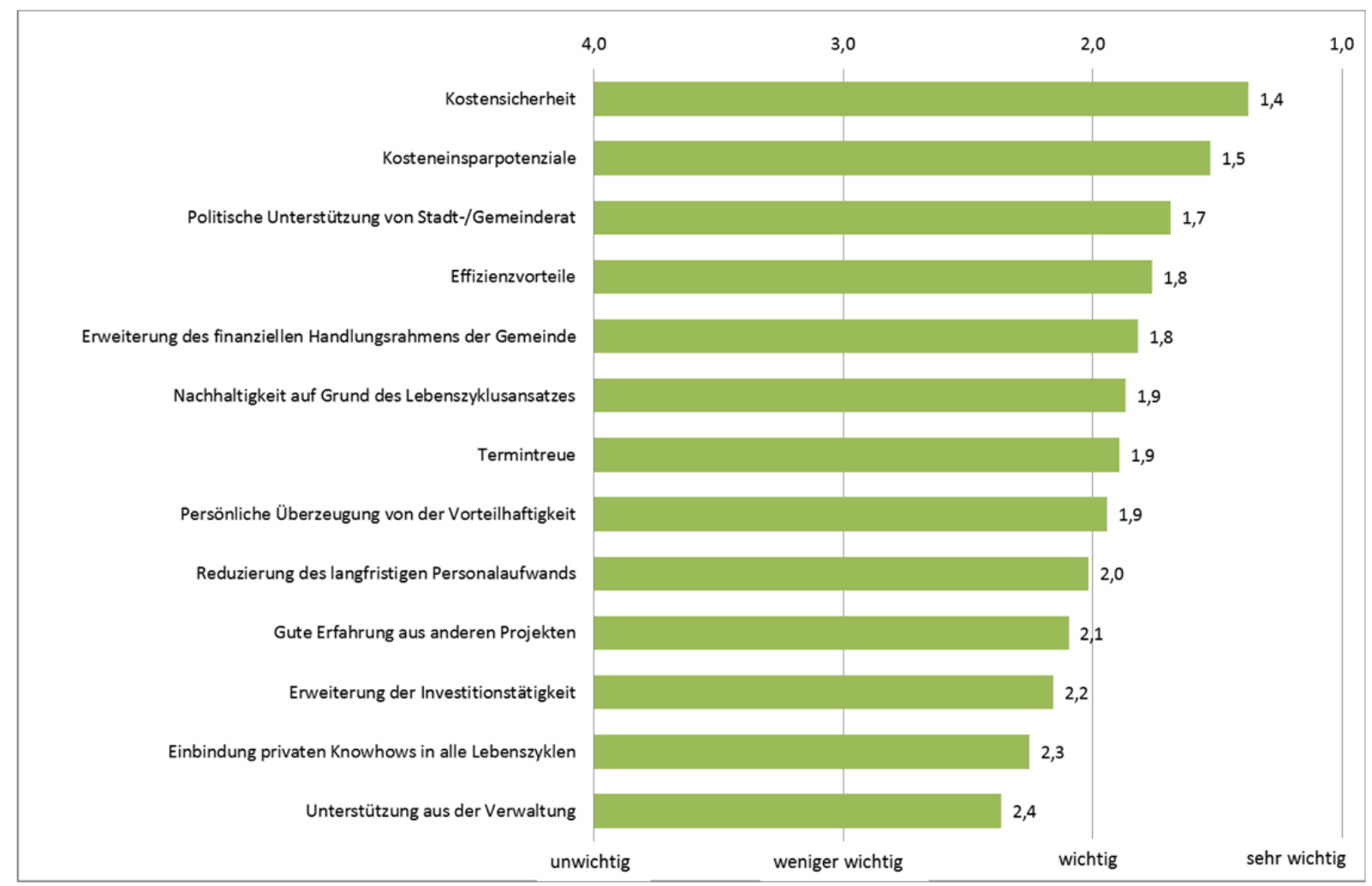

Abbildung 15: Erwartungen an ÖPP-Projekte, $n=75$

Quelle: Eigene Erhebung, eigene Darstellung. 


\section{UNIVERSITÄT LEIPZIG}

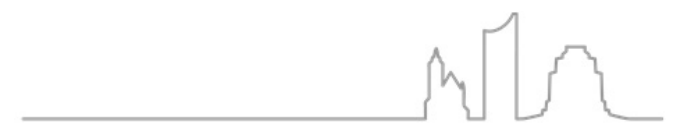

ÖPP - Kompetenzzentrum Sachsen

am Institut für Öffentliche Finanzen und Public Management

Seite $38 \mid 58$

Die Entscheidung für die Nutzung von ÖPP-Modellen ist in hohem Maße mit den sich für die Kommune daraus erwarteten Vorteilen verknüpft. Für die Kommunen im Freistaat stehen insbesondere finanzielle Aspekte im Vordergrund (Abbildung 15). Die vertraglich festgelegte Zahlung eines regelmäßigen Entgelts bei ÖPP-Projekten gewährleistet Kostensicherheit über den gesamten Projektzeitraum hinweg und wird von den Kommunen als wichtigster Vorteil erachtet. Durch den ÖPP-inhärenten Lebenszyklusgedanken sind die über den Zeitraum des Vertragshorizonts auftretenden Kosten für Sanierung und Instandhaltung bereits in das vorab fixierte Entgelt miteinbezogen. Nachfolgend sind Kosteneinsparpotenziale und allgemeine Effizienzvorteile gegenüber der konventionellen Realisierung von Investitionen sowie die Orientierung am Lebenszyklusansatz weitere wichtige Kriterien im Rahmen der Entscheidungsfindung. Hier herrschen große Erwartungen an öffentlich-private Partnerschaften. Aufgrund dessen ist es nicht verwunderlich, dass ÖPP-Projekte nicht immer alle diese erhofften Erwartungen erfüllen können und dies mitunter kritische Bewertungen von ÖPP nach sich zieht.

Als weiterer wichtiger Aspekt im Zusammenhang mit ÖPP wird die Reduzierung des langfristigen Personalaufwands bewertet. Hier zeigt sich, dass alternative Beschaffungsvarianten in die Gesamtstrategie der Haushaltskonsolidierung „passen“ müssen, um die Kommunen zu überzeugen.

Interessant sind die Aussagen zur Erweiterung des finanziellen Handlungsrahmens der Gemeinde $(1,8)$ und zur allgemeinen Erweiterung der Investitionstätigkeit $(2,2)$. Der erst genannte Aspekt bezieht sich sicherlich primär auf die Effizienzvorteile, die im Rahmen der zielgerichteten Umsetzung einer lebenszyklusorientierten Beschaffung erwartet werden. Weniger wichtig aber immer noch unterschwellig vorhanden ist jedoch die Erwartung, durch die Nutzung von ÖPP insgesamt ein höheres Investitionsvolumen erreichen zu können. Die Gefahr der Nutzung von ÖPP-Projekten zur teilweisen Umgehung von limitierenden Verschuldungsregeln im Zusammenhang mit der Investitionsfinanzierung in Kommunen ist zumindest in einigen Fällen zu reflektieren. Werden allerdings nochmals die als am wichtigsten erachteten Aspekte analysiert (Kostensicherheit, Effizienzvorteile), so zeigt sich im Gesamtbild, dass die Kommunen öffentlich-private Partner- 


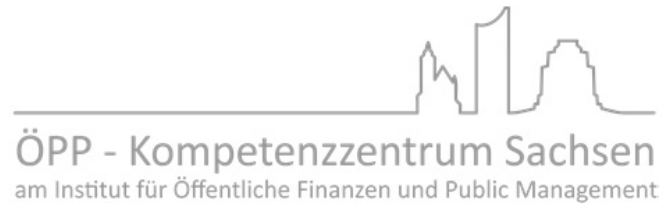

Seite 39 | 58

schaften vor allem als Beschaffungsvariante für ohnehin geplante Projekte in Erwägung ziehen und deutlich weniger auf den Aspekt der Zusätzlichkeit abzielen.

Bemerkenswert ist auch die Bewertung der organisatorischen und politischen Rahmenbedingungen für die praktische Umsetzung eines ÖPP-Projekts. So wird die politische Unterstützung in den Gemeinde- und Stadträten als sehr wichtig erachtet $(1,7)$, während die Bedeutung der Unterstützung aus der Verwaltung deutlich dagegen abfällt $(2,2)$. Daraus kann abgeleitet werden, dass die Widerstände im „Inneren“ der Verwaltung, die letztlich ein solches Projekt initiiert, als weniger bedeutsam eingestuft werden als die politischen Widerstände, die in der öffentlichen Befassung mit dem Thema erwartet werden.

Aufschlussreich ist die Zerlegung dieses Ergebnisses im Zusammenhang mit der grundsätzlichen Einstellung zu ÖPP als Beschaffungsvariante, die in der Abbildung 10 dokumentiert ist. Werden hierbei nur diejenigen Kommunen betrachtet, die vorwiegend positiv oder vorwiegend negativ eingestellt waren, ergibt sich das in Abbildung 16 dargestellte Ergebnis. ${ }^{28}$ Hieraus lassen sich Vermutungen darüber ableiten, welche Aspekte von ÖPP zu einer eher zustimmenden oder ablehnenden Haltung zu öffentlich-privaten Partnerschaften führen. interpretieren. Dennoch lassen sich Tendenzaussagen treffen. 


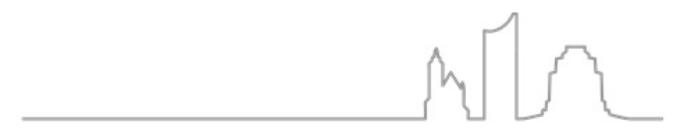

ÖPP - Kompetenzzentrum Sachsen am Institut für Öffentliche Finanzen und Public Management

Seite $40 \mid 58$

Welche Aspekte sind für Sie für eine mögliche Nutzung von ÖPP als Beschaffungsvariante von besonderer Bedeutung? Differenzierung nach Einstellung zu ÖPP

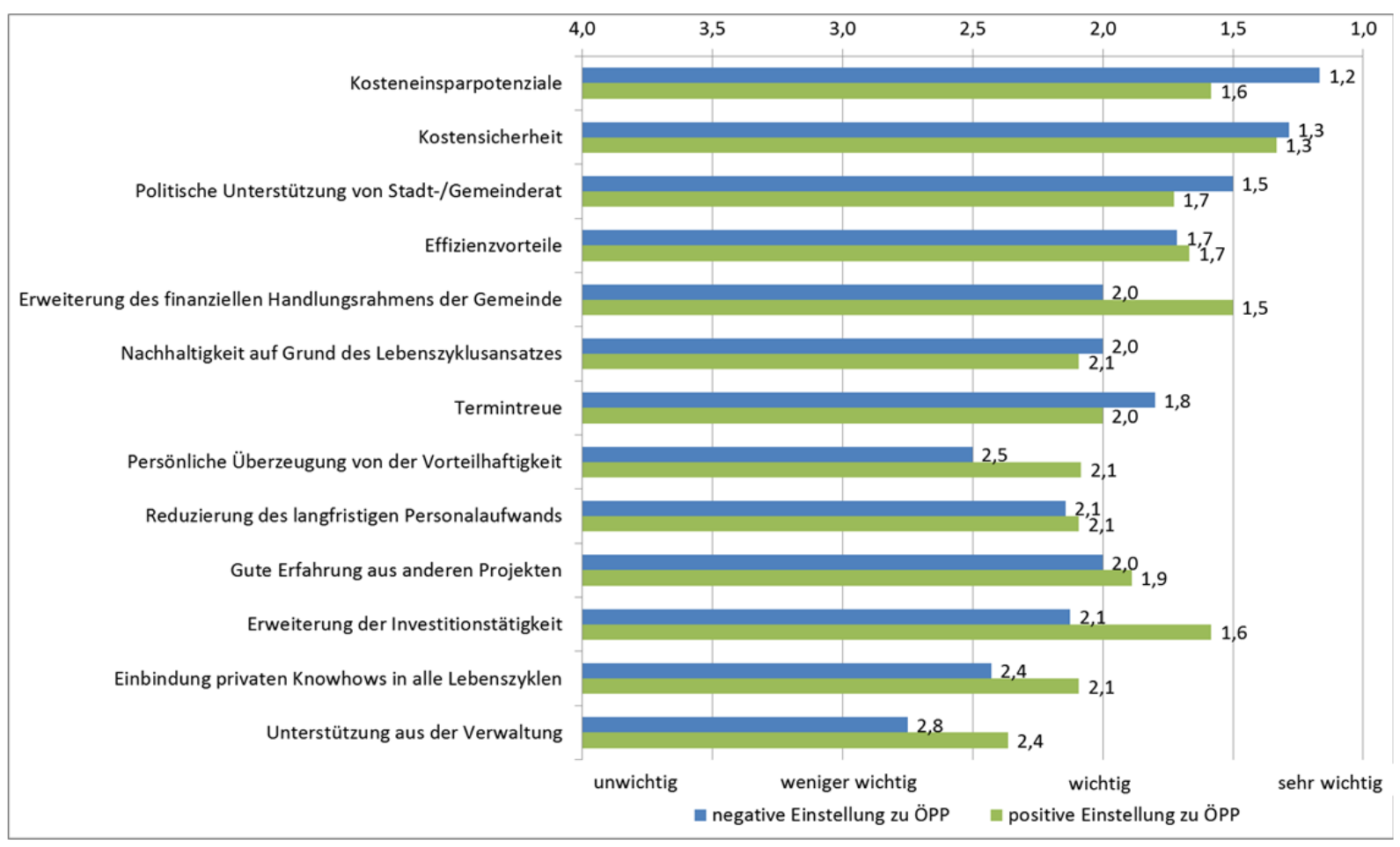

Abbildung 16: Erwartungen an ÖPP-Projekte, Differenziert nach Einstellung zu ÖPP, $n=75$ Quelle: Eigene Erhebung, eigene Darstellung.

Eine positive Bewertung von ÖPP geht mit höheren Erwartungen an die positiven finanziellen Folgen für die Kommune einher. Dabei wird deutlich häufiger als bei einer negativen Einstellung die Erweiterung der allgemeinen Investitionstätigkeit erhofft. Daneben wird das Einbinden privaten Knowhows grundsätzlich positiver gesehen. Letztlich spielt dabei auch die persönliche Einstellung der Akteure eine wichtigere Rolle als in der Vergleichsgruppe. Bei den eher negativ gegenüber ÖPP Eingestellten zeigt sich vor allem eine Abweichung beim Aspekt der Kostensicherheit. Dies kann als Ausdruck von Vorbehalten interpretiert werden, die nur durch eine transparente, nachvollziehbare und sichere Kalkulation von der Durchführung eines ÖPP-Projekts überzeugt werden können.

Im Nachgang zu den Erwartungen der sächsischen Kommunen an die Potenziale öffentlich-privater Partnerschaften wurden die Teilnehmer in der Befragung gebeten, zu eini- 


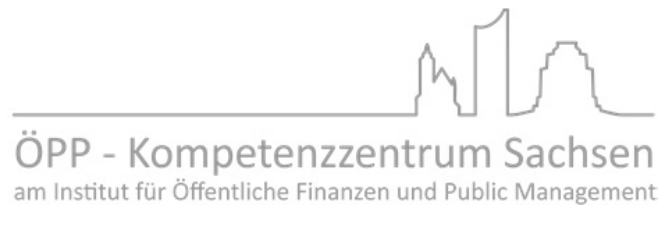

Seite $41 \mid 58$

gen Aussagen Stellung zu nehmen, die im Zusammenhang mit ÖPP in der öffentlichen Diskussion regelmäßig eine Rolle spielen. Dabei geht es nicht um „richtige“ oder "falsche" Antworten, sondern um die Bestimmung des allgemeinen Meinungsbildes rund um die Beschaffung öffentlicher Leistungen in den Kommunen zwischen öffentlicher Hand und privatwirtschaftlichen Akteuren.

Insgesamt sind die Meinungen der sächsischen Kommunen über ÖPP gespalten. Dies ergibt sich aus der Auswertung des Meinungsbilds zu den spontanen Antworten der Teilnehmer zu generellen ÖPP-Aussagen (Abbildung 17). Zusammengefasst zeigen die Ergebnisse mehrere Grundrichtungen.

Erstens finden die Aussagen überwiegende Zustimmung, die eine intensive Planungsphase und die Notwendigkeit externer Berater, jedoch spiegelbildlich einen geringeren Aufwand in der Betriebsphase thematisieren (Ränge 1, 5 und 6). In dieser Hinsicht decken sich die Einschätzungen der sächsischen Kommunen mit der Grundsystematik des ÖPP-Verfahrens.

Zweitens wird mehrheitlich die Auffassung eines umfänglichen Risikoübergangs auf die Kommune vertreten. Diese Einschätzung ist insofern interessant, als bei der Realisierung als ÖPP eine aktive Auseinandersetzung mit den Risiken über die gesamte Lebensdauer des Projekts hinweg stattfindet und insbesondere in der Betriebsphase Risiken an den privaten Partner übergeben werden, was bei konventionellen Verfahren in der Regel nicht gegeben ist. Die Einschätzungen zeigen, dass das Thema Risikoallokation bereits in der Frühphase einer Annäherung an das Thema ÖPP thematisiert werden sollte.

Drittens ist eine leichte Zustimmung zu den Aussagen festzustellen, ÖPP ermögliche eine hohe Planungs- und Kostensicherheit (Ränge 3 und 4). Hierbei unterscheiden sich die Ergebnisse aber nur unwesentlich von der indifferenten „Neutralposition“ von 2,5. Hier zeigt sich die angebrachte Skepsis der Kommunen gegenüber pauschalen Erwartungen an die Wirtschaftlichkeit des ÖPP-Verfahrens, die erst durch entsprechende transparente Wirtschaftlichkeitsuntersuchungen zu belegen ist. 


\section{Wie beurteilen Sie nachfolgende Aussagen? Bitte antworten Sie spontan!}

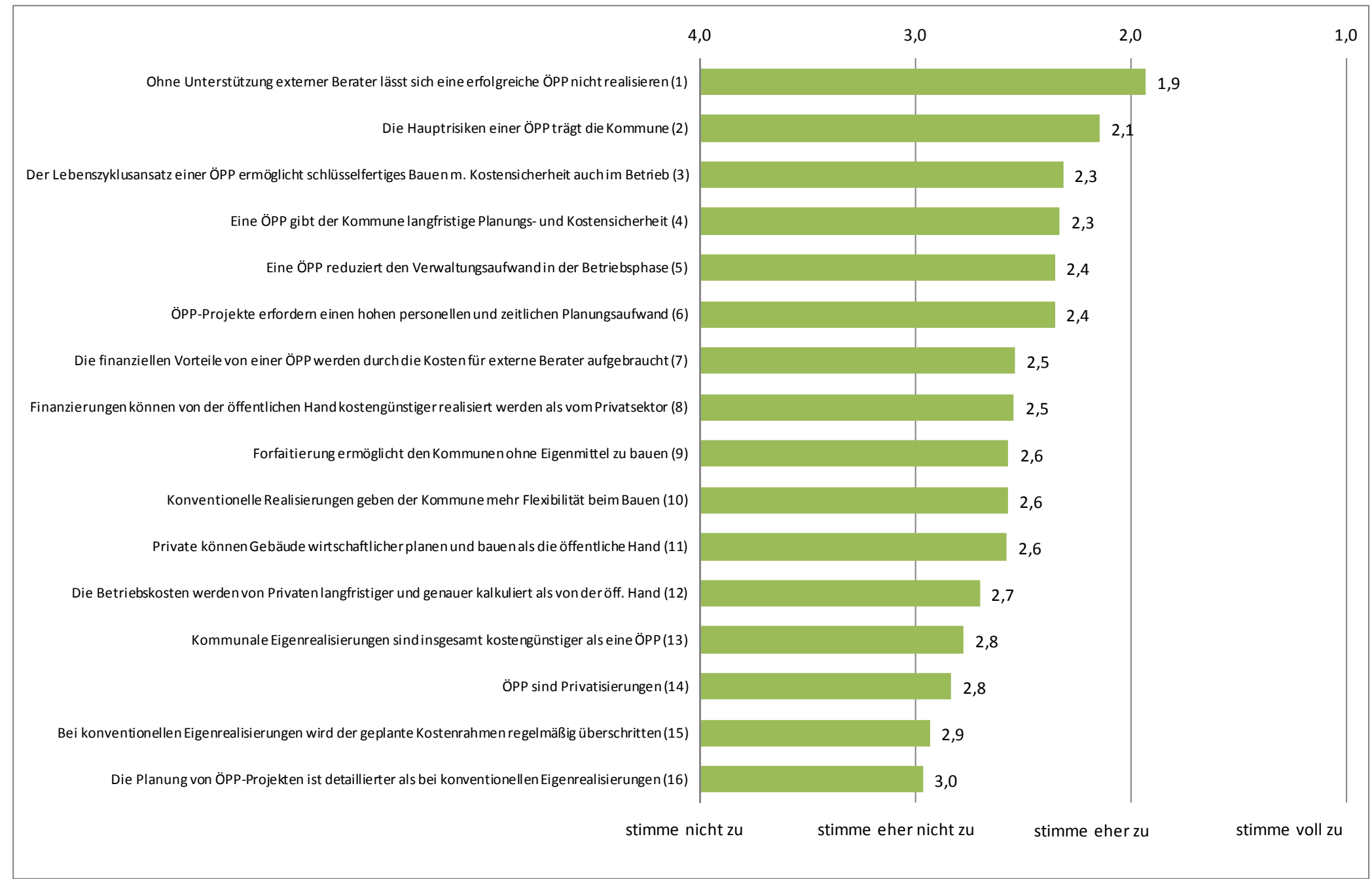

Abbildung 17: Meinungsbild zu generellen ÖPP-Aussagen, $n=81$

Quelle: Eigene Erhebung, eigene Darstellung. 


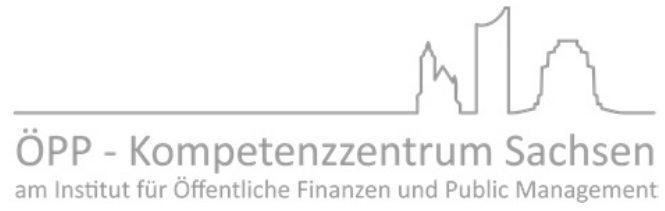

Seite 43 | 58

Interessant sind die Aussagen, die eher Ablehnung hervorrufen. Darunter ist die oft pauschal geäußerte Vermutung, dass es sich bei ÖPP um Privatisierungen handelt. Dies überrascht in dem Maße, wie das Privatisierungsargument oft von ÖPP-Gegnern in der öffentlichen Debatte ins Feld geführt wird ${ }^{29}$. Offenbar scheint sich in vielen Kommunen jedoch bereits die Einsicht durchgesetzt zu haben, dass ÖPP keine faktischen Privatisierungen darstellen, sondern dass lediglich die operative Durchführung des Bauprojekts an einen privaten Dritten abgegeben wird.

Erstaunlich ist hingegen, dass bei ÖPP-Verfahren keine detailliertere Planung als erforderlich vermutet wird, was aber tatsächlich der Fall ist und auch konträr zur Notwendigkeit externer Berater (Rang 1 der Bewertung durch die Kommunen) steht.

Des Weiteren findet sich ein großer Bereich der Indifferenz rund um den (theoretischen) Mittelwert von 2,5. Hierunter fallen insbesondere die Aussagen, die die konventionelle und die ÖPP-Variante direkt vergleichen (Ränge 7 bis 11). Insofern kann festgehalten werden, dass aus der Sicht der Kommunen keines der beiden Verfahren per se besser oder schlechter als das andere ist. Diese Einschätzung kann vom ÖPP-Kompetenzzentrum Sachsen unterstützt werden, kommt es doch auf den konkreten Einzelfall an. irrweg.de/index.php?id=6220. 


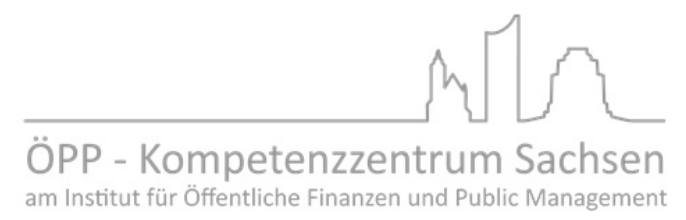

Seite $44 \mid 58$

\section{Informationsmöglichkeiten und -bedarf}

Die vorwiegende Aufgabe des ÖPP-Kompetenzzentrums Sachsen ist die Erstberatung der Kommunen zum Themengebiet ÖPP. Das Kompetenzzentrum informiert die Städte und Gemeinden, die Landkreise, aber auch die Einrichtungen des Freistaates über das Konzept ÖPP als eine alternative Beschaffungsvariante und gibt innen dabei einen Überblick über die Voraussetzungen und die Anforderungen, die bei einem ÖPP-Projekt zu beachten sind. Als kompetenter und unabhängiger Ansprechpartner verpflichtet sich das Kompetenzzentrum in den Beratungen bezüglich lebenszyklusorientierter Beschaffungsvorhaben neben den Chancen ebenso die Risiken und Herausforderungen von ÖPP aufzuzeigen. Vor dem Hintergrund dieses Aufgabenspektrums sind die entsprechenden Interessen und Bedarfe der sächsischen Kommunen von besonderer Bedeutung.

Würden Sie eine Veranstaltung zum Thema ÖPP besuchen?

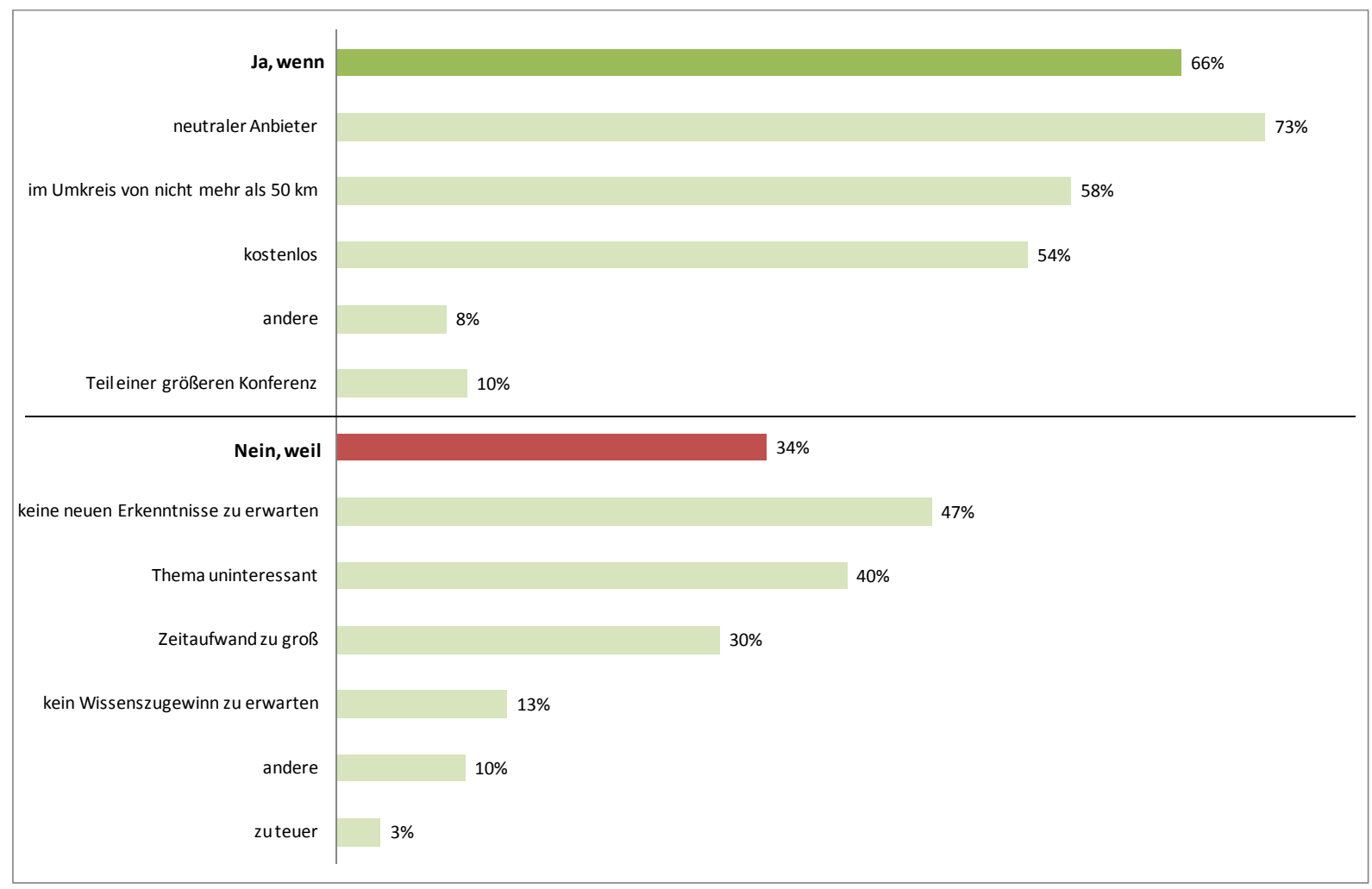

Abbildung 18: Gründe für und gegen Besuche von ÖPP-Veranstaltungen, $n=92$ Quelle: Eigene Erhebung, eigene Darstellung. 
Es wurde bereits deutlich, dass die sächsischen Kommunen dem Thema ÖPP durchaus offen gegenüberstehen (vgl. Abbildung 10), jedoch gleichzeitig das Wissen über diese Beschaffungsalternative auf kommunaler Ebene bisher eher gering ist (vgl. Abbildung 12). Insofern ist es erfreulich, dass zwei Drittel der antwortenden Kommunen an Informationsveranstaltungen zum Thema ÖPP teilnehmen würden. Hierbei legen sie besonderen Wert auf die Neutralität des Informationsgebers (73\%), eine geringe Entfernung zum Veranstaltungsort (58\%) und ein möglichst kostenfreies Angebot (54\%). Auf diese Bedürfnisse wird sich das ÖPP-Kompetenzzentrum Sachsen einstellen und entsprechende Veranstaltungen konzipieren. Allerdings hat auch ein Drittel der Kommunen kein Interesse an weiteren Informationen zu ÖPP. Als Grund geben fast die Hälfte dieser Kommunen an, dass keine neuen Erkenntnisse zu erwarten sind (47\%). Dies ist vor dem Hintergrund des geringen konkreten Wissensstandes zum Thema allerdings verwunderlich. Ferner wird im Thema ÖPP von rund 40 \% der Kommunen grundsätzlich keine Relevanz gesehen. 


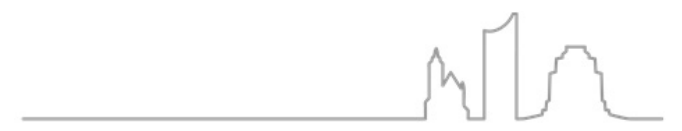

ÖPP - Kompetenzzentrum Sachsen am Institut für Öffentliche Finanzen und Public Management

Seite 46 | 58

Haben Sie bereits Veranstaltungen zum Thema ÖPP besucht? Wenn ja, wie viele?

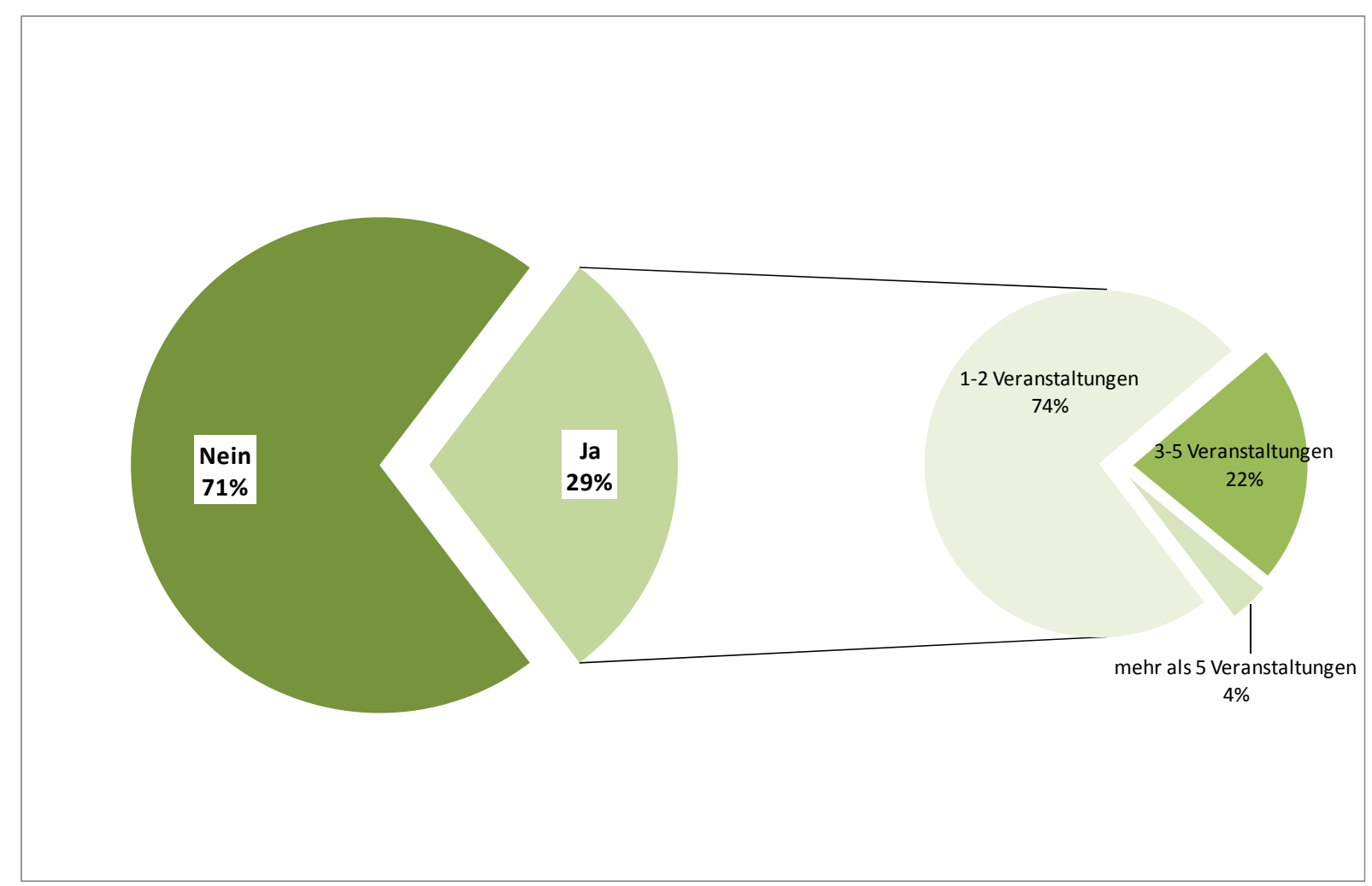

Abbildung 19: Erfahrung mit ÖPP-Veranstaltungen, $n=92$

Quelle: Eigene Erhebung, eigene Darstellung.

Das Interesse an Informationsveranstaltungen beruht natürlich ebenso auf Erfahrungswerten. Dementsprechend wurden die Kommunen befragt, ob sie bereits Teilnahmen an ÖPP-Informationsveranstaltungen vorweisen können. Die überwiegende Mehrheit (71\%) hat noch nicht an einer solchen Veranstaltung teilgenommen. Von den Kommunen, die bereits informative Veranstaltungen besuchten, haben $74 \%$ an ein bis zwei; $22 \%$ bereits an drei bis fünf und $4 \%$ sogar an bereits mehr als fünf Veranstaltungen teilgenommen. Dies verdeutlicht, dass in Sachsen mit Blick auf die Tatsache, dass zwei Drittel der Kommunen unter gewissen Umständen durchaus eine Informationsveranstaltung besuchen würden, auf kommunaler Seite durchaus ein großer Bedarf sowie ein großes Informationsinteresse zum Thema ÖPP bestehen. Das ÖPP-Kompetenzzentrum Sachsen sieht sich in der Verantwortung diese Aufgabe anzunehmen und den Kommunen die 
Möglichkeit der Teilnahme an informativen Veranstaltungen mit einem hohen Anspruch an die Objektivität und Neutralität in der Darstellung von ÖPP zu ermöglichen.

Haben Sie schon einmal etwas vom ÖPP-Kompetenzzentrum Sachsen gehört?

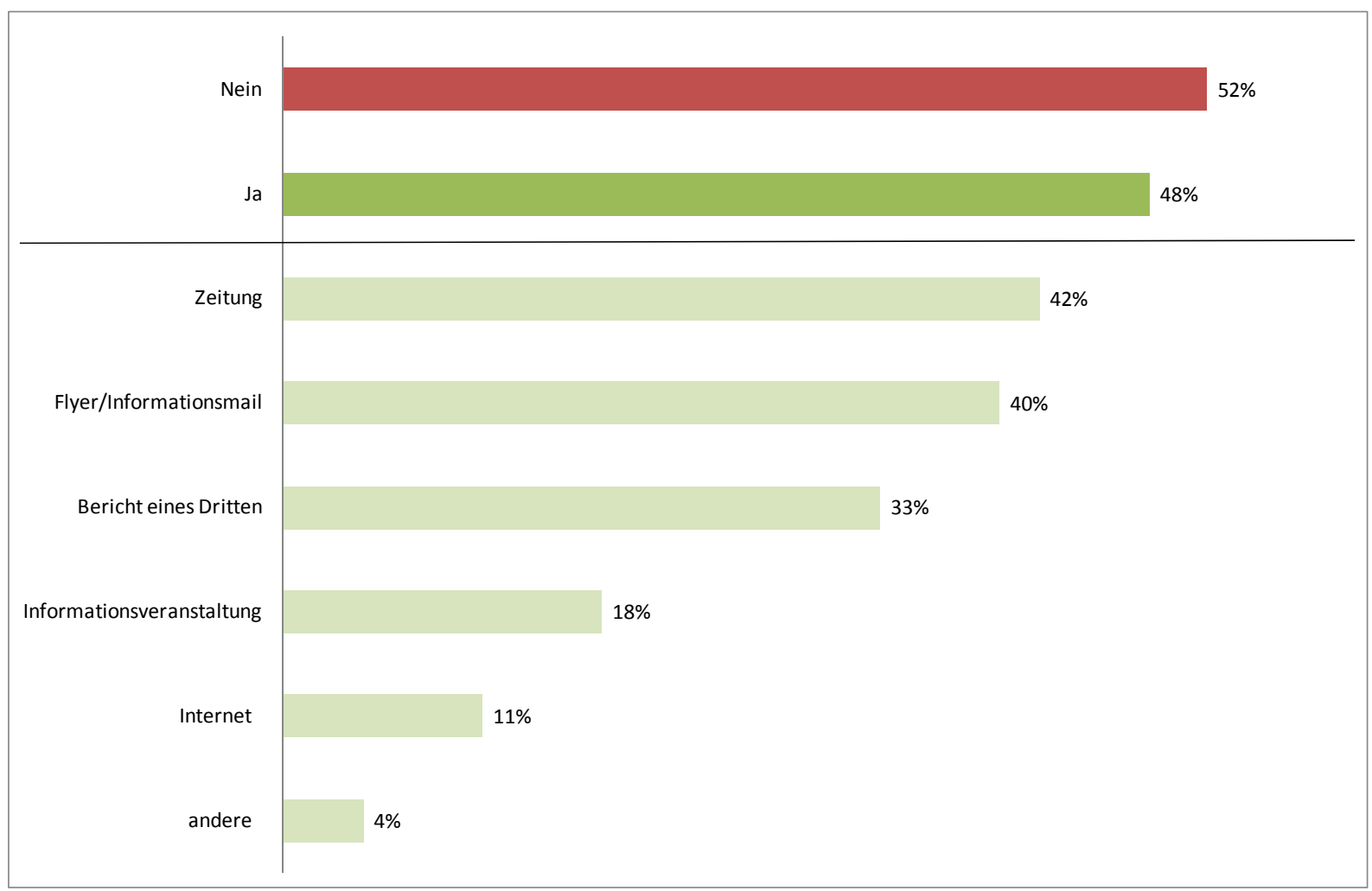

Abbildung 20: Bekanntheitsgrad des ÖPP-Kompetenzzentrums Sachsen, $n=93$

Quelle: Eigene Erhebung, eigene Darstellung.

Das ÖPP-Kompetenzzentrum Sachsen nahm seine beratende Tätigkeit im Juni 2011 auf. Innerhalb von vier Monaten - bis zum Beginn der Umfrage im Oktober 2011 - gelang es, immerhin fast $50 \%$ der antwortenden Kommunen auf die Gründung des Kompetenzzentrums aufmerksam zu machen. Als Informationsmultiplikatoren dienten dabei insbesondere Zeitungsberichte, Veranstaltungen sowie Flyer und Informationsmails. Ein beinah ebenso wichtiger Verbreitungsweg waren Berichte Dritter. Aber auch Webinhalte und E-Mails mit dem Thema ÖPP wurden beachtet. Dies lässt den Schluss zu, dass ÖPP und dessen Entwicklungen im Freistaat Sachsen durchaus mit Interesse verfolgt werden. Innerhalb kurzer Zeit ist es dem ÖPP-Kompetenzzentrum Sachsen zudem gelungen, eini- 


\section{UNIVERSITATT LEIPZIG}

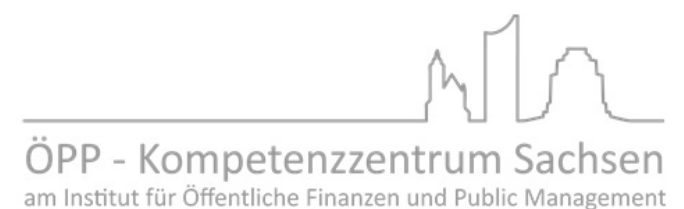

am Institut für Öffentliche Finanzen und Public Management

Seite $48 \mid 58$

ge direkte Kontakte aufzubauen. Immerhin $22 \%$ derjenigen, die schon einmal etwas vom Kompetenzzentrum gehört haben, hatten einen direkten Kontakt durch eine Informationsveranstaltung, ein persönliches Gespräch oder beides. Angesicht von knapp über $50 \%$ der Kommunen, bei denen bisher noch keine Berichte zum ÖPP-Kompetenzzentrum Sachsen angekommen sind, besteht noch Potenzial zur weiteren Informationsverbreitung. Dabei steht insbesondere die Verbesserung des direkten Kontakts in Form von Veranstaltungen und Gesprächen im Vordergrund. 


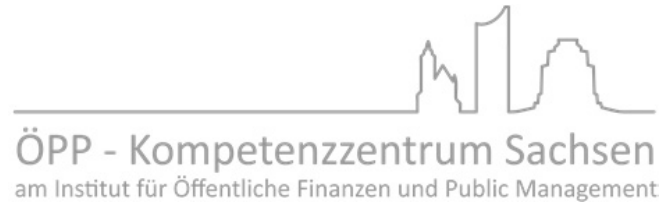

Seite 49 | 58

\section{Zusammenfassung und Ausblick}

Bei ÖPP wird der Lebenszyklus der Infrastruktureinrichtung in Form einer Wirtschaftlichkeitsuntersuchung (WU) analysiert. Dabei werden alle Phasen des Projektes ganzheitlich als wirtschaftliche Einheit betrachtet, wodurch im Vergleich zur bisherigen konventionellen Realisierung Synergie- und Effizienzpotenziale aufgedeckt und zum Vorteil der Kommune realisiert werden können. Im ÖPP-Verfahren müssen diese in einem mehrstufigen Verfahren in Form einer Wirtschaftlichkeitsuntersuchung aufgezeigt und belegt werden. Unabhängig von einer ÖPP-Realisierung, die nur stattfindet, wenn am Ende der Wirtschaftlichkeitsvergleich die Vorteilhaftigkeit gegenüber einer konventionellen Realisierung nachweist, werden dafür alle notwendigen Parameter bereits bei der Planung ermittelt und festgelegt. Dies führt zum einen zu einer transparenten und nachvollziehbaren Darstellung der gesamten Projektkosten. Andererseits werden dadurch verbindliche und detaillierte Vorgaben geschaffen, die ein kontinuierliches Projektcontrolling anhand von Zielwerten ermöglichen.

ÖPP hat sich in den letzten Jahren von einem Finanzierungsinstrument, das nicht nur von den Aufsichtsbehörden, sondern auch von den Bürgern, politischen Gruppierungen, Parteien und den Gewerkschaften kritisch betrachtet wurde, immer mehr zu einer lebenszyklusorientierten Beschaffungsalternative weiterentwickelt. Dies wurde prinzipiell neben vielen kritischen Detailanmerkungen zur Umsetzung ebenso jüngst von den Rechnungshöfen bestätigt. ${ }^{30}$ Damit korrespondierend, haben sich die Handlungsfelder von ÖPP ausgeweitet. Diese Entwicklungen gilt es den Kommunen zusammen mit Informationen zu vermitteln, die aufzeigen, wie nachhaltige Beschaffungsprozesse im Freistaat Sachsen im Einklang mit den Transparenzanforderungen der Bürger und den Vorgaben der Rechtsaufsichtsbehörden umgesetzt werden können. 


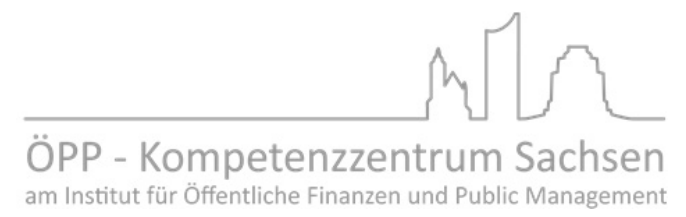

Seite $50 \mid 58$

Die Ergebnisse der Umfrage zeigen, dass hierin ein großer Vorteil für die sächsischen Kommunen liegen kann. Die enorme Diskrepanz zwischen guten und schlechten Projektrealisierungen gilt es abzubauen. Verbindliche Vorgaben für die Wirtschaftlichkeitsuntersuchung können dabei auch bei konventionellen Projekten für eine bessere Vergleichbarkeit, mehr Transparenz und Kontrollmöglichkeiten sorgen. Um den zukünftigen Bedarf in den wichtigsten Infrastrukturbereichen abdecken zu können und dabei sowohl das Leistungsangebot der Kommune und deren Qualitätsansprüche aufrecht zu erhalten, wird ein effizienter und nachhaltiger Ressourceneinsatz immer wichtiger. Alternative Beschaffungskonzepte, die entsprechende Potentiale aufzeigen und nutzbar machen, werden dabei auch im Freistaat Sachsen von immer größerer Bedeutung. Die Kommunen stehen diesen Alternativen grundsätzlich offen gegenüber, benötigen jedoch eine breitere Informationsbasis, um Chancen und Risiken besser abwägen zu können. Im Freistaat Sachsen gilt es zudem, vorhandene rechtliche Unsicherheiten zu beseitigen. 


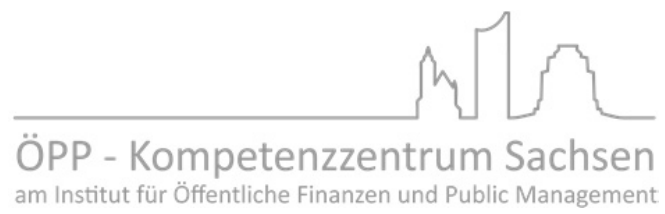

Seite $51 \mid 58$

\section{Anhang}

\section{Fragebogen zum Investitionsbedarf und zu kommunalon Bauprojekton in Sachson im Zusammenhang mit Öffontlich-Privaton- Partnorschaften (ÖPP)}

\section{0) Vorbemerkungen}

Gegenstand der Umfrage sind aktuelle und zukünftige Bauprojekłe der sächsischen Kommunen (einschließlich ihrer kommunalen Unternehmen) sowie deren Einstellung gegenüber ÖffentlichPrivaten-Partnerschaften (ÖPP)/Public-Private-Partnerships (PPP).

Die Datenerhebung dient wissenschaftlichen Zwecken. Die Einzeldatensätze werden streng vertraulich behandelt und nicht an Dritte weitergegeben. Alle Veröffentlichungen erfolgen anonymisiert. Ein Rückschluss auf einzelne Kommunen wird dabei nicht möglich sein.

Um möglichst belastbare und repräsentative Ergebnisse zu kommen, sind wir auf einen hohen Rücklauf angewiesen. Ihre Mitwirkung ist essenziell für das Oelingen der Studie! Sind zu einzelnen Fragen keine exakten Angaben möglich, bitten wir Sie um Schätzungen. Sollten Sie trotzdem einzelne Angaben nicht machen können oder wollen, bitten wir Sie uns den Fragebogen dennoch - auch unvollstāndig ausgefüllt - auf jeden Fall zurück zu senden.

Bitte unterstützen Sie unsere Studie und senden Sie den ausgefüllten Fragebogen per E-Mail, Post oder FAX bis zum 23.10.2011 an uns zurück.

\section{1) Allgemeine Informationen}

Gomøinde/Landkreis

Postfach/Straße

PLz/Ort

Ansprechpartmer

Tolofon

E-Mail-Adresse

\section{Universität Leiprig}

ÖPP-Kompetenzrentrum Sachsen

Postfach 100920

04009 Leipxig
Telofon: 0341.97.33588

Faxc 0341-97.33589

Emailt redlichowifa.uni-leipxig-de 


\section{UNIVERSITÄT LEIPZIG}

ÖPP - Kompetenzzentrum Sachsen am Institut für Öffentliche Finanzen und Public Management

Seite $52 \mid 58$

\section{ÖPP-Kompetenzzentrum Sachsen}

2) Investitionsbedarf und derzeitige Baumaßnahmen

a. In wolchon dor im Folgondon gonannton kommunalon Investitionsberoiche worden in Ihror Kommune derzoit Baumaßnahmon (Noubauton und Instandhaltung) durchgoführt bzw. augonblicklich goplant?

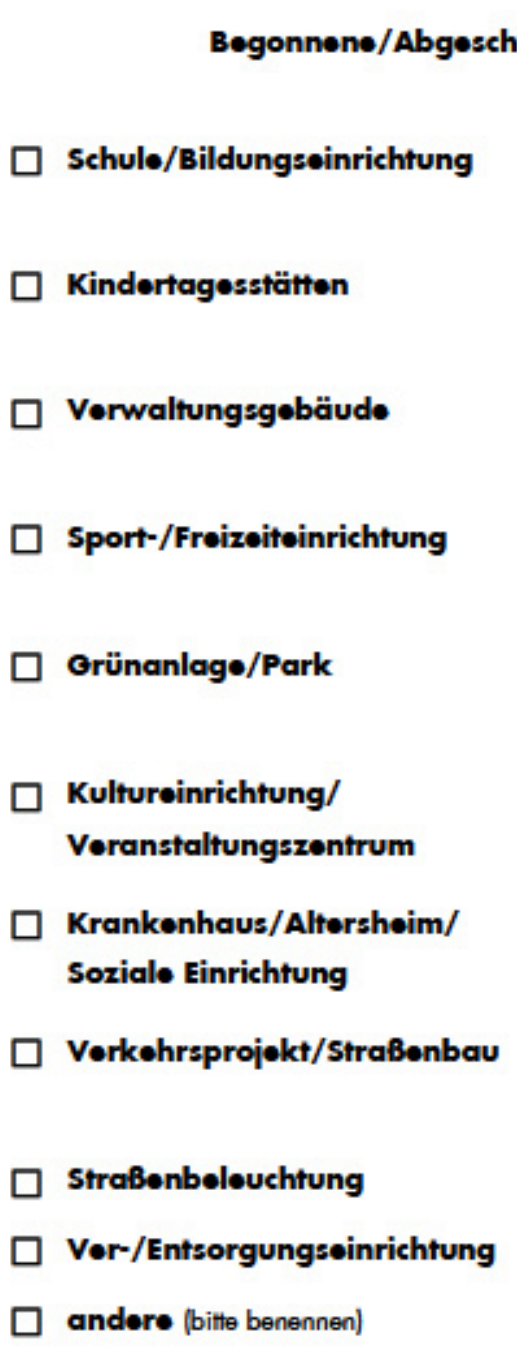

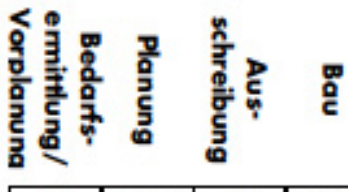
1.Projekt
ggf. 2. Projekt
1.Projekt

ggf. 2. Projekt

1.Projekt

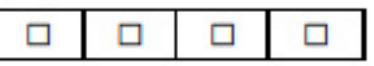

\begin{tabular}{|l|l|l|l|}
$\square$ & $\square$ & $\square$ & $\square$ \\
\hline
\end{tabular}
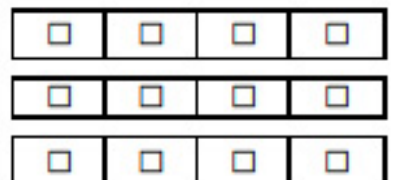

ggf. 2. Projekt

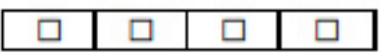

1.Projekt

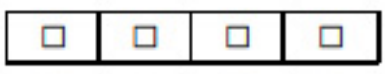

ggf. 2. Projekt

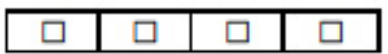

$$
\text { 1.Projekt }
$$

ggf. 2. Projekt
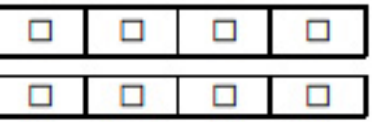

$$
\text { 1.Projekt }
$$

ggf. 2. Projekt

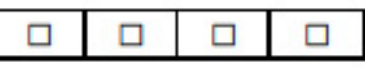

1.Projekt

ggf. 2. Projekt
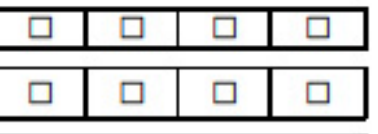

1.Projekt

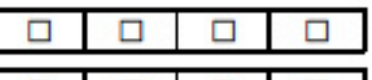

ggf. 2. Projekt
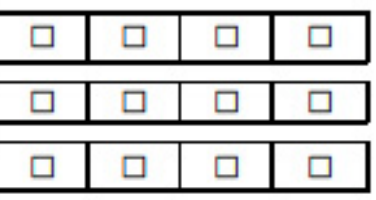

\begin{tabular}{|l|l|l|l|}
\hline$\square$ & $\square$ & $\square$ & $\square$ \\
\hline
\end{tabular}

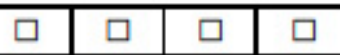




\section{UNIVERSITATT LEIPZIG}

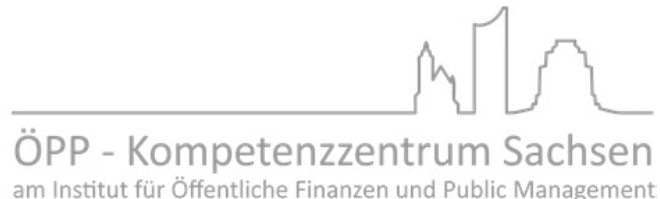

Seite $53 \mid 58$

\section{ÖPP-Kompetenzzentrum Sachsen}

b. Haben Sie zur Projektrealisiorung schon •inmal alternative Beschaffungsvarianten genutzt?

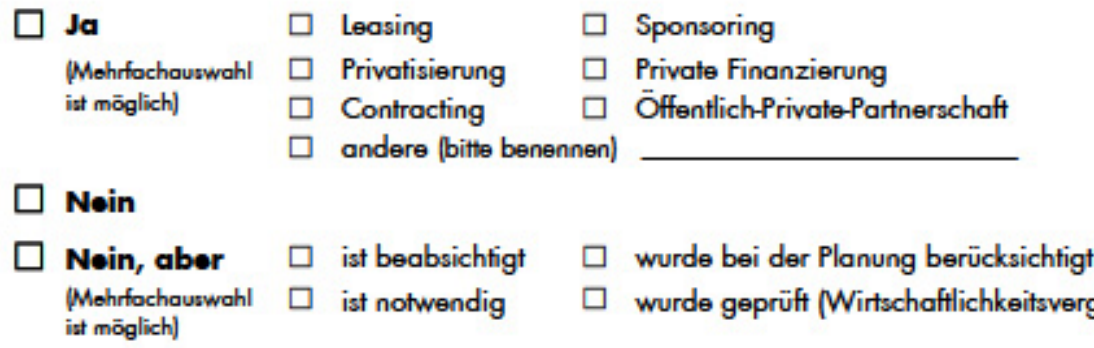
ist möglich)

c. In wolchon Borøichon sind in don nächston fünf Jahron in Ihror Kommune Investitionen notwendig? Wie hoch ist aus Ihrer Sicht dor jewoilige Investitionsbedarf in Euro, und wie hoch schätzon Si॰ diesen gomossen an der Loistungskraft Ihrer Kommune ein?

\begin{tabular}{|c|c|c|c|c|c|c|c|}
\hline & & Inv & Jahritio & sbed & in in & $\begin{array}{l}\text { den nć } \\
\text { oistun }\end{array}$ & $\begin{array}{l}\text { isten fünf } \\
\text { kraft }\end{array}$ \\
\hline & & 을. & 을.울 & 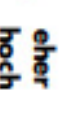 & হo & 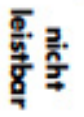 & $\begin{array}{l}\text { Summe in } \\
\text { Mio. Euro }\end{array}$ \\
\hline$\square$ & Schulo/Bildungsoinrichtung & $\square$ & $\square$ & $\square$ & $\square$ & $\square$ & \\
\hline$\square$ & Kindertagesstätten & $\square$ & $\square$ & $\square$ & $\square$ & $\square$ & \\
\hline$\square$ & Verwaltungegebäude & $\square$ & $\square$ & $\square$ & $\square$ & $\square$ & \\
\hline$\square$ & Sport-/Freizeiteinrichtung & $\square$ & $\square$ & $\square$ & $\square$ & $\square$ & \\
\hline$\square$ & Grünanlage/Park & $\square$ & $\square$ & $\square$ & $\square$ & $\square$ & \\
\hline$\square$ & $\begin{array}{l}\text { Kultureinrichtung/ } \\
\text { Veranstaltungszentrum }\end{array}$ & $\square$ & $\square$ & $\square$ & $\square$ & $\square$ & \\
\hline$\square$ & $\begin{array}{l}\text { Krankenhaus/Altersheim/ } \\
\text { Sozialo Einrichtung }\end{array}$ & $\square$ & $\square$ & $\square$ & $\square$ & $\square$ & \\
\hline$\square$ & Verkehrsprojekt & $\square$ & $\square$ & $\square$ & $\square$ & $\square$ & \\
\hline$\square$ & Straßenbeleuchtung & $\square$ & $\square$ & $\square$ & $\square$ & $\square$ & \\
\hline$\square$ & Ver-/Entsorgungseinrichtung & $\square$ & $\square$ & $\square$ & $\square$ & $\square$ & \\
\hline$\square$ & andere (bitte benennen) & $\square$ & $\square$ & $\square$ & $\square$ & $\square$ & \\
\hline & $\begin{array}{l}\text { orsität Loipxig } \\
\text { Kompetenxientrum Sachsen } \\
\text { ach } 100920 \\
99 \text { Leipxig }\end{array}$ & $\begin{array}{l}\text { Talofo } \\
\text { Faxc } \\
\text { Emai }\end{array}$ & $\begin{array}{l}: 0341 \\
341.97 \\
\text { indlic }\end{array}$ & $\begin{array}{l}33588 \\
589 \\
\text { wifa.v }\end{array}$ & & & \\
\hline
\end{tabular}




\section{UNIVERSITAT LEIPZIG}

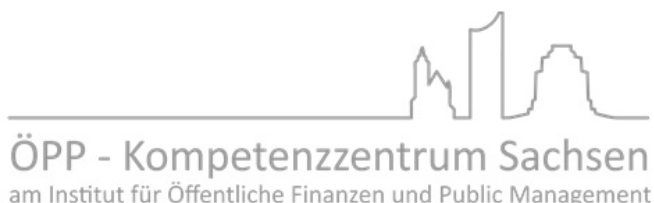

am Institut für Öffentliche Finanzen und Public Management

Seite 54 | 58

\section{ÖPP-Kompetenzzentrum Sachsen}

d. Inwiowøit sind boi Ihron über konventionollø Eigenrealisiorung vollzogenen Projekten die nachfolgenden Punkte erreicht worden?

\begin{tabular}{|c|c|c|c|c|c|c|}
\hline Planungszoit & $\begin{array}{c}\text { woit } \\
\text { unter dor } \\
\text { Planung }\end{array}$ & $\begin{array}{c}\text { unter } \\
\text { der } \\
\text { Planung }\end{array}$ & $\begin{array}{c}\text { innerhalb } \\
\text { der } \\
\text { Planung }\end{array}$ & $\begin{array}{c}\text { über } \\
\text { der } \\
\text { Planung }\end{array}$ & $\begin{array}{l}\text { weit } \\
\text { Über der } \\
\text { Planung }\end{array}$ & $\begin{array}{c}\text { keine } \\
\text { Angabe } \\
\text { möglich }\end{array}$ \\
\hline bestes Projekt & $\square$ & $\square$ & $\square$ & $\square$ & $\square$ & $\square$ \\
\hline schlechtestes Projekt & $\square$ & $\square$ & $\square$ & $\square$ & $\square$ & $\square$ \\
\hline \multicolumn{7}{|l|}{ Planungskosten } \\
\hline bestes Projekt & $\square$ & $\square$ & $\square$ & $\square$ & $\square$ & $\square$ \\
\hline schlechtestes Projekt & $\square$ & $\square$ & $\square$ & $\square$ & $\square$ & $\square$ \\
\hline \multicolumn{7}{|l|}{ Baukoston } \\
\hline bestes Projekt & $\square$ & $\square$ & $\square$ & $\square$ & $\square$ & $\square$ \\
\hline schlechtestes Projekt & $\square$ & $\square$ & $\square$ & $\square$ & $\square$ & $\square$ \\
\hline \multicolumn{7}{|l|}{ Bauzeit } \\
\hline bestes Projekt & $\square$ & $\square$ & $\square$ & $\square$ & $\square$ & $\square$ \\
\hline schlechtestes Projekt & $\square$ & $\square$ & $\square$ & $\square$ & $\square$ & $\square$ \\
\hline \multicolumn{7}{|l|}{ Bauqualität } \\
\hline bestes Projekt & $\square$ & $\square$ & $\square$ & $\square$ & $\square$ & $\square$ \\
\hline schlechtestes Projekt & $\square$ & $\square$ & $\square$ & $\square$ & $\square$ & $\square$ \\
\hline \multicolumn{7}{|l|}{ Betriebskosten } \\
\hline bestes Projekt & $\square$ & $\square$ & $\square$ & $\square$ & $\square$ & $\square$ \\
\hline schlechtestes Projekt & $\square$ & $\square$ & $\square$ & $\square$ & $\square$ & $\square$ \\
\hline \multicolumn{7}{|l|}{ Betriebsqualität } \\
\hline bestes Projekt & $\square$ & $\square$ & $\square$ & $\square$ & $\square$ & $\square$ \\
\hline schlechtes Projekt & $\square$ & $\square$ & $\square$ & $\square$ & $\square$ & $\square$ \\
\hline \multicolumn{7}{|l|}{ Personeller Aufwand } \\
\hline bestes Projekt & $\square$ & $\square$ & $\square$ & $\square$ & $\square$ & $\square$ \\
\hline schlechtestes Projekt & $\square$ & $\square$ & $\square$ & $\square$ & $\square$ & $\square$ \\
\hline
\end{tabular}

•. Könnten Sie sich vorstellon •inem privaten Unternehmen folgend• Projektleistungen zu übertragen?

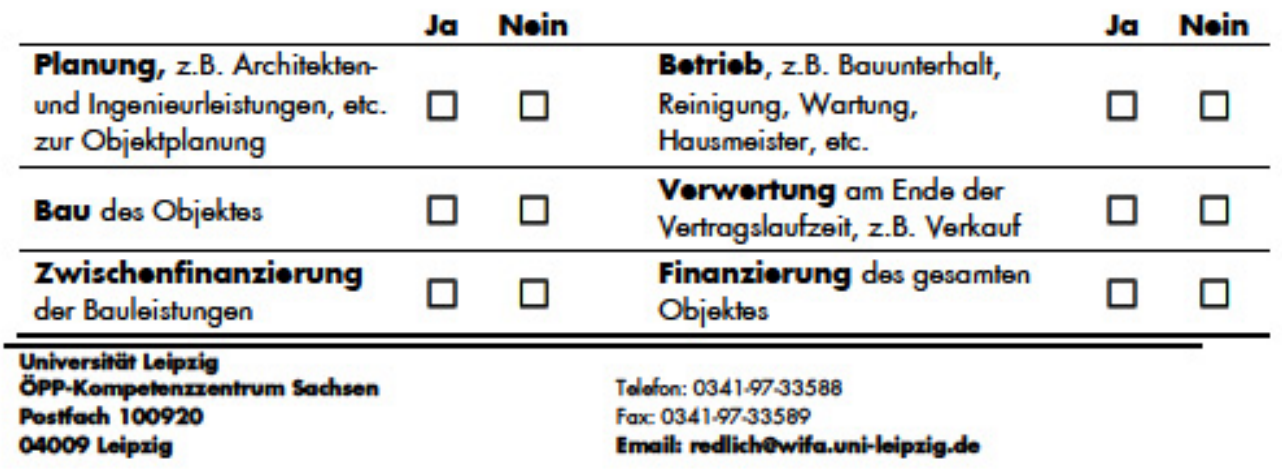




\section{UNIVERSITAT LEIPZIG}

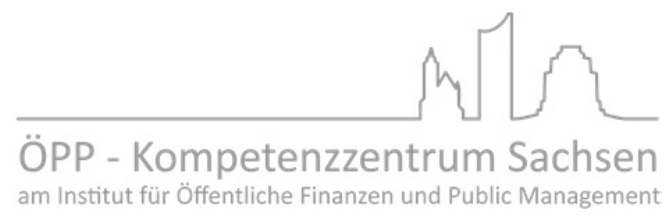

Seite $55 \mid 58$

\section{ÖPP-Kompetenzzentrum Sachsen}

f. Gibt es in lhrer Kommune oin in Betrieb gegangenes oder aktuollos, d.h. begonnenes ÖPP-Projekt?

$\begin{array}{lcc}\text { Ja (Mohrfachauswahl } & \square \text { begonnen } & \square \text { in Botrieb gegangen } \\ \text { ist möglich) } & \text { Anzahl } \\ \text { Noin } & \square \text { keines }\end{array}$

Was sind bzw. waren di॰ Gründ॰ für die Nichtnutzung von ÖPP als Beschaffungsvarianten? (Mohrfachauswahl ist möglich)

\begin{tabular}{|l|l|}
\hline$\square$ & Komplexität des Verfahrens \\
\hline$\square$ & $\begin{array}{l}\text { Bislang nicht bekannt/ nicht } \\
\text { damit beschäftigt }\end{array}$ \\
\hline$\square$ & Vorbehalte in der Verwaltung \\
\hline$\square$ & $\begin{array}{l}\text { Gemeinde-/Stadträte waren } \\
\text { dagegen }\end{array}$ \\
\hline
\end{tabular}

\begin{tabular}{|l|l|}
\hline$\square$ & Allg. rechtliche Unsicherheiten \\
\hline
\end{tabular}

\begin{tabular}{|l|l|}
\hline$\square$ & $\begin{array}{l}\text { Gesetzliche Rahmen- } \\
\text { bedingungen in Sachsen }\end{array}$ \\
\hline
\end{tabular}

$\square$ Ablohnung der kommunalen Aufsichtsbehörden

\begin{tabular}{|l|l|}
\hline$\square$ & Eigenrealisiorung bevorzugt \\
\hline$\square$ & $\begin{array}{l}\text { Zusätzlich• finanziell• } \\
\text { Belastungen befürchtet }\end{array}$ \\
\hline
\end{tabular}

$\square$ Verwaltung verfügt nicht Über notwendige ÖPP-Fachkenntnisse

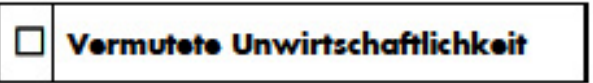
\begin{tabular}{|l|l|}
$\square$ & $\begin{array}{l}\text { Personelle Ressourcen reichen } \\
\text { für ÖPP-Realisiorung nicht }\end{array}$ \\
5
\end{tabular}

\begin{tabular}{|l|l|l|l|}
\hline$\square$ & Langfristigkeit der Verträg• \\
\hline
\end{tabular} andere (bitte benonnon)

\section{3) Einstellung zu Öffentlich-Privaten-Partnerschaften}

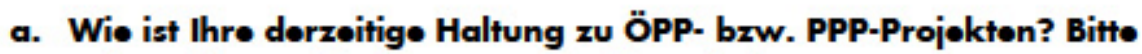
gøbøn Siø uns •in॰ kurze Begründung dafür.

$\square$ vorwiegend positiv

Begründung:

$\square$ noutral

$\square$ vorwiegend negativ

$\square$ noch køin॰ Moinung 
Seite $56 \mid 58$

\section{ÖPP-Kompetenzzentrum Sachsen}

b. Wie schätzon Sie das Wissen über ÖPP in Ihrer

Kommunalverwaltung insgesamt •in?

$\begin{array}{ccccccc} & \text { sehr gut } & \text { gut } & \text { eher gut } & \text { eher gering } & \text { gering } & \text { kein Wissen } \\ \text { Arbeitsebene } & \square & \square & \square & \square & \square & \square \\ \text { Entschøidungsträger } & \square & \square & \square & \square & \square & \square\end{array}$

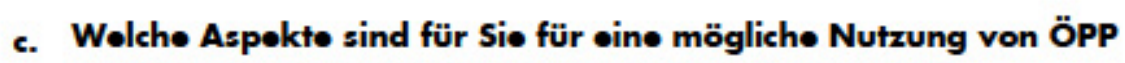
als Beschaffungsvariante von besonderer Bedeutung?

(Mohrfachauswahl ist möglich)

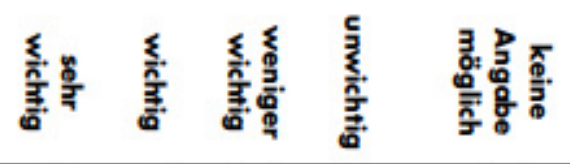

\begin{tabular}{lccccc}
\hline Kosteneinsparpotential• & $\square$ & $\square$ & $\square$ & $\square$ & $\square$ \\
\hline \hline Kostensichorhøit & $\square$ & $\square$ & $\square$ & $\square$ & $\square$ \\
\hline \hline Tormintrou• & $\square$ & $\square$ & $\square$ & $\square$ & $\square$ \\
\hline \hline
\end{tabular}

\begin{tabular}{llllll}
\hline $\begin{array}{l}\text { Reduzierung des langfristen } \\
\text { Personalaufwandes }\end{array}$ & $\square$ & $\square$ & $\square$ & $\square$ & $\square$ \\
\hline
\end{tabular}

\begin{tabular}{llllll} 
Personalaufwandes & & & & \\
\hline Unterstützung aus der Vorwaltung & $\square$ & $\square$ & $\square$ & $\square$ & $\square$
\end{tabular}

\begin{tabular}{|c|c|c|c|c|c|}
\hline $\begin{array}{l}\text { Persönlicho Überzeugung von der } \\
\text { Vorteilhaftigkeit }\end{array}$ & $\square$ & $\square$ & $\square$ & $\square$ & $\square$ \\
\hline $\begin{array}{l}\text { Politische Unterstützung von Stadt- } \\
\text { /Oemeinderat }\end{array}$ & $\square$ & $\square$ & $\square$ & $\square$ & $\square$ \\
\hline $\begin{array}{l}\text { Nachhaltigkeit auf Orund dos } \\
\text { Lebenszyklusansatzes }\end{array}$ & $\square$ & $\square$ & $\square$ & $\square$ & $\square$ \\
\hline $\begin{array}{l}\text { Gute Erfahrungen aus anderen } \\
\text { Projekten }\end{array}$ & $\square$ & $\square$ & $\square$ & $\square$ & $\square$ \\
\hline $\begin{array}{l}\text { Einbindung privaten Knowhows in } \\
\text { allo Lebenszyklen }\end{array}$ & $\square$ & $\square$ & $\square$ & $\square$ & $\square$ \\
\hline $\begin{array}{l}\text { Erwoitorung dor } \\
\text { Investitionstätigkeit }\end{array}$ & $\square$ & $\square$ & $\square$ & $\square$ & $\square$ \\
\hline Effizionzvorteile & $\square$ & $\square$ & $\square$ & $\square$ & $\square$ \\
\hline $\begin{array}{l}\text { Erwoitorung dos finanziellon } \\
\text { Handlungsrahmens dor Oomeinde }\end{array}$ & $\square$ & $\square$ & $\square$ & $\square$ & $\square$ \\
\hline andere (bitte benennen) & $\square$ & $\square$ & $\square$ & $\square$ & $\square$ \\
\hline $\begin{array}{l}\text { Universifith Loiprig } \\
\text { OPP-Kompetonzzentrum Sachsen } \\
\text { Posffach } 100920 \\
04009 \text { Leipzig }\end{array}$ & & & it-le & & \\
\hline
\end{tabular}




\section{ÖPP-Kompetenzzentrum Sachsen}

\section{d. Wie beurteilen Sie nachfolgonde Aussagon?}

\section{Bitte Antworten Sie spontan!}

\begin{tabular}{|c|c|c|c|c|c|}
\hline OPP sind Privafisierungen. & $\square$ & $\square$ & $\square$ & $\square$ & $\square$ \\
\hline $\begin{array}{l}\text { Der Lebenszyklusansatz einer OPP ermöglicht } \\
\text { schlüsselfertiges Bauen mit Kostensicherheit auch im } \\
\text { Betrieb. }\end{array}$ & $\square$ & $\square$ & $\square$ & $\square$ & $\square$ \\
\hline $\begin{array}{l}\text { Private können Gebäude wirtschafflicher planen und } \\
\text { bauen als die öffentliche Hand. }\end{array}$ & $\square$ & $\square$ & $\square$ & $\square$ & $\square$ \\
\hline $\begin{array}{l}\text { Finanzierungen können von der öffentlichen Hand } \\
\text { kastengünstiger realisiert werden als vom Privatsektor. }\end{array}$ & $\square$ & $\square$ & $\square$ & $\square$ & $\square$ \\
\hline $\begin{array}{l}\text { Ohne Unterstützung externer Berater lässt sich eine } \\
\text { erfolgreiche ÖPP nicht realisieren. }\end{array}$ & $\square$ & $\square$ & $\square$ & $\square$ & $\square$ \\
\hline $\begin{array}{l}\text { Kommunale Eigenrealisierungen sind insgesamt } \\
\text { kostengünstiger als eine OPP. }\end{array}$ & $\square$ & $\square$ & $\square$ & $\square$ & $\square$ \\
\hline $\begin{array}{l}\text { Bei konventionellen Eigenrealisierungen wird der } \\
\text { geplante Kostenrahmen regelmäßig überschritten. }\end{array}$ & $\square$ & $\square$ & $\square$ & $\square$ & $\square$ \\
\hline $\begin{array}{l}\text { Die Planung von ÖPP-Projekten ist detaillierter als bei } \\
\text { konventionellen Eigenrealisierungen }\end{array}$ & $\square$ & $\square$ & $\square$ & $\square$ & $\square$ \\
\hline $\begin{array}{l}\text { Die Betriebskosten werden von Privaten langfristiger } \\
\text { und genaver kalkuliert als von der öffentlichen Hand. }\end{array}$ & $\square$ & $\square$ & $\square$ & $\square$ & $\square$ \\
\hline Die Hauptrisiken einer ÖPP trägt die Kommune. & $\square$ & $\square$ & $\square$ & $\square$ & $\square$ \\
\hline $\begin{array}{l}\text { Die finanziellen Vorteile von einer ÖPP werden durch } \\
\text { die Kosten für externe Berater aufgebraucht. }\end{array}$ & $\square$ & $\square$ & $\square$ & $\square$ & $\square$ \\
\hline $\begin{array}{l}\text { ÖPP-Projekte erfordern einen hohen personellen und } \\
\text { zeitlichen Planungsaufwand. }\end{array}$ & $\square$ & $\square$ & $\square$ & $\square$ & $\square$ \\
\hline $\begin{array}{l}\text { Eine OPP reduziert den Verwaltungsaufwand in der } \\
\text { Betriebsphase. }\end{array}$ & $\square$ & $\square$ & $\square$ & $\square$ & $\square$ \\
\hline $\begin{array}{l}\text { Forfaitierung ermöglicht den Kommunen ohne } \\
\text { Eigenmittel zu bauen. }\end{array}$ & $\square$ & $\square$ & $\square$ & $\square$ & $\square$ \\
\hline $\begin{array}{l}\text { Eine ÖPP gibt der Kommune langfristige Planungs- } \\
\text { und Kostensicherheit. }\end{array}$ & $\square$ & $\square$ & $\square$ & $\square$ & $\square$ \\
\hline $\begin{array}{l}\text { Konventionelle Realisierungen geben der Kommune } \\
\text { mehr Flexibilitüt beim Baven. }\end{array}$ & $\square$ & $\square$ & $\square$ & $\square$ & $\square$ \\
\hline $\begin{array}{l}\text { Universität Leipxig } \\
\text { ÖPP-Kompetonzrentrum Sachsen } \\
\text { Postfach } 100920 \\
04009 \text { Leipxig }\end{array}$ & 3589 & & & & \\
\hline
\end{tabular}




\section{UNIVERSITATT LEIPZIG}

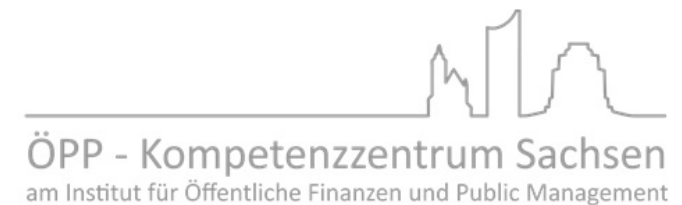

Seite $58 \mid 58$

\section{ÖPP-Kompetenzzentrum Sachsen}

\section{4) Informationsmöglichkeiten und -bedarf}

a. Habon Sie schon oinmal etwas vom ÖPP-Kompotenzzentrum Sachson gohört?
Ja
$\square$ Zeitung
$\square$ Informationsveranstaltung
Mohrfochauswahl
$\square$ Flyer/Informationsmail
$\square$ Bericht eines Dritten ist mōglich)
$\square$ andere (bitte benennen)

$\square$ Noin

b. Habon Sie bereits Veranstaltungen zum Thema ÖPP besucht?
$\square$ Ja
Anzahl
mohrheitlich im Jahr
$\square$ Nein

c. Würden Siø •in॰ Voranstaltung zum Thøma ÖPP bosuchon?

$\square \mathbf{J a} / J a$, wenn (Mohrfachauswahl ist möglich)

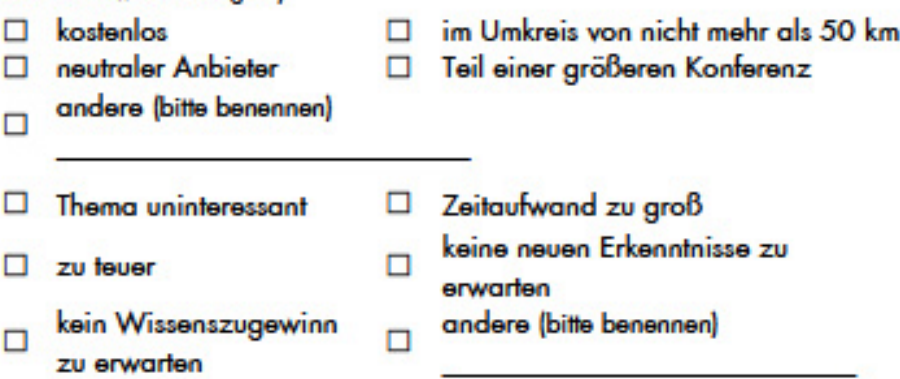

$\square$ Noin, da

Mehrfochauswahl ist mōglich)

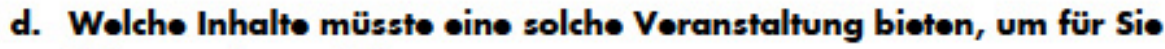
interessant zu soin? (Mohrfachauswahl ist möglich)

$\square$ Best-Practice Beispiele

$\square$ Kontaktgesprächø

$\square$ Orundlagenwissen $\square$ Begrifflichkeiten

$\square$ Projektablauf und -umsetzung

$\square$ Wirtschafflichkeitsuntersuchungen

\section{Erfahrungsaustausch}

$\square$ (Neue) ÖPP Themenfelder aufzeigen

$\square$ Spezialwissen zU (Mohrfochauswahl ist möglich)

$\square$ ÖPP-Varianten und Risiken

$\square$ Projektablauf und -umsetzung

$\square$ Wirtschafflichkeitsuntersuchungen

$\square$ Finanzierungsfragen

$\square$ Risikoverteilung und -analyse

$\square$ andere (bitte benennen)

Universität Leiprig ÖPP.Kompetenxzentrum Sachsen Postfach 100920 04009 Leiprig
Tolofon: 0341.97.33588

Faxc 0341.97.33589

Emailt redlichowifa.uni-leiprig-de 
Das Kompetenzzentrum für kommunale Infrastruktur Sachsen (KOMKIS) stellt eine kostenfreie Informations- und Beratungsplattform für die kommunale Ebene in Sachsen dar. Im Schnittstellenbereich zwischen Verwaltung, Wissenschaft und Politik agiert das KOMKIS als kompetenter Informationsgeber, neutralen Vermittler und inhaltlicher Ansprechpartner zu Themen der kommunalen Infrastrukturbeschaffung, -erhaltung und -bewirtschaftung.

Weitere Veröffentlichungsformate abrufbar unter www.uni-leipzig.de/komkis:

\section{KOMKIS Dialog}

\section{KOMKIS Position}

\section{KONKIS Praxis}

KOMKIS Report

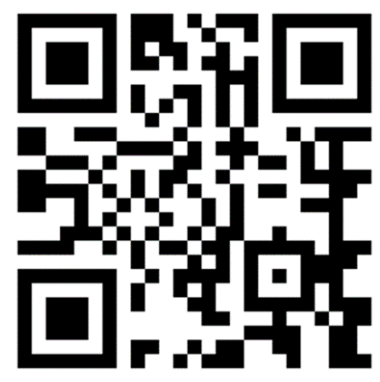

